\title{
KASL clinical practice guidelines: Management of non- alcoholic fatty liver disease
}

\author{
Seong Hee Kang ${ }^{1, *}$, Hye Won Lee, ${ }^{2, *}$, Jeong-Ju Yoo ${ }^{3, *}$, Yuri Cho ${ }^{4, *}$, Seung Up Kim ${ }^{2, *}$, Tae Hee Lee ${ }^{5}$, Byoung Kuk Jang ${ }^{6}$, \\ Sang Gyune $\mathrm{Kim}^{3}$, Sang Bong Ahn ${ }^{7}$, Haeryoung Kim ${ }^{8}$, Dae Won Jun', Joon-Il Choi ${ }^{10}$, Do Seon Song ${ }^{11}$, Won Kim ${ }^{12}$, \\ Soung Won Jeong ${ }^{13}$, Moon Young Kim ${ }^{1}$, Hong Koh ${ }^{14}$, Sujin Jeong ${ }^{15}$, Jin-Woo Lee ${ }^{16}$, and Yong Kyun Cho ${ }^{17}$ on behalf of \\ The Korean Association for the Study of the Liver (KASL) \\ ${ }^{1}$ Department of Internal Medicine, Yonsei University Wonju College of Medicine, Wonju; ${ }^{2}$ Department of Internal Medicine, Yonsei \\ University College of Medicine, Seoul; ${ }^{3}$ Department of Internal Medicine, Soonchunhyang University Bucheon Hospital, Bucheon; \\ ${ }^{4}$ Center for Liver and Pancreatobiliary Cancer, National Cancer Center, Goyang; ${ }^{5}$ Department of Internal Medicine, Konyang University \\ College of Medicine, Daejeon; ${ }^{6}$ Department of Internal Medicine, Keimyung University School of Medicine, Daegu; ${ }^{7}$ Department of Inter- \\ nal Medicine, Nowon Eulji Medical Center, Eulji University School of Medicine, Seoul; ${ }^{8}$ Department of Pathology, Seoul National Univer- \\ sity Hospital, Seoul National University College of Medicine, Seoul; ${ }^{9}$ Department of Internal Medicine, Hanyang University College of \\ Medicine, Seoul; ${ }^{10}$ Department of Radiology, Seoul St. Mary's Hospital, College of Medicine, The Catholic University of Korea, Seoul; \\ ${ }^{11}$ Department of Internal Medicine, St. Vincent's Hospital, College of Medicine, The Catholic University of Korea, Seoul; ${ }^{12}$ Department of \\ Internal Medicine, Seoul Metropolitan Government Boramae Medical Center, Seoul National University College of Medicine, Seoul; \\ ${ }^{13}$ Department of Internal Medicine, Soonchunhyang University Seoul Hospital, Soonchunhyang University College of Medicine, Seoul; \\ ${ }^{14}$ Division of Gastroenterology, Hepatology and Nutrition, Department of Pediatrics, Severance Children's Hospital, Yonsei University \\ College of Medicine, Seoul; ${ }^{15}$ Division of Pediatric Gastroenterology Hepatology and Nutrition, CHA Bundang Medical Center, CHA \\ University, Seongnam; ${ }^{16}$ Department of Internal Medicine, Inha University Hospital, Inha University School of Medicine, Incheon; \\ ${ }^{17}$ Division of Gastroenterology and Hepatology, Department of Internal Medicine, Kangbuk Samsung Hospital, Sungkyunkwan Univer- \\ sity School of Medicine, Seoul, Korea
}

\begin{abstract}
Abbreviations:
AGREE II, Appraisal of Guidelines for Research and Evaluation II; ALT, alanine aminotransferase; AST, aspartate aminotransferase; AUC, area under the receiver operating characteristic curve; BMI, body mass index; CAP, controlled attenuation parameter; $C K D$, chronic kidney disease; $C T$, computed tomography; CVD, cardiovascular disease; ELF, enhanced liver fibrosis; FIB-4, fibrosis-4 index; FLI, fatty liver index; GLP-1, glucagon-like peptide-1; GRADE, Grading of Recommendations, Assessment, Development and Evaluation; GREACE, GREek Atorvastatin and Coronary-heart-disease Evaluation; HCC, hepatocellular carcinoma; HIS, hepatic steatosis index; KASL, the Korean Association for the Study of the Liver; LDL-C, low density lipoprotein cholesterol; LT, liver transplantation; MAFLD, metabolic (dysfunction)-associated fatty liver disease; METs, metabolic equivalents of task; MRE, magnetic resonance elastography; MRI-PDFF, MRI proton density fat fraction; MRI, magnetic resonance imaging; MRS, MR spectroscopy; NAFL, nonalcoholic fatty liver; NAFLD, nonalcoholic fatty liver disease; NAS, NAFLD activity score; NASH, nonalcoholic steatohepatitis; NFS, NAFLD fibrosis score; NLFS, NAFLD liver fat score; PIVENS, Pioglitazone versus Vitamin E versus Placebo for the Treatment of Nondiabetic Patients with Nonalcoholic Steatohepatitis; PNPLA3, the patatin-like phospholipase domain-containing 3; PPAR-y, peroxisome proliferator activated receptor gamma; SAMM50, sorting and assembly machinery component $50 ;$ SWE, shear wave elastography; T2DM, type 2 diabetes mellitus; TM6SF2, transmembrane 6 superfamily, member 2
\end{abstract}

\section{Corresponding author : Yong Kyun Cho}

Division of Gastroenterology and Hepatology, Department of Internal Medicine, Kangbuk Samsung Hospital, Sungkyunkwan University School of Medicine, 29 Saemunan-ro, Jongno-gu, Seoul 03181, Korea Tel: +82-2-2001-8557, Fax: +82-2-2001-2610 E-mail: choyk2004.cho@samsung.com, choyk2004@hanmail.net https://orcid.org/0000-0002-9231-006X

*Seong Hee Kang, Hye Won Lee, Jeong-Ju Yoo, Yuri Cho, and Seung Up Kim equally contributed to this work as co-first authors. 


\section{INTRODUCTION}

\section{Preamble}

The prevalence of nonalcoholic fatty liver disease (NAFLD) is increasing rapidly worldwide as the obese and diabetic populations increase, and it has been estimated to be $20-30 \%$ in Korea. Considering the increased popularity of a westernized diet and lifestyle, lack of exercise, and the resulting increase in obesity and diabetes, NAFLD is predicted to become more prevalent in the future and to become a major cause of chronic liver disease. In some patients, NAFLD progresses to end-stage liver diseases such as cirrhosis and hepatocellular carcinoma (HCC), and it is an independent cardiovascular risk factor.

In 2013, the Korean Association for the Study of the Liver (KASL) enacted a clinical practice guideline for the diagnosis and treatment of NAFLD to improve understanding of the disease and provide useful clinical information and direction for healthcare providers. The research results that have accumulated since then necessitate a revision. Accordingly, the clinical practice guidelines committee began revising the guidelines to reflect the results of Korean and international research and develop new recommendations based on a systematic approach that reflects evidencebased medicine and expert opinions. However, evidence remains insufficient, and many studies are currently being conducted. As medical evidence and new findings accumulate in the future, these guidelines will require ongoing supplementation and revision.

\section{Target population}

Patients diagnosed with NAFLD based on clinical, biochemical, radiological, or pathological findings in the absence of significant alcohol consumption and liver diseases such as viral hepatitis were the primary research population involved in the development of these guidelines. These guidelines are also based on data from pediatric and adolescent NAFLD patients, whose unique findings distinguish them from adult NAFLD patients.

\section{Intended users}

The aim of these guidelines is to provide useful clinical information and direction to healthcare providers involved in the diagnosis and treatment of NAFLD patients. Moreover, these guidelines are intended to provide definite and practical information to resident physicians, practitioners, and trainers.

\section{Developer and funding information}

The Clinical Practice Guideline Committee for the Management of NAFLD (Committee) was organized in accordance with proposals by the approval of the KASL Board of Executives and consists of 16 gastroenterologists, one pathologist, one radiologist, and two pediatricians specializing in hepatology. All expenses were paid by KASL. Each committee member collected and analyzed the source data in his or her own field, and the members then wrote the manuscript together.

\section{Evidence collection}

The committee systematically collected and reviewed the international and domestic literature published in PubMed, MEDLINE, KoreaMed, and other databases. The literature was limited to research papers published in the English and Korean languages. The keywords used were 'nonalcoholic fatty liver disease,' 'nonalcoholic fatty liver,' 'nonalcoholic steatohepatitis,' 'fatty liver,' 'hepatic steatosis,' and 'steatohepatitis.' In addition, keywords related to specific clinical questions were included.

\section{Levels of evidence and grades of recommendations}

The literature gathered for data collection was analyzed in a systematic review, and the quality of evidence was classified based on the modified Grading of Recommendations, Assessment, Development and Evaluation (GRADE) system (Table 1). According to the types of studies, randomized, controlled studies were approached from a high level of evidence, while observational studies were approached from a low level of evidence. Subsequently, the level of evidence basis sets in corresponding stud- 
Table 1. The grading of recommendations, assessment, development, and evaluation (GRADE) system

\begin{tabular}{|c|c|c|}
\hline Criteria & & \\
\hline \multicolumn{3}{|l|}{ Quality of evidence } \\
\hline High quality & Further research is very unlikely to change our confidence in the estimate of the effect. & A \\
\hline Moderate quality & $\begin{array}{l}\text { Further research is likely to have an important impact on our confidence in the estimate of the effect } \\
\text { and may change the estimate. }\end{array}$ & B \\
\hline Low quality & $\begin{array}{l}\text { Further research is very likely to have an important impact on our confidence in the estimate of the } \\
\text { effect and is likely to change the estimate. Any change of estimate is uncertain. }\end{array}$ & C \\
\hline \multicolumn{3}{|l|}{$\begin{array}{l}\text { Strength of } \\
\text { recommendation }\end{array}$} \\
\hline Strong & $\begin{array}{l}\text { Factors influencing the strength of the recommendation include the quality of the evidence, presumed } \\
\text { patient-important outcomes, and cost. }\end{array}$ & 1 \\
\hline Weak & $\begin{array}{l}\text { Variability in preference and values or greater uncertainty. The recommendation is made with less } \\
\text { certainty, higher cost or resource consumption. }\end{array}$ & 2 \\
\hline
\end{tabular}

ies was elevated or lowered by accounting for the factors influencing the quality of the studies. Through follow-up studies, the level of evidence was defined as follows: A, indicating the highest level of evidence with the smallest possibility of any changes in the conclusion; $B$, indicating a moderate level of potential changes; and $C$, indicating the lowest level of evidence with the greatest possibility of any changes.

The strength of each recommendation was suggested according to the GRADE system. In addition to the level of evidence, the results of studies were considered based on aspects of clinical multipliers and socio-economic factors, such as cost. Grading of the recommendations was performed as follows: 1, strong recommendation or 2, weak recommendation. A strong recommendation indicated, for example, that the interventions could be applied in most patients with strong certainty, there was a greater possibility of desirable effects, and there was high-quality evidence, as well as presumed patient-important outcomes, cost-effectiveness, preference, and compliance. A weak recommendation indicated a suggestion made with less certainty but that could be considered favorable for many patients. Alternative interventions could be chosen for "weak recommendations", according to cost and the preferences of the patients or medical practitioners.

These Clinical Practice Guidelines for the Management of NAFLD have been developed through the reviews of medical experts to be used practically for treatment, research, and education. These recommendations are not absolute standards for treatment, and adoption of these guidelines in clinical practice can differ for individual patients.

\section{List of key questions}

The committee considered the following clinical questions as key components to be covered in the guidelines.

1. What are the definition and categories?

2. What are the incidence rate and prevalence rate?

3. How does NAFLD progress?

4. What causes NAFLD-related deaths?

5. What are the risk factors of NAFLD?

6. What are NAFLD's comorbidities?

7. Who should be targeted for NAFLD screening, and how is screening conducted?

8. Which non-invasive surrogates are available to diagnose hepatic steatosis?

9. Which non-invasive surrogates are available to diagnose NASH?

10. Which non-invasive surrogates are available to assess liver fibrosis?

11. Which differential tests are available for advanced fibrosis?

12. What are the indications for liver biopsy?

13. What are the histopathological features of NAFLD?

14. Is surveillance for HCC necessary?

15. How can HCC be prevented?

16. Who should be treated, and what is the aim of the treatment?

17. What do lifestyle modifications include?

18. What is the effect of moderate or less alcohol consumption?

19. What are the types, indications, effects, and side effects of medications for NAFLD?

20. What are the indications for and post-operative manage- 
ment of bariatric surgery?

21. What are the indications for liver transplantation (LT) and post-LT management?

Regarding NAFLD in children and adolescents:

1. What is the prevalence rate?

2. How does NAFLD progress?

3. What genetic diseases are associated with risk factors?

4. Is related NAFLD related to family history and genetic predisposition?

5. Who should be targeted for NAFLD screening, and how is screening conducted?

6. What are the diagnostic methods?

7. Who should be treated, and how?

\section{Review of the manuscript and approval process}

The manuscripts written by the committee members were reviewed and approved through meetings of the committee. The quality of the manuscripts was evaluated based on the integrity of the contents and the standards of Appraisal of Guidelines for Research and Evaluation II (AGREE II). The guidelines were also reviewed at a meeting of an external review board consisting of 11 specialists in the field of hepatology and at a symposium open to all KASL members, and they were then further modified prior to publication. The final manuscript was endorsed by the Board of Executives of KASL.

\section{Release of the guidelines and plan for updates}

The Korean version of the KASL Clinical Practice Guideline for the Management of NAFLD was released at Liver Week 2021 (May 15, 2021), and published in the Clinical and Molecular Hepatology (July 2021). This guideline in Korean is available on the KASL website (http://www.kasl.org). Updates are planned when new reliable evidence has accumulated. Detailed plans for updates will be posted on the KASL website.

\section{DEFINITION}

\section{What are the definition and categories?}

NAFLD is a condition characterized by finding fat infiltration of the liver on radiological exams or biopsy without significant alcohol intake, viral hepatitis, medication intake that would cause a fatty liver, or other obvious cause. NAFLD is defined as a disease with findings suitable for clinical, biochemical, imaging, and pathological examinations. NAFLD is a generic term that encompasses the spectrum of nonalcoholic fatty liver (NAFL), nonalcoholic steatohepatitis (NASH), and NASH cirrhosis (Table 2). The significant safe limits of daily alcohol intake that distinguish NAFLD from alcoholic fatty liver disease range from 10-40 g (pure alcohol), though that range varies between studies. Therefore, definite criteria are difficult to recommend. The Clinical Practice Guideline of the European Association for the Study of the Liver agreed to define the amount of significant alcohol consumption as weekly alcohol consumption $\geq 210 \mathrm{~g}$ in men and $\geq 140 \mathrm{~g}$ in women. ${ }^{1}$ No ethnic differences have been reported regarding safe alcohol limits that do not produce liver damage. The KASL Clinical Practice Guideline for NAFLD uses the amount of significant alcohol consumption stated above in clinical treatment and in studies for international comparison with the results of future studies.

The term NAFLD was introduced by Schaffner in $1986 .{ }^{2}$ However, as information about the causes and mechanisms of the disease accumulated, an opinion emerged that the term NAFLD does not reflect the condition's heterogeneous pathogenesis and various courses. Furthermore, the overestimation of the exclusion of alcohol has sparked heated debate about the threshold of "signif-

Table 2. Definition of nonalcoholic fatty liver disease-related terms

\begin{tabular}{ll}
\hline Term & Definition \\
\hline NAFLD & NAFLD is a generic term encompassing a spectrum of liver disorders, including nonalcoholic fatty liver, NASH, and \\
NAFL (simple steatosis) & $\begin{array}{l}\text { This condition is characterized by fat infiltration of the liver without findings of ballooning degeneration or fibrosis. } \\
\text { NASH }\end{array}$ \\
$\begin{array}{l}\text { This condition is characterized by fat infiltration of the liver along with findings of inflammation associated with } \\
\text { ballooning degeneration. It is occasionally associated with fibrosis. }\end{array}$ \\
$\begin{array}{l}\text { NASH condition is characterized by cirrhosis associated with NAFL or NASH, or cirrhosis occurring in patients with NAFL } \\
\text { or NASH as proven by past histology. }\end{array}$
\end{tabular}

NAFLD, nonalcoholic fatty liver disease; NASH, nonalcoholic steatohepatitis; NAFL, nonalcoholic fatty liver. 
icant" alcohol consumption required for the diagnosis of NAFLD, and the potential (contradictory) role of alcohol consumption in these "non-alcohol" diseases has been repeatedly raised. In 2019, a consensus by 32 experts suggested alternative terminology, metabolic (dysfunction)-associated fatty liver disease (MAFLD), to more accurately reflect the pathogenesis of this disease. ${ }^{3}$ The diagnosis of MAFLD is based on evidence of fat accumulation in the liver in the presence of one of the following three criteria: overweight/obesity, type 2 diabetes mellitus (T2DM), and evidence of metabolic dysregulation. Further research results are needed to verify the validity of this term.

\section{EPIDEMIOLOGY}

\section{What are the incidence rate and prevalence rate?}

\section{Incidence}

In 2007, researchers published results from tracking 5,237 men for more than 4 years and reported for the first time that the annual incidence of NAFLD was 74.1 cases per 1,000 persons. ${ }^{4}$ The annual incidence rate of NAFLD diagnosed by abdominal ultrasonography in health screening examinees was about 48.2 cases per 1,000 persons (range, 13.4-77.7). ${ }^{5-11}$ As diagnosed by the hepatic steatosis index (HSI), the annual incidence rate was 21.1 cases per 1,000 persons..$^{12}$ According to a meta-analysis in Asia, the annual incidence rate in Korea was 45.1 cases per 1,000 persons. ${ }^{13,14}$

\section{Prevalence}

The prevalence of NAFLD varies depending on the study population, definition of NAFLD, and diagnostic modality. In 2002, the prevalence among 1,074 people receiving health checkups and diagnosed by abdominal ultrasound was $48.6 \%{ }^{15}$ The prevalence among 141,610 people receiving health checkups in the Seoul and Gyeonggi area and diagnosed by abdominal ultrasound was $25.2 \%$ (male, 34.4\%; female, $12.2 \%$ ), ${ }^{16}$ and the prevalence in other studies varied from $21 \%$ to $44 \% .^{17-23}$ In a meta-analysis, the prevalence in Korea, as diagnosed by ultrasonography, was $32.9 \% .^{13}$

The prevalence diagnosed using the fatty liver index (FLI) was $12.6-16.1 \%,{ }^{22,24}$ and the prevalence diagnosed with transient elastography was $42.9 \% .{ }^{25}$ The prevalence diagnosed by liver biopsy among 589 living liver donors in Korea was 51\%. ${ }^{26}$

\section{Lean/non-obese NAFLD}

People with normal body weight (body mass index [BMl; $\left.\mathrm{kg} / \mathrm{m}^{2}\right]$ of less than $23 \mathrm{~kg} / \mathrm{m}^{2}$ for Asians, less than $25 \mathrm{~kg} / \mathrm{m}^{2}$ for Westerners) or non-obese weight (BMI of less than $25 \mathrm{~kg} / \mathrm{m}^{2}$ for Asians, less than $30 \mathrm{~kg} / \mathrm{m}^{2}$ for Westerners) can also be diagnosed with NAFLD, but data on the incidence rate among those people in Korea are limited. In 2004, the prevalence of NAFLD was $16.1 \%$ among 460 people with a BMI between $18.5 \mathrm{~kg} / \mathrm{m}^{2}$ and $25 \mathrm{~kg} / \mathrm{m}^{2}$ who received domestic health checkups. ${ }^{27}$ In several domestic studies, the average prevalence of non-obese NAFLD was $18.8 \%$ $(12.4-27.1 \%)^{28-34}$

\section{Summary}

1. The annual incidence of NAFLD in Korea is about 45 cases per 1,000 persons.

2. The prevalence of NAFLD in Korea is approximately $30 \%$.

3. The prevalence of nonalcoholic fatty liver disease in the domestic non-obese population is about $19 \%$.

\section{Natural course and cause of death}

\section{How does NAFLD progress?}

Because the natural course of NAFLD can only be confirmed through repeated liver biopsy, it has been reported only in small studies. The incidence of NASH was reported to vary from 8.5\% to $64.0 \%$ over a $3.0-6.6$ years follow-up period, a large variation that appears to result from differences in the number of patients, various follow-up periods, and diagnostic criteria. ${ }^{35-37}$

In a meta-analysis comparing NAFL and NASH, the percentage of patients who progressed to more than one stage of liver fibrosis were similar at $39.1 \%$ and $34.5 \%$, respectively, but the time it took those patients to progress more than one stage was 14.3 years and 7.1 years, respectively. NASH thus showed faster progression. ${ }^{38}$

In a cohort study of NASH patients, the incidence of cirrhosis varied by race and region, with an average of $21-26 \%$ of patients progressing to cirrhosis in eight years. ${ }^{39,40}$ According to a study of an LT waitlist, the number of patients with end-stage liver disease because of NAFLD had tripled from 10 years previously, making NAFLD the second most common reason for needing LT. ${ }^{41}$

Recently, HCC caused by NAFLD has rapidly increased, becoming the third most common cause of HCC development in United States, and that number is expected to increase by $9 \%$ per year. ${ }^{42,43}$ This trend is believed to be due to the rapid increase in 
the prevalence of obesity, which is a risk factor for NAFLD. NAFLD is associated with a higher incidence of HCC than other etiologies of liver disease in the absence of advanced fibrosis or cirrhosis. ${ }^{4-46}$

\section{What causes NAFLD-related deaths?}

According to data from the U.S. National Vital Statistics System, the mortality rate of NAFLD has increased in the past decade. ${ }^{47}$ In a meta-analysis, patients with NAFLD had a 1.6 times higher mortality rate than the general population. The major causes of death were cardiovascular disease (CVD), malignancy, and liver disease, and in the presence of steatohepatitis, liver disease-related deaths increased. ${ }^{48-50}$ In several cohort studies, the prognosis of patients with NAFLD was most closely related to the degree of liver fibrosis. ${ }^{51,52}$ In a large-scale cohort study based on liver biopsy, the mortality rate of NAFL patients was 1.7 times that of the normal control group; the mortality rate of patients who had steatohepatitis without hepatic fibrosis was 2.1 times that of the normal control group; patients with liver fibrosis had a mortality rate 2.4 times that of the normal control group; patients with cirrhosis had a mortality rate that was 3.8 times that of the normal control group. Thus, the mortality rate increased with the degree of liver fibrosis. $^{53}$

\section{Summary}

1. Liver fibrosis can progress faster in NASH than in NAFL.

2. The incidence of liver cirrhosis and HCC associated with NAFLD is increasing, and HCC can develop even in the absence of liver cirrhosis.

3. The main causes of death among patients with NAFLD are CVD, malignant tumors, and liver diseases, and liver diseaserelated mortality increases when steatohepatitis and liver fibrosis are present.

\section{What are the risk factors of NAFLD?}

NAFLD is closely related to obesity, diabetes, dyslipidemia, and metabolic syndrome (Fig. 1). Obesity is a well-known risk factor for NAFLD, and the prevalence of NAFLD increases as BMI increases. ${ }^{54}$ Among obese patients who underwent bariatric surgery, the prevalence of NAFL, NASH, and significant liver fibrosis were $61-91 \%$, 30-37\%, and $29.3 \%$, respectively. ${ }^{55.56}$ Metabolic syndrome, which consists of abdominal obesity, impaired fasting blood sugar, hypertriglyceridemia, low high-density cholesterolemia, and hypertension, is a major risk factor for NAFLD, just like

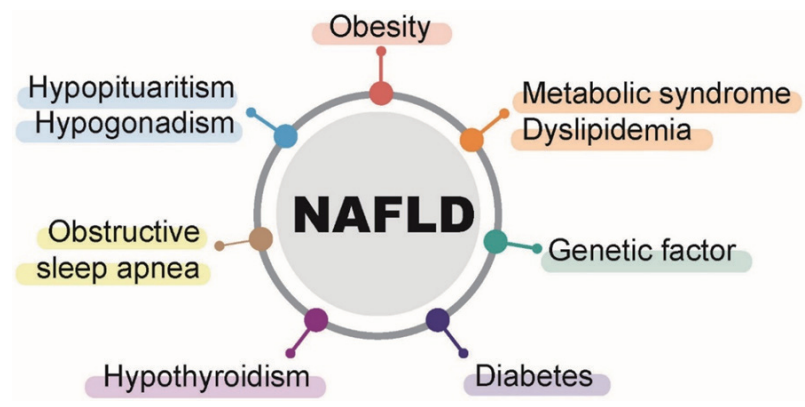

Figure 1. Risk factors for nonalcoholic fatty liver disease.

obesity. In the presence of metabolic syndrome, the prevalence of NAFLD was $50 \% .57,58$ The prevalence of NAFLD was also high in diabetic patients, $60-75 \% .^{14}$ In patients with dyslipidemia, another risk factor, the prevalence of NAFLD was $50 \% .^{59,60}$

In the presence of hypothyroidism, the prevalence of NAFLD increases by 1.6 times, $^{61}$ and in the presence of polycystic ovary syndrome, the incidence increases by about 2.2 times. ${ }^{62}$ In addition, obstructive sleep apnea, ${ }^{63}$ hypopituitarism ${ }^{64}$ hypogonadism $^{65}$ pancreatoduodenal resection, ${ }^{66}$ and psoriasis ${ }^{67}$ increase the prevalence of NAFLD.

Decreased physical activity and sarcopenia increase the risk of NAFLD. ${ }^{68,69}$ The prevalence and incidence of NAFL increased in the group with reduced physical activity. ${ }^{70-72}$ In the presence of sarcopenia, the risk of NAFLD increased by about four times regardless of obesity or metabolic syndrome. ${ }^{68,69}$ When sarcopenia was accompanied by NAFLD, the risk of advanced liver fibrosis increased by 1.8 times. $^{69}$

Genetic factors play a major role in the occurrence of NAFLD. Typically, the patatin-like phospholipase domain-containing 3 (PNPLA3) and transmembrane 6 superfamily, member 2 (TM6SF2) single nucleotide polymorphisms affect the development and progression of the disease. In Korea, PNPLA3 and sorting and assembly machinery component 50 (SAMM50) were associated with the prevalence and severity of NAFLD. ${ }^{73}$

\section{Summary}

1. Major risk factors for NAFLD include obesity, diabetes, dyslipidemia, and metabolic syndrome.

\section{What are NAFLD's comorbidities?}

NAFLD is closely related to systemic metabolic diseases, ${ }^{74}$ and it is an independent risk factor for the occurrence of various non- 
hepatic diseases, including CVD, T2DM, metabolic syndrome, chronic kidney disease (CKD), and malignant tumors. ${ }^{75-77}$

\section{CVD}

In a retrospective cohort study of 1,804 patients with NAFLD in Denmark in the 2000s, the mortality rate from CVD was higher than that in the normal control group. ${ }^{50}$ Several cohort studies that followed also found NAFLD to be an independent risk factor for CVD. ${ }^{78,79}$ In a study that followed patients with histologically diagnosed NAFLD for an average of 26.4 years, the mortality rate increased by 1.3 times, and the risk of CVD increased by 1.6 times compared with the normal control group, with both increases associated with the degree of liver fibrosis. ${ }^{78}$ A meta-analysis of patients with NAFLD diagnosed histologically or radiologically concluded that the risk of CVD was increased by about 1.6 times compared with the normal control group. The risk of CVD also increased when liver fibrosis was assessed using the NAFLD fibrosis score (NFS) or liver biopsy. ${ }^{80}$ According to two Korean cohort studies, NAFLD was independently associated with the incidence of coronary artery calcification and atherosclerosis, which are direct causes of CVD. ${ }^{18,81}$

\section{T2DM}

T2DM and NAFLD influence each other. ${ }^{82}$ In a large-scale cohort study of healthy Koreans, the prevalence and incidence of T2DM in patients with NAFLD (assessed using the NFS) increased with the degree of hepatic fibrosis. ${ }^{17}$ In a meta-analysis of Korean studies, the prevalence of diabetes in patients with NAFLD was $14.2 \%$, higher than the $5.2 \%$ of the control group. ${ }^{83}$ The results of a meta-analysis of other studies also showed an increase of about 2.2 times in the incidence of T2DM. ${ }^{84}$

\section{Metabolic syndrome}

Metabolic syndrome is a major risk factor for the occurrence of NAFLD and is a common comorbid disease. A prospective Korean cohort study of 46,874 men reported that patients with mild and moderate NAFLD (diagnosed by abdominal ultrasound) had a risk of metabolic syndrome 1.5 and 2 times higher, respectively, than the control group. ${ }^{85}$ In a meta-analysis of Korean studies, the incidence of metabolic syndrome was $40.7 \%$ in patients with NAFLD and $11.2 \%$ in the control group. ${ }^{83}$

\section{CKD}

CKD and NAFLD share risk factors such as T2DM and hypertension, ${ }^{86}$ and CKD frequency increases in patients with NAFLD. ${ }^{87-89}$
In a meta-analysis of about 63,000 people, the prevalence of CKD increased by 2.1 times, and the incidence rate increased by 1.7 times compared with the control group. ${ }^{90}$ The prevalence and incidence of CKD were 2.5 times and 2.1 times higher in NASH than NAFLD. In a Korean cohort study, patients with NAFLD had a 1.2 times higher risk of developing CKD than the control group, and that risk increased with the stage of liver fibrosis. ${ }^{91}$

\section{Other diseases}

Arrhythmia, osteoporosis, colon adenoma, colon cancer, and breast cancer all have increased incidence in patients with NAFLD. ${ }^{92-94}$ However, more follow-up studies are needed to confirm clear relationships between NAFLD and those diseases.

\section{Summary}

1. NAFLD is often associated with comorbidities such as cardiovascular disease, T2DM, metabolic syndrome, CKD, and malignant tumors.

\section{DIAGNOSIS}

\section{Who should be targeted for NAFLD screening, and how is screening conducted?}

Screening for NAFLD should be considered in cases of persistent liver enzyme elevation. Because the cost effectiveness of screening in diabetic patients has been confirmed ${ }_{1}^{95}$ patients with diabetes should receive screening tests for NAFLD regardless of their liver enzyme levels. In addition, subjects with metabolic syndrome (which is closely associated with insulin resistance), obesity, and other risk factors for NAFLD can be considered for screening tests. ${ }^{17,96}$

The primary screening test for NAFLD is ultrasonography. When NAFLD is suspected in the ultrasonography results, other tests (computed tomography [CT], magnetic resonance imaging [MRI], serologic tests, transient elastography, etc.) can be performed. 


\section{[Recommendations]}

1. Subjects who have persistent liver enzyme elevation or diabetes should be screened for NAFLD. (A1)

2. Subjects with metabolic syndrome (which is closely associated with insulin resistance, obesity, and other risk factors for NAFLD) can be considered for screening. (B1)

3. Abdominal ultrasonography is the primary screening modality. (B1)

\section{Non-invasive examinations}

Because the prognosis of NAFLD differs significantly depending on the histological findings, the diagnosis of hepatic steatosis and fibrosis and assessment of their severity are clinically crucial. To date, liver biopsy is the gold standard in assessing hepatic necroinflammation, steatosis, and fibrosis. However, liver biopsy is expensive, invasive, carries a risk of complications, is subject to intra-/inter-observer interpretational variability, and can suffer from sampling errors when an insufficient amount of liver tissue is collected. ${ }^{97,98}$ Therefore, noninvasive radiological surrogates such as ultrasonography and panels of serological tests are widely used.

\section{Which non-invasive surrogates are available to diagnose hepatic steatosis?}

\section{Radiological surrogates}

Abdominal ultrasonography is the first-line imaging modality for screening asymptomatic patients with abnormal liver enzyme levels. However, it suffers from subjective interpretation, examination difficulties in obese patients, and low sensitivity when the amount of hepatic steatosis is less than $30 \%$. Moreover, ultrasonography cannot distinguish NASH from NAFL. ${ }^{99-101}$ When hepatic steatosis assessed using MR spectroscopy (MRS) was used for reference, the diagnostic accuracy of ultrasonography was lower than that of non-contrast CT and MRI. ${ }^{102}$ However, ultrasonography is appropriate as a screening test, because it offers 1) robust diagnostic performance for moderate or severe steatosis, 2) the ability to evaluate the entire hepatobiliary system in addition to detecting the presence of hepatic steatosis, and 3) wide availability.

Controlled attenuation parameter (CAP) is a feature of transient elastography that can quantify the degree of fat deposition in the liver parenchyma by measuring ultrasound attenuation. ${ }^{103,104} \mathrm{Ac}$ cording to a recent Korean study enrolling people who received regular health checkups, the normal CAP range is $156-287 \mathrm{~dB} / \mathrm{m}^{105}$
The area under the receiver operating characteristic curve (AUC) of CAP used to diagnose a moderate to severe degree of steatosis was 0.88 (sensitivity, 83.3\%; specificity, 81.6\%), and the cutoff value was $276 \mathrm{~dB} / \mathrm{m}$ in a Korean study of living LT donors. ${ }^{106}$ In another Korean study, the AUCs of CAP for mild, moderate, and severe degrees of steatosis in patients with chronic liver diseases, including NAFLD, were $0.885,0.894$, and 0.800 , respectively, and the cutoff values were $250 \mathrm{~dB} / \mathrm{m}, 299 \mathrm{~dB} / \mathrm{m}$, and $327 \mathrm{~dB} / \mathrm{m}$, respectively. ${ }^{107}$ In a recent meta-analysis, the AUCs of CAP for mild, moderate, and severe degrees of steatosis were $0.96,0.82$, and 0.70 , respectively. ${ }^{108}$ CAP can be used as a monitoring tool for hepatic steatosis, and it can be examined simultaneously with transient elastography. ${ }^{109-111}$ Other ultrasound-based methods, including image-based quantitative analysis of liver parenchymal echo texture and measuring the attenuation of ultrasound energy, are under investigation. ${ }^{112,113}$

Hepatic steatosis is associated with low attenuation on CT scans, which can be used for the quantitative assessment of hepatic steatosis. Because the attenuation of enhanced $C T$ is affected mainly by the amount of blood flow, unenhanced CT is favored for the measurement of hepatic steatosis, and the attenuation of liver and spleen parenchyma are frequently compared. For moderate to severe steatosis, the specificity of CT was reported to be high, but its sensitivity and positive predictive value were low. ${ }^{101,114,115}$ Furthermore, its diagnostic performance for mild steatosis was suboptimal. The specificity and sensitivity of unenhanced CT for diagnosing moderate to severe steatosis were $100 \%$ and $53.8 \%$, respectively, when $\mathrm{CT}$ attenuation of hepatic parenchyma was less than 48 HU. ${ }^{115}$ However, CT raises concerns about radiation hazards, and CT evaluations of hepatic steatosis are limited in patients with infiltrative liver diseases that deposit iron, copper, glycogen or amiodarone in the liver parenchyma because CT attenuation is affected by those materials. ${ }^{116,117}$ Dual energy $C T$, which adopts two different tube potentials for image acquisition, can perform material decomposition and has been used to quantify the degree of hepatic steatosis. ${ }^{102}$

MRI is superior to ultrasonography for measuring a small amount of fat in the liver, and it is the most precise imaging tool for evaluating NAFLD. Quantitative MRI measurements of hepatic fat deposition using the Dixon technique can be classified into MRS and MRI proton density fat fraction (MRI-PDFF). ${ }^{118}$ MRS can directly measure the signal from acryl groups of triglycerides, and MRS findings correlate closely with histological results and show high sensitivity to hepatic steatosis. ${ }^{119,120}$ MRI-PDFF uses differences in the precession frequency of water and fat protons and can 
map the entire liver for the degree of steatosis. Therefore, it can measure the degree of fat deposition in any part of the liver parenchyma. MRI-PDFF in different MRI units is in high agreement with histological findings, and its diagnostic performance in detecting severe steatosis ( $\geq 67 \%$ ) was high (AUC, 0.95 ). ${ }^{121,122}$ In a recent meta-analysis, the AUCs for differentiating grade 1-3 steatosis, grade 2-3 steatosis, and grade 3 steatosis were $0.98,0.91$, and 0.90 , respectively. ${ }^{123}$ MRI-PDFF showed superior diagnostic performance to CAP in assessing hepatic steatosis in a prospective study. ${ }^{124}$ MRS and MRI-PDFF can measure the degree of steatosis precisely, irrespective of iron deposition or fibrosis. ${ }^{125}$ Despite the superior diagnostic performance of MRS and MRI-PDFF, their limited availability and high cost remain problems.

\section{Panels}

In addition to radiological examinations, various panels of serological tests have been proposed to diagnose hepatic steatosis and assess its severity (Table 3). These panels can be calculated using clinical information such as age, sex, and the results from serological tests. These panels do not directly diagnose hepatic steatosis, unlike ultrasonography, but they can help physicians who suspect the presence of hepatic steatosis to decide whether further assessments are justified. Large-scale studies frequently use these noninvasive panels to test for hepatic steatosis instead of ultrasonography, which has a high cost.

The FLI was proposed by Bedogni et al. ${ }^{126}$ in an Italian study that examined 216 subjects with liver disease and 280 subjects with healthy livers. In that study, 228 patients had ultrasonography-defined NAFLD. The FLI is calculated based on triglycerides, gamma-glutamyl transpeptidase, BMI, and waist circumference. If the $\mathrm{FLI}$ is less than 30 , NAFLD can be excluded (negative likelihood ratio, 0.2 ), and if the FLI is more than 60, NAFLD can be di- agnosed (positive likelihood ratio, 4.3). An FLI score of more than 60 has a positive predictive value of $99 \%$ and a negative predictive value of $15 \%$. The AUC of the FLI was 0.84 . The FLI showed acceptable accuracy among a Korean population. ${ }^{127,128}$

The NAFLD liver fat score (NLFS) was proposed by Kotronen et al. ${ }^{129}$ in a Finnish study comprising 470 subjects. That study used MRS to diagnose NAFLD. The NLFS is calculated based on metabolic syndrome, T2DM, fasting insulin, aspartate aminotransferase (AST), and the AST/alanine aminotransferase (ALT) ratio. Its cutoff is -0.640 (sensitivity, $86 \%$; specificity, $71 \%$ ). If the NLFS is less than -0.640 , NAFLD can be excluded, and if it is more than -0.640 , NAFLD can be diagnosed. The AUC of the NLFS was $0.86-0.87$. NLFS showed acceptable accuracy in a Korean population. ${ }^{130}$

The HSI was proposed by Lee et al. ${ }^{131}$ in a Korean cohort study of 10,724 subjects (5,462 with ultrasonography-defined NAFLD). The HSI is calculated based on sex, BMI, AST, ALT, and T2DM. If the HSI is less than 30, NAFLD can be excluded (negative likelihood ratio of 0.2 , sensitivity of $93.1 \%$ ), and if it is more than 36 , NAFLD can be diagnosed with high predictive accuracy (positive likelihood ratio of 6.1 , specificity of $92.4 \%$ ). The AUC of the HSI was 0.81 . The HSI showed acceptable accuracy among a Korean population. ${ }^{132}$

The noninvasive surrogates just described show acceptable accuracy in most cross-section studies and have been used to trace changes in hepatic steatosis in certain studies. However, the usefulness of those noninvasive surrogates in monitoring disease progression and evaluating treatment response should be further investigated.

Table 3. Panels for hepatic steatosis

\begin{tabular}{|c|c|c|c|c|}
\hline Panels & Equations & Cutoff & $\begin{array}{l}\text { Diagnostic } \\
\text { tools (cohort) }\end{array}$ & $\begin{array}{c}\text { Validated in Korean } \\
\text { population }\end{array}$ \\
\hline Fatty liver index (FLI) ${ }^{126}$ & $\begin{aligned}= & \left(e^{0.953 \times \log _{e}(\text { triglycerides })+0.139 * B M I+0.718 \times \log _{\mathrm{e}}(\mathrm{GGT})+0.053 \times \text { waist circumference - }}\right. \\
& 15.745)\end{aligned}$ & $\geq 60,<30$ & $\begin{array}{l}\text { Ultrasonography } \\
\text { (Italy) }\end{array}$ & Yes \\
\hline $\begin{array}{l}\text { NAFLD liver fat score } \\
(\text { NLFS) })^{129}\end{array}$ & $\begin{aligned}= & -2.89+1.18 \times \text { metabolic syndrome }(\text { yes }=1 / \mathrm{no}=0)+0.45 \\
& \times \text { diabetes }(\text { yes }=2 / \mathrm{no}=0)+0.15 \times(\text { fasting insulin, } \mu \mathrm{U} / \mathrm{L}) \\
& +0.04 \times \text { AST }+0.94 \times \text { AST } / \text { ALT ratio }\end{aligned}$ & $>-0.64$ & MRS (Finland) & Yes \\
\hline $\begin{array}{l}\text { Hepatic steatosis index } \\
(\mathrm{HSI})^{131}\end{array}$ & $=8 \times \mathrm{ALT} / \mathrm{AST}+\mathrm{BMI}(+2$, if diabetes; +2 , if female) & $\geq 36,<30$ & $\begin{array}{l}\text { Ultrasonography } \\
\text { (Korea) }\end{array}$ & Yes \\
\hline
\end{tabular}

BMI, body mass index; GGT, gamma-glutamyl transpeptidase; AST, aspartate aminotransferase; ALT, alanine aminotransferase. 


\section{[Recommendations]}

1. Abdominal ultrasonography, CAP, unenhanced $C T$, MRS, and MRI-PDFF are acceptable modalities for diagnosing hepatic steatosis. (A1)

2. If radiological examinations are infeasible, panels for hepatic steatosis can be used to assess hepatic steatosis. (B1)

\section{Which non-invasive surrogates are available to diagnose NASH?}

NASH is significantly associated with liver fibrosis progression and HCC. Non-invasive modalities to diagnose NASH are limited, but a prediction model based on liver stiffness, CAP (assessed using transient elastography), and ALT levels was recently proposed by a Korean study. ${ }^{133}$ Some studies insist that NASH can be distinguished from NAFL using cytokeratin-18 fragments (sensitivity, $66 \%$; specificity, $82 \%$ ). ${ }^{134,135}$ A few studies claim that CT or MRI can be used to differentiate NASH from NAFLD, but no clear diagnostic criterion has been set. ${ }^{101,136}$ Based on the association between the viscosity shown in shear wave dispersion imaging and necroinflammation of the liver parenchyma, a recent study showed that shear wave dispersion imaging could be helpful in diagnosing NASH. ${ }^{137}$ The AUC of magnetic resonance elastography (MRE) alone and that for the combined use of MRE and MRIPDFF in differentiating NASH from NAFL was $0.82-0.93 .{ }^{138,139}$

Recently, multiparametric MR indices, which score the results from various MRI techniques, have been under investigation. A recent Korean study found that a multiparametric MRI index using MRE, MRS, and T1 mapping to differentiate NASH from NAFL showed sensitivity of $80 \%$, specificity of $85.2 \%$, and an AUC of $0.883 .^{140}$ In a meta-analysis that systematically reviewed all studies using MRI to differentiate NASH from NAFL, the pooled sensitivity and specificity were $87.4 \%$ and $74.3 \%$, respectively. ${ }^{110}$

\section{[Recommendations]}

1. Non-invasive diagnosis of NASH remains limited, so it should be diagnosed by liver biopsy. (A1)

\section{Which non-invasive surrogates are available to assess liver fibrosis?}

The assessment of liver fibrosis is crucial in patients with NAFLD because the degree of liver fibrosis is significantly associated with long-term outcomes such as the development of HCC and liver-related death. ${ }^{78}$ Furthermore, it is important to noninvasively assess the regression or progression of liver fibrosis during the course of anti-fibrotic therapy.

\section{Radiological surrogates}

Ultrasound-based measurement techniques for liver fibrosis take advantage of shear wave elastography (SWE). They can be divided into two categories: 1) measuring the elasticity of the liver parenchyma using SWE without acquiring imaging data (transient elastography) and 2) image-based sonoelastography that acquires both elasticity and 2D image data (point SWE and 2D SWE). Transient elastography is widely used in clinical practice, and many researchers have reported its high performance in quantifying liver fibrosis in NAFLD patients. In a recent meta-analysis, transient elastography showed high sensitivity and specificity for evaluating the degree of liver fibrosis in NAFLD patients..$^{48,135,141}$ However, the accuracy of transient elastography is limited in obese patients, who commonly have NAFLD, making it unavailable in $5-20 \%$ of patients. ${ }^{48,142}$ A recent study reported that using an XL probe rather than an $\mathrm{M}$ probe can significantly lower the failure rate of transient elastography. ${ }^{119,143}$ Image-based techniques have the advantage of acquiring both elasticity data and 2D images simultaneously. The failure rate is lower than that of transient elastography because operators can choose the area of the liver parenchyma to acquire elasticity data. The AUC of point SWE for quantifying liver fibrosis in NAFLD patients was higher than 0.8. ${ }^{144,145}$ The performance of point SWE for advanced liver fibrosis was excellent $\left(100 \%\right.$ sensitivity and $91 \%$ specificity). ${ }^{146}$ In a recent meta-analysis, the diagnostic performance of point SWE for liver fibrosis was similar to that of transient elastography. ${ }^{147}$ 2D SWE can obtain elasticity data from a wider area than point SWE, and the reported failure rate of 2D SWE was lower than that of point SWE. ${ }^{148,149}$ In a prospective study, 2D SWE, MRE, and transient elastography had similar AUCs for advanced hepatic fibrosis $(0.920,0.929$, and 0.915 , respectively). ${ }^{150}$

MRE shows high diagnostic accuracy for liver fibrosis. ${ }^{138,151,152}$ In contrast to transient elastography, which can examine the elasticity of only a small portion of liver tissue, MRE can evaluate the entire liver parenchyma. ${ }^{152}$ MRE also has other advantages: operator non-dependency and no limitations for obese patients. MRE is the most accurate non-invasive test for liver fibrosis, with a diagnostic performance superior to that of transient elastography. ${ }^{124,141,153}$ In a meta-analysis, MRE correlated well with each stage of liver fibrosis, with AUCs for each stage of $0.84-0.93 . .^{154,155}$ The failure rate of MRE was less than $5 \%$, which is significantly better than that of transient elastography. MRE was not significantly af- 
Table 4. Panels for liver fibrosis

\begin{tabular}{|c|c|c|c|c|}
\hline Panels & Equations & Cutoff & $\begin{array}{l}\text { Diagnostic } \\
\text { tools }\end{array}$ & $\begin{array}{c}\text { Validated in Korean } \\
\text { population }\end{array}$ \\
\hline $\begin{array}{l}\text { NAFLD fibrosis score } \\
\text { (NFS) }\end{array}$ & $\begin{aligned}= & -1.675+0.037 \times \text { age }(\text { years })+0.094 \times \mathrm{BMI}\left(\mathrm{kg} / \mathrm{m}^{2}\right) \\
& +1.13 \times \text { impaired fasting glucose or diabetes }(y e s=1 \\
& \text { no }=0)+0.99 \times \text { AST/ALT ratio }-0.013 \times \text { platelet count } \\
& \left(\times 10^{9} / \mathrm{L}\right)-0.66 \times \text { serum albumin }(\mathrm{g} / \mathrm{dL})\end{aligned}$ & $<-1.455,>0.676$ & Liver biopsy & Yes \\
\hline $\begin{array}{l}\text { Fibrosis-4 index } \\
(\text { FIB-4) }\end{array}$ & $=$ Age $($ years $) \times A S T[U / L] /\left(\right.$ platelets $\left[10^{9} / \mathrm{L}\right] \times(\text { ALT }[U / L])^{1 / 2}$ & $<1.3,>2.67$ & Liver biopsy & Yes \\
\hline 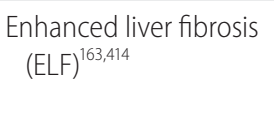 & $\begin{array}{l}\text { Patented (hyaluronic acid, tissue inhibitor of } \\
\text { metalloproteinase 1, amino terminal peptide of } \\
\text { procollagen III as constituent variables) }\end{array}$ & 0.3576 & Liver biopsy & Yes \\
\hline
\end{tabular}

NAFLD, nonalcoholic fatty liver disease; BMI, body mass index; AST, aspartate aminotransferase; ALT, alanine aminotransferase.

fected by the MRI manufacturer or the strength of the magnet. ${ }^{156}$ In addition, MRE showed robust reproducibility in repetitive examinations. ${ }^{157}$ However, the high cost of MRE limits its availability in clinical practice. In patients with iron deposition in the liver parenchyma, it is difficult to perform MRE, and the presence of other infiltrative diseases, such as profound hepatic steatosis, hepatic congestion, or acute inflammation, can attenuate the diagnostic accuracy of MRE. ${ }^{158,159}$

\section{Panels}

In addition to radiological examinations, various panels of serological tests have been proposed to diagnose liver fibrosis (Table 4). Well-validated panels are summarized here.

Of the noninvasive panels for liver fibrosis, the NFS has been studied the most. The NFS was proposed in a US study by Angulo et al. ${ }^{160}$ that comprised 733 subjects with biopsy-proven NAFLD. Two cutoffs were proposed: <-1.455 (low probability, negative predictive value of $88-93 \%$ ) and $>0.676$ (high probability, positive predictive value of $82-90 \%) \cdot{ }^{160} \mathrm{~A}$ meta-analysis based on 13 studies with 3,064 subjects showed that the AUC of the NFS for advanced liver fibrosis was 0.85 . If the NFS is less than -1.455 , advanced liver fibrosis can be excluded with a sensitivity of $90 \%$ and a specificity of $60 \%$, and if NFS is more than 0.676 , advanced liver fibrosis can be diagnosed with a sensitivity of $67 \%$ and a specificity of 97\%. ${ }^{48,160-172}$ Among 412 Korean subjects with biopsy-proven NAFLD, an NFS of less than -1.455 allowed advanced liver fibrosis to be excluded with a high negative predictive value $(86.6 \%)$, and an NFS of more than 0.676 allowed advanced liver fibrosis to be diagnosed with a positive predictive value of $50 \% .{ }^{173}$ In another Korean study, which recruited 315 subjects with biopsy-proven NAFLD, the cutoff values ( $<-1.455$ and $>0.676)$ showed an AUC of 0.84 in diagnosing advanced liver fibrosis (negative predictive value of $89.3-95.7 \%) .^{174}$ However, cases that fall between the cutoff values (indeterminate probability) still require a liver biopsy. ${ }^{48}$

The fibrosis-4 index (FIB-4) was proposed by Sterling et al. in a study comprising 832 subjects with human immunodeficiency virus/hepatitis C virus co-infection. FIB-4 is calculated using the platelet count, age, AST, and ALT. The AUC of FIB-4 for advanced liver fibrosis was 0.765 . When the FIB-4 is less than 1.30, advanced liver fibrosis can be excluded (accuracy, 90\%), and when FIB-4 is more than 2.67, advanced liver fibrosis can be diagnosed (accuracy, 80\%). ${ }^{175} \mathrm{~A}$ recent study of subjects with biopsy-proven NAFLD showed that the diagnostic accuracy of the NFS and FIB-4 was significantly higher than that of other noninvasive panels for liver fibrosis and similar to that of MRE in diagnosing advanced liver fibrosis. ${ }^{141}$ However, because the diagnostic accuracy of FIB-4 was inferior to that of the NFS in a Korean study, further validation studies are required. ${ }^{173}$

The enhanced liver fibrosis (ELF) panel has recently been used to assess liver fibrosis in Europe. ELF was proposed by Guha et al. ${ }^{163}$ in a UK study comprising 192 subjects with biopsy-proven NAFLD. ELF is calculated based on three proteins associated with liver fibrosis: hyaluronic acid, tissue inhibitor of metalloproteinase 1, and amino terminal peptide of procollagen III. The cutoff value and AUC of ELF for advanced liver fibrosis were 0.3576 and 0.90 , respectively (sensitivity, $80 \%$; specificity, $90 \%$; positive predictive value, $71 \%$; negative predictive value, $94 \%)^{163}$

Other serological surrogates for liver fibrosis, such as M2BPGi and AsAGP, have been proposed. ${ }^{176-179}$ However, because few data for subjects with NAFLD are available, further validation studies are required. The noninvasive surrogates described above show acceptable accuracy and prognostic values in most crosssection studies. However, the usefulness of noninvasive surro- 
gates in monitoring disease progression and evaluating treatment response should be further investigated.

\section{[Recommendations]}

1. Radiological examinations such as transient elastography, point SWE, 2D SWE, and MRE are helpful in assessing hepatic fibrosis. (A1)

2. If radiological examinations are infeasible, panels such as NFS or FIB-4 can be used to diagnose liver fibrosis. (B1)

\section{Which differential tests are available for advanced fibrosis?}

In NAFLD, liver fibrosis testing uses serologic tests, image tests, or liver biopsy. Because liver biopsy cannot be performed in all patients, an algorithm can be used to differentiate advanced fibrosis (Fig. 2). Advanced fibrosis can be differentiated primarily using transient elastography, FIB-4, and the NFS. ${ }^{180}$

When subjects are classified as intermediate risk by transient elastography, FIB-4, or the NFS, additional tests such as M2BPGi, AsAGP, ELF, SWE, or MRE can be performed. If the algorithms suggest advanced fibrosis, additional tests to re-evaluate the liver fibrosis or a liver biopsy should be considered.

\section{[Recommendations]}

1. Non-invasive methods such as transient elastography, FIB-4, and NFS are prioritized to discriminate advanced liver fibrosis. (A1)

2. Serological tests, imaging tests, and liver biopsies may be performed as additional liver fibrosis evaluations. (B1)

\section{Liver biopsy}

\section{What are the indications for liver biopsy?}

Non-invasive tests to replace liver biopsy have been developed and shown high accuracy. ${ }^{122,181,182}$ However, liver biopsy remains the gold standard for diagnosing NAFLD. ${ }^{183}$ In practice, it is difficult to perform liver biopsy in all patients suspected of having NAFLD. ${ }^{184,185}$ However, liver biopsy can help with diagnosis, treatment planning, and distinguishing between NAFLD and other liver diseases (autoimmune hepatitis, drug-induced hepatitis, Wilson's disease, etc.). Liver biopsy is necessary when NASH or advanced liver fibrosis is suspected, as well as when other liver diseases cannot be excluded. ${ }^{186-188}$

Liver biopsy has several limitations. First, sampling error is a concern because only a small portion of the liver tissue is sampled during liver biopsy. Second, intra- and inter-observer variability occurs. ${ }^{189-191}$ Third, it carries the risk of complications such as bleeding and infection, as well as increased medical costs. There-

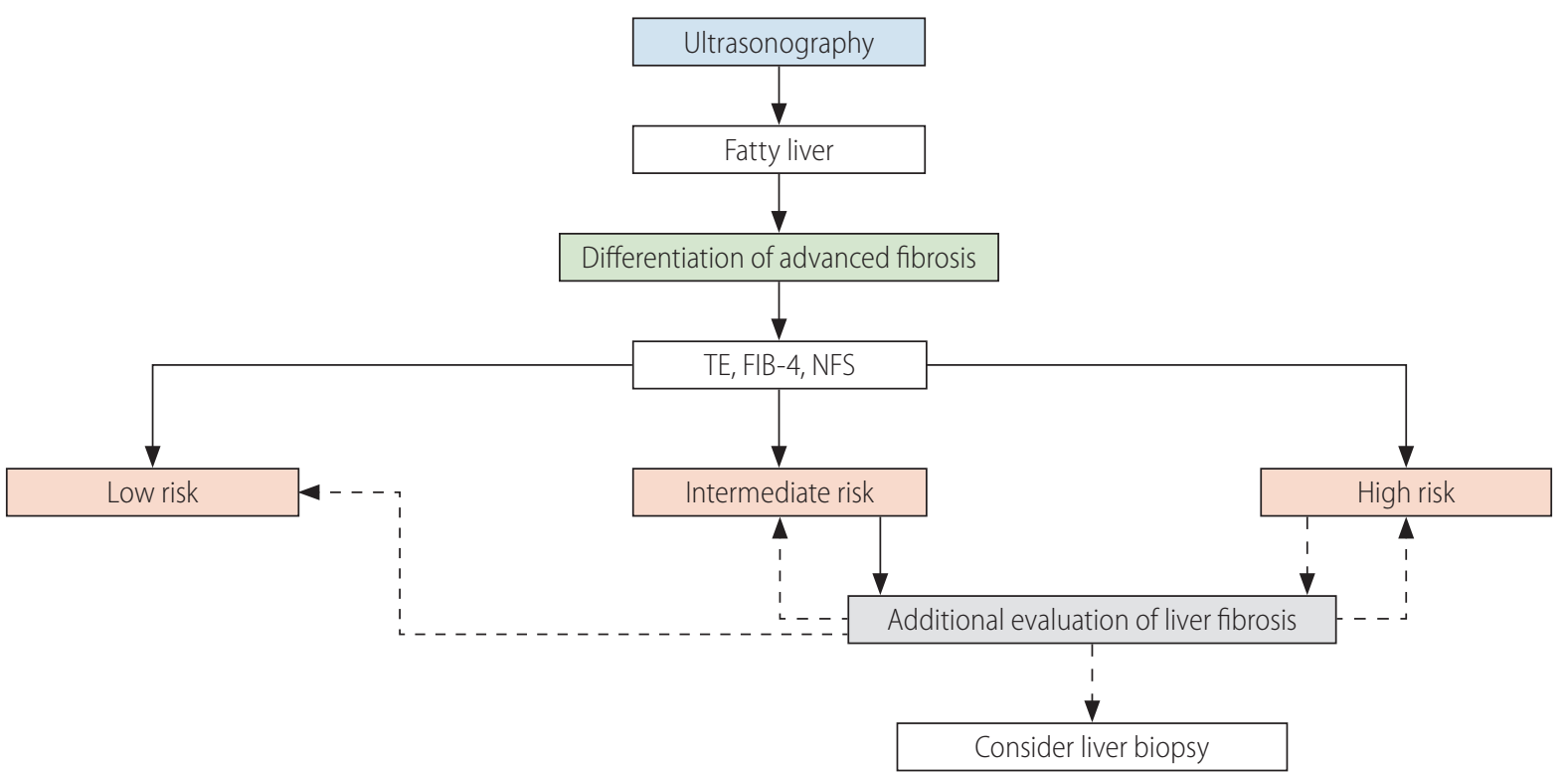

Figure 2. Algorithm to differentiate advanced fibrosis. TE, transient elastography; FIB-4, fibrosis-4 index; NFS, nonalcoholic fatty liver disease fibrosis score. 
fore, it is difficult to perform or repeat liver biopsy in all patients. ${ }^{192}$ To minimize discrepancies, it is recommended that a sufficient amount of tissue be collected, a thick needle (16-18 gauge) be used, and two or more samples of a sufficient length be collected. ${ }^{97}$

\section{[Recommendations]}

1. Liver biopsy should be considered in patients suspected of having NASH or advanced liver fibrosis. (B1)

2. Liver biopsy should be considered when the presence or severity of coexisting chronic liver disease cannot be excluded. (B1)

\section{What are the histopathological features of NAFLD?}

The role of liver biopsy in NAFLD diagnosis lies in differentiating simple steatosis (NAFL) from NASH, evaluating the extent of fibrosis (stage), and excluding the possibility of other liver diseases. NAFL is defined as the presence of $\geq 5 \%$ steatotic hepatocytes without evidence of hepatocellular injury in the form of hepatocyte ballooning ${ }^{193}$ The degree of steatosis is graded as $1+$ (mild, 5-33\%), 2+ (moderate, 34-66\%), and 3+ (severe, $\geq 67 \%$ ). NASH is diagnosed when there is evidence of hepatocellular injury (hepatocellular ballooning) and lobular inflammation in addition to steatosis. ${ }^{193-195}$ Fibrosis, when present, is staged as stage 1 (perivenular, perisinusoidal, or periportal fibrosis), stage 2 (both zone 3 and periportal fibrosis), stage 3 (bridging fibrosis), and stage 4 (cirrhosis). ${ }^{195}$

\section{HCC surveillance and prevention}

\section{Is surveillance for HCC necessary?}

Because the incidence of liver cirrhosis and HCC associated with NAFLD is increasing rapidly, the risk of HCC should be assessed and surveillance should be established in all NAFLD patients. Because the incidence of HCC in patients with NAFLD-related cirrhosis is more than $1.5 \%$ per year, ${ }^{196,197} \mathrm{HCC}$ surveillance is recommended if liver cirrhosis is clinically suspected. ${ }^{198-201}$

Although the incidence of HCC in patients with NAFLD was 10 times higher than that in the normal control group, ${ }^{202}$ the incidence of HCC is very low in patients with early liver fibrosis (FO2). However, when patients with early liver fibrosis have HCC risk factors (obesity, metabolic syndrome, diabetes, etc.), they become more likely to develop HCC. Thus, surveillance should be individualized. $^{203,204}$
Abdominal ultrasound is the primary surveillance test for HCC. However, in overweight or obese patients, it can be difficult to perform accurately. ${ }^{205,206}$ In those cases, CT or MRI can be used instead.

\section{How can HCC be prevented?}

Smoking is associated with liver fibrosis and is known to be a risk factor for the development of HCC. In meta-analyses and cohort studies, smoking increased the risk of developing HCC by 1.5 and 1.8 times, respectively. ${ }^{207,208}$ Therefore, smoking cessation is recommended for NAFLD patients. The effect of alcohol consumption on the development of HCC varies between studies, but in a meta-analysis, drinking increased the incidence of HCC by 1.2-2.1 times. Patients with liver cirrhosis associated with NAFLD should abstain from alcohol because drinking it increases the risk of HCC and liver-related mortality. ${ }^{209,210}$

In a 32-year cohort study, diabetes increased the incidence of HCC by 4.6 times. ${ }^{211}$ A meta-analysis also showed that diabetes increased the incidence of HCC. ${ }^{211-215}$ Metformin decreased the incidence of $\mathrm{HCC}$, but the use of sulfonylurea and insulin increased the incidence of HCC by 1.6 and 2.6 times, respectively. ${ }^{216}$ Peroxisome proliferator activated receptor gamma (PPAR- $\gamma$ ) agonist and glucagon-like peptide-1 (GLP-1) agonist were effective in the recovery of NASH, but they did not show a significant association with the development of HCC. ${ }^{217-220}$

Dyslipidemia is associated with NASH and CVD, but the relationship with liver disease-related mortality or HCC is still lacking. In a meta-analysis, statin use reduced the risk of developing HCC by $37 \% .{ }^{221}$ However, results in patients with NAFLD remain insufficient. 222,223

Obesity is associated with both liver fibrosis and $\mathrm{HCC}^{224} \mathrm{Al}-$ though weight loss and exercise improve both steatosis and fibrosis, there are insufficient studies showing that weight loss and exercise therapy reduce the incidence of HCC. Further research is thus needed on the association between weight loss and HCC incidence.

\section{[Recommendations]}

1. Patients with liver cirrhosis associated with NAFLD need HCC surveillance. (A1)

2. To reduce the development of HCC in patients with NAFLD, smoking cessation, alcohol abstinence, and weight loss are recommended. (B1) 


\section{TREATMENT}

\section{Who should be treated, and what is the aim of the treatment?}

NAFLD is commonly associated with metabolic diseases such as obesity, diabetes, and insulin resistance. Given that NAFLD is associated with increased mortality from CVD and liver-related complications, ${ }^{225,226}$ NAFLD patients require management and treatment to improve their prognosis. Treatments for NAFLD aim to reduce the incidence and mortality of CVD and liver-related complications, and they include both pharmacologic and non-pharmacologic options to improve intrahepatic inflammation and fibrosis and treat comorbid metabolic diseases. Lifestyle modifications such as weight reduction, dietary control, and exercise and treatment of comorbidities such as diabetes, obesity, hypertension, and dyslipidemia are the cornerstones of treatment for NAFLD and should be applied to all NAFLD patients, regardless of the degree of inflammation or fibrosis. However, pharmacologic treatments should be applied selectively because NAFLD progresses slowly and encompasses a spectrum of conditions from NAFL to NASH cirrhosis.

The most important histologic marker indicating long-term prognosis is the severity of fibrosis, ${ }^{51,52,227}$ with stage 2 or more fibrosis ( $\geq F 2$ ) being an independent predictor of liver-related complications and mortality. ${ }^{51,52,228}$ The most important factor in the progression of fibrosis is the presence of steatohepatitis. Fibrosis progresses more rapidly in patients with steatohepatitis than in those without it, ${ }^{36,38}$ and changes in steatohepatitis are associated with the progression of fibrosis. ${ }^{229,230}$ Therefore, patients with hepatic fibrosis or steatohepatitis can receive pharmacologic treatment to improve their long-term prognosis.

\section{[Recommendations]}

1. Patients with NAFLD need lifestyle modifications and treatment for comorbidities. (A1)

2. Patients with NASH or hepatic fibrosis need management or treatment for histologic improvement. (A1)

\section{Lifestyle modifications}

\section{What do lifestyle modifications include?}

\section{Weight reduction}

Among overweight or obese (BMI $>25.0 \mathrm{~kg} / \mathrm{m}^{2}$ ) NAFLD pa- tients, weight loss through lifestyle changes significantly reduced their liver fat content as revealed by imaging ${ }^{231,232}$ or liver biopsy. ${ }^{233-235}$ In patients histologically diagnosed with NAFLD, weight loss of more than $5-7 \%$ resulted in decreased intrahepatic fat content and inflammation, ${ }^{233,234}$ with greater weight loss correlating with greater histologic improvement. ${ }^{234}$ Liver fibrosis also improved in $45 \%$ of patients whose weight loss was more than $10 \% .{ }^{234}$ In a meta-analysis of studies about weight loss through lifestyle modification, anti-obesity drugs, and surgical treatment, weight loss was associated with a decrease in intrahepatic fat, NAFLD activity score (NAS), and liver enzymes. ${ }^{236}$ Even in nonobese NAFLD patients, intrahepatic fat content improved with a weight loss of $3-5 \% .{ }^{237}$ Therefore, weight loss is important in NAFLD patients regardless of the presence of obesity.

In NAFLD patients with obesity, the rate of weight loss affects steatohepatitis. A study showed that weight reduction that targeted a gradual decrease (maximum of $1 \mathrm{~kg} /$ week of body weight) improved both NASH and NAS. ${ }^{238}$ However, a rapid decrease (more than $1.6 \mathrm{~kg} /$ week of body weight) worsened portal inflammation and fibrosis in some morbidly obese patients, ${ }^{239}$ and rapid weight loss through bariatric surgery can lead to acute hepatic failure. ${ }^{240}$ Therefore, progressive weight loss of less than $1 \mathrm{~kg} /$ week is recommended over rapid weight loss in NAFLD patients with obesity.

\section{Dietary therapy}

Reducing the intake of total energy and controlling food intake are crucial aspects of NAFLD treatment. In prospective, randomized, controlled studies, reductions in energy intake caused weight loss, decreased intrahepatic fat content, decreased liver enzyme levels, and decreased insulin resistance. ${ }^{232,241,242} \mathrm{~A}$ daily intake of 1,500-1,800 kcal in men and 1,200-1,500 kcal in women can reduce total energy intake by more than $500 \mathrm{kcal} /$ day. ${ }^{243}$ However, daily caloric intake should be optimally adjusted according to age, sex, weight, and physical activity.

Recently, the association between the ratio of macronutrients (carbohydrates, fats, and proteins) and the development of obesity and NAFLD has been studied. Carbohydrate intake was associated with metabolic syndrome and the severity of intrahepatic inflammation. ${ }^{24,245}$ In Western studies, low-carbohydrate diets were more effective than low-fat diets in reducing liver fat content. ${ }^{242}$ In Korea, increased carbohydrate and fructose intake was associated with an increased prevalence of fatty liver and elevated liver enzymes, ${ }^{246}$ and low-carbohydrate dietary training was more effective than low-fat dietary training in reducing both liver en- 
zymes and liver fat content. ${ }^{247}$ However, both low-fat and lowcarbohydrate diets effectively reduced liver fat content. ${ }^{241}$ The decrease in liver fat content did not differ depending on the type of diet; liver fat content decreased in patients who lost more than $7 \%$ of their body weight regardless of whether they ate a lowcarbohydrate or high-carbohydrate diet. ${ }^{232}$ In a meta-analysis comparing low-carbohydrate and low-fat diets, the two did not differ in reducing liver fat content. ${ }^{248}$ Therefore, total energy intake is a more important factor in NAFLD treatment than the composition ratio of macronutrients.

The Mediterranean diet pattern emphasizes vegetables, fruits, whole grains, and legumes, and the principal source of dietary lipids is olive oil. It also includes the moderate consumption of fish and shellfish, white meat, eggs, and dairy products, with red meat and processed meats eaten rarely and in small quantities. ${ }^{249}$ It has a high content of monounsaturated fatty acids. The Mediterranean diet reduces liver fat content and makes insulin resistance significantly better than low-fat diets regardless of body weight, ${ }^{250,251}$ and adherence to the Mediterranean diet was more important than adherence to a low-fat diet. ${ }^{251,252}$

Dietary control along with weight loss can help reduce hepatic fat content. However, studies of specific nutrients and dietary habits have been conducted on only small numbers of patients, and few have shown histologic improvement to hepatic inflammation or fibrosis. It is difficult to maintain adherence to appropriate dietary habits in the long run. Therefore, it is necessary to study an appropriate diet to which patients can maintain adherence for a long time that produces histological improvement. In addition, dietary effects can vary depending on genetic predisposition, ${ }^{253}$ such as the presence of PNPLA3 or TM6SF2 variants, and dietary control needs to be individualized for each patient.

\section{Exercise}

NAFLD is associated with a low level of physical activity. In large-scale Korean cohort studies, prolonged sitting time and decreased physical activity were positively associated with the prevalence of NAFLD regardless of $\mathrm{BMI}_{1}{ }^{254}$ and moderate to vigorous exercise decreased the risk of developing a fatty liver or improved the resolution of an existing fatty liver. ${ }^{255}$ In biopsy-proven NAFLD patients, vigorous exercise ( $\geq 6$ metabolic equivalents of task [METS]) was associated with a lower frequency of NASH and advanced fibrosis. ${ }^{256}$ Exercise itself decreases insulin resistance and reduces liver fat content regardless of body weight changes. . $57-262^{26}$ In a meta-analysis, exercise was found to be effective in reducing the liver fat content. ${ }^{263-265}$ Aerobic exercise was mainly recommended at moderate or vigorous intensity (greater than $50-70 \%$ of maximal heart rate), and exercise for 30-60 minutes more than three times per week for at least 6 weeks was found to be effective. . $58,262,266,267$ Resistance exercise was recommended at $50-70 \%$ of maximal strength (1-repetition maximum) for 30-60 minutes more than three times per week. ${ }^{25,266,267}$ According to the World Health Organization and United States Department of Health and Human Services, moderate-intensity physical activities include brisk walking, dancing, gardening, and carrying or moving an object of less than $20 \mathrm{~kg}$, and vigorous-intensity physical activities include running, fast cycling, aerobics, fast swimming, and carrying or moving objects of more than $20 \mathrm{~kg}$ (Table 5). ${ }^{268,269}$

It is unclear which exercise is most effective. Some randomized controlled studies comparing aerobic exercise and resistance exercise have shown that aerobic exercise more effectively reduces liv-

Table 5. Examples of moderate and vigorous physical activity

\begin{tabular}{ll}
\hline Moderate-intensity physical activity & \multicolumn{1}{c}{ Vigorous-intensity physical activity } \\
\hline (3-6 METs) & $(>6 \mathrm{METs})$ \\
\hline Brisk walking & Running \\
\hline Dancing & Walking/climbing briskly up a hill \\
\hline Slow cycling & Fast cycling \\
\hline Gardening & Aerobics \\
Recreational swimming & Fast swimming \\
\hline Active involvement in games and sports with children & Competitive sports and games (e.g., football, volleyball, basketball) \\
\hline General building tasks (e.g., roofing, painting) & Digging or shoveling \\
\hline Carrying/moving objects of less than $20 \mathrm{~kg}$ & Carrying/moving objects of more than $20 \mathrm{~kg}$ \\
\hline Walking domestic animals & \\
\hline
\end{tabular}

METs, metabolic equivalents of task. 
er fat content than resistance exercise, ${ }^{270}$ but some studies show similar effects from both exercise types. ${ }^{26,267}$ In recent systematic reviews, both aerobic and resistance exercise similarly reduced the liver fat content..$^{271,272}$ However, resistance exercise could be more feasible than aerobic exercise for NAFLD patients with poor cardiorespiratory fitness or those who cannot tolerate aerobic exercise because it requires much lower energy consumption. ${ }^{271} \mathrm{Be}-$ cause exercise-mediated improvements in liver fat can be reversed to baseline levels after cessation, it is necessary to maintain exercise habits. ${ }^{273}$ Therefore, the selection of exercise needs to be individualized so that it can be maintained continuously considering each patient's preferences and cardiopulmonary fitness.

\section{[Recommendations]}

1. In overweight or obese NAFLD patients, weight loss of more than $5-7 \%$ results in decreased intrahepatic fat content, and weight loss of more than $7-10 \%$ is required to improve hepatic inflammation and fibrosis. (A1)

2. To reduce intrahepatic fat content, a reduction in the total energy intake of more than $500 \mathrm{kcal} /$ day is required. (A1)

3. To reduce intrahepatic fat content, at least moderate-intensity exercise for more than 30 minutes more than 3 times per week is required. (B1)

\section{What is the effect of moderate or less alcohol consump- tion?}

The effects of moderate or less alcohol consumption should be considered because NAFLD, by definition, includes patients whose alcohol consumption is insignificant. However, alcohol consumption is not easy to distribute randomly, so the effects of alcohol consumption on NAFLD can be evaluated only through longitudinal observational studies. Significant alcohol consumption (male $\geq 210 \mathrm{~g} /$ week, female $\geq 140 \mathrm{~g} /$ week) can cause alcohol-related liver disease and should be avoided. However, the effects of light or moderate drinking vary. In some studies, light or moderate drinking (male $<210 \mathrm{~g} /$ week, female $<140 \mathrm{~g} /$ week) appears to be protective against fatty liver and hepatic fibrosis, ${ }^{274-279}$ but in other studies it was associated with the progression of NAFLD. ${ }^{196,280-282}$ In a large cohort study in Korea, light drinking (less than $10 \mathrm{~g} /$ day) was associated with worsening in noninvasive markers of fibrosis, $^{283,284}$ but further studies are needed.

\author{
[Recommendation] \\ 1. Moderate or less alcohol use in NAFLD patients requires \\ attention. (B1)
}

\section{What are the types, indications, effects, and side effects of medications for NAFLD?}

\section{Insulin sensitizers}

\section{Pioglitazone}

Pioglitazone, a PPAR- $\gamma$ agonist, reduces insulin resistance in the liver, muscle, and adipose tissue, and also reduces the amount of fat in the liver and hepatocellular injury by alleviating hepatic mitochondrial oxidative dysfunction. ${ }^{285-288}$ In four randomized controlled studies, histologic improvement of steatohepatitis was observed in patients with or without diabetes who were treated with pioglitazone (30 or $45 \mathrm{mg} /$ day) compared to placebo-treated patients. ${ }^{21,289-291}$ However, no improvement was observed in liver fibrosis, a major indicator predicting the progression of liver disease. ${ }^{289-293}$ In the Pioglitazone versus Vitamin E versus Placebo for the Treatment of Nondiabetic Patients with Nonalcoholic Steatohepatitis (PIVENS) trial, 247 nondiabetic NASH patients were randomized to pioglitazone (30 mg/day), vitamin E (800 IU/day), or placebo and followed for 96 weeks. The primary endpoint of this study was a $\geq 2$ point reduction in the NAS (one or more point improvement in hepatocellular ballooning and one or more point improvement in either the lobular inflammation or steatosis scores). Compared with placebo, pioglitazone showed improvement in NASH (34\% vs. 19\%, $P=0.04)$. This study concluded that the improvements observed with pioglitazone were not statistically significant because they did not reach the prespecified level of significance $(P<0.025)$ for the primary outcome. However, there were discrepancies in the presence of hepatocellular ballooning between the results of pathological assessments performed locally and those performed centrally from deeper cuts prepared from the biopsy specimens obtained, and those classification errors were much higher in the subjects taking pioglitazone. The resolution of steatohepatitis, the secondary outcome, was higher in the pioglitazone group than the placebo group ( $47 \%$ vs. $21 \%$, $P=0.001)$. In conclusion, pioglitazone can be considered as a treatment option for NASH diagnosed by liver biopsy in patients with or without diabetes mellitus.

However, weight gain ${ }^{294}$ is a common side effect of pioglitazone treatment. Other potential side effects of long-term pioglitazone 
use in NASH patients with diabetes mellitus include lower extremity edema, muscle cramps, as well as an increased risk of fractures $^{295}$ bladder cancer, ${ }^{296}$ and congestive heart failure. ${ }^{297}$

\section{Metformin}

Metformin, a commonly prescribed drug for T2DM, was expected to be beneficial in treating NASH patients, as it reduces insulin resistance in the liver and muscles. Moreover, metformin inhibits hepatic fat accumulation and glucose excretion by activating adenosine monophosphate-activated protein kinase, and also decreases the expression of tumor necrosis factor-a. ${ }^{298,299}$ However, metformin has little or no effect on liver histology. ${ }^{300,301}$ since metformin has a weight loss effect, it can compensate for the weight gain associated with pioglitazone when the two medications are used together. However, several studies, including randomized controlled studies, showed that the co-administration of metformin and pioglitazone did not improve histological findings in the liver, insulin resistance in the liver, or liver enzyme levels compared with controls. ${ }^{300,302-307}$ Only in a retrospective study, long-term use (more than 6 years) of metformin in patients with diabetes mellitus and histologically proven NASH or advanced fibrosis lowered the risk of overall mortality, LT, and HCC. ${ }^{308}$ Another retrospective study showed that diabetes mellitus increased the risk of death and liver-related complications such as HCC, and that metformin use lengthened the survival and decreased the risk of decompensated cirrhosis and HCC in 299 patients with NAFLD-associated Child-Pugh class A cirrhosis. ${ }^{309}$

\section{GLP-1 agonist}

Liraglutide, a synthetic long-acting GLP-1 receptor agonist, has been approved to treat diabetes mellitus and obesity. In a small phase 2 clinical trial of 52 patients with biopsy-proven NASH, patients receiving subcutaneous injections of liraglutide $(1.8 \mathrm{mg} /$ day for 48 weeks) achieved greater weight loss and resolution of NASH than those receiving placebo. ${ }^{218}$ However, its development as a medication for NASH has been interrupted by its frequent gastrointestinal side effects such as diarrhea, constipation, and loss of appetite.

In a phase 2 trial of semaglutide, a GLP-1 analogue, 320 patients with NASH were randomized to receive daily subcutaneous semaglutide (0.1 mg, $0.2 \mathrm{mg}$, or $0.4 \mathrm{mg}$ ) or placebo for 72 weeks. The proportions of patients who experienced NASH resolution without the exacerbation of hepatic fibrosis were 40\%, 36\%, and $59 \%$, respectively, in the treatment groups and $17 \%$ in the placebo group $\left(P<0.001\right.$, semaglutide of $0.4 \mathrm{mg}$ vs. placebo). ${ }^{310} \mathrm{How}$ - ever, the groups did not differ significantly with regard to fibrosis improvement. The mean percentage of weight loss was 13\% for the $0.4 \mathrm{mg}$ semaglutide group and $1 \%$ for the placebo group, with the semaglutide group reporting more frequent nausea, constipation, and vomiting than the placebo group. Based on those results, semaglutide is expected to prove its benefit as a treatment for NASH through additional phase 3 clinical trials.

\section{[Recommendations]}

1. Pioglitazone is effective in improving steatohepatitis in NASH confirmed by liver biopsy, regardless of diabetes mellitus, but safety concerns about long-term treatment should be considered. (B1)

2. Metformin can be used as a first-line treatment for diabetes mellitus in patients with concomitant NAFLD who also have diabetes mellitus. (B1)

\section{Antioxidants}

\section{Vitamin E (alpha-tocopherol)}

Vitamin E decreases oxidative stress (which worsens NASH) and improves liver inflammation. ${ }^{311,312}$ In the PIVENS study, which was a large-scale phase 3 trial, the administration of 96-week highdose vitamin E (800 IU/day) produced significant improvement in liver histology compared to placebo (43\% vs. $19 \%, P=0.001){ }^{291}$ but it did not improve liver fibrosis. ${ }^{292}$ The proportion of NASH resolution, a secondary endpoint, was $36 \%$ in the vitamin $E$ group, which was higher than that in the control group (21\%). Therefore, the use of vitamin $\mathrm{E}$ can be considered as biopsy-proven NASH treatment in patients without diabetes mellitus.

However, the long-term use of vitamin $\mathrm{E}$ also carries safety concerns because of the increased risk of prostate cancer or hemorrhagic stroke. ${ }^{313}$ Although the finding is controversial, high doses of vitamin E (>400 IU/day) are associated with an increased mortality rate, requiring safety precautions. ${ }^{314-316}$ According to a retrospective study of 236 patients with biopsy-proven NASH with bridging fibrosis or compensated cirrhosis, the use of $800 \mathrm{IU} /$ day of vitamin $\mathrm{E}$ for more than 2 years decreased the risk of death, LT and decompensated cirrhosis in patients both with and without diabetes mellitus. However, the incidence of HCC, vascular disease, and non-hepatic cancers did not differ between the vitamin E users and controls. ${ }^{317}$ 


\section{[Recommendation]}

1. High-dose vitamin E (800 IU/day) can improve NASH confirmed by liver biopsy in non-diabetic patients, but safety should be considered for long-term administration. (B1)

\section{Lipid-lowering drugs}

CVD is the most common cause of death for NAFLD patients, so it is important to modify its risk factors. ${ }^{78,318-320}$ An increase in plasma lipoprotein increases the carotid intima-media thickness and atherosclerotic plaques, which cause CVD, and thus it is necessary to prevent and treat dyslipidemia. ${ }^{321}$ Lipid lowering agents such as statins (hydroxy-methyl-glutaryl coenzyme A reductase inhibitors) ${ }^{322}$ can be considered in NAFLD patients with dyslipidemia. ${ }^{323,324}$ In a post-hoc analysis of the GREek Atorvastatin and Coronary-heart-disease Evaluation (GREACE) study, statin use decreased aminotransferases and poor cardiovascular outcomes in NAFLD patients with aminotransferases up to three times higher than the upper normal limit. Less than $1 \%$ of patients (seven of 880 patients) withdrew from the study due to hepatotoxicity associated with the statin treatment; thus statin treatment seems to safely lower liver enzymes and reduce cardiovascular morbidity in patients with NAFLD. ${ }^{325}$ In a study using data from the National Health Information database of South Korea, statin treatment decreased not only the risk of NAFLD occurrence but also the development of fibrosis attributed to NALFD, regardless of diabetes mellitus. ${ }^{326}$ Strict control of low density lipoprotein cholesterol (LDL-C) is emphasized because many NAFLD patients treated with statins still did not meet their LDL-C treatment targets, which can itself increase the incidence of $C V D .{ }^{327}$ A common adverse effect of statins is the asymptomatic elevation of aminotransferases, which usually appears within 1 year of starting statins and recovers spontaneously. ${ }^{328}$ This increase in liver enzyme levels depends on the statin dose. ${ }^{329}$ However, because statin users and controls did not differ in terms of persistent and significant elevation of liver enzyme levels ${ }^{328}$ or the incidence of liver and biliary tract disease, ${ }^{330}$ the administration of a statin is possible in chronic liver diseases, including NAFLD. ${ }^{331,332}$ However, the administration of statins to patients with decompensated cirrhosis or acute liver failure should be avoided. ${ }^{333-377}$ Statins can be used in NAFLD and NASH, and they are considered as a first-line treatment to lower LDL-C and prevent atherosclerotic CVD. If the response to the statin is insufficient, ezetimibe can be added. ${ }^{338}$ Omega-3 fatty acids are not recommended as a treatment for NASH because only some study results showed an effect on $\mathrm{NASH}_{1}^{339}$ whereas others did not. ${ }^{340,341}$ However, they may be considered for use in hypertriglyceridemia with NAFLD. ${ }^{30,342,343}$

\section{[Recommendations]}

1. Because the incidence and mortality rate of CVD in NAFLD are high, it is necessary to actively control the risk factors of CVD. (A1)

2. In the case of dyslipidemia in NAFLD, a statin can be used to prevent CVD. (B1)

3. Omega-3 fatty acids are not recommended as a treatment for NASH, but they can be used in NAFLD with hypertriglyceridemia. (B1)

\section{New NASH drugs in development}

The pathophysiology of NASH is complicated, and its interactions with other metabolic diseases have not been fully elucidated. Therefore, NASH treatments are currently under development for a wide range of targets. The main targets are changes in intestinal microflora and intestinal permeability, oxidative stress, insulin resistance, apoptosis, lipotoxicity, inflammation, bile acid metabolism, and liver fibrosis. At the time of this writing, six new drugs are in phase 3 clinical trials or have published intermediate results (Table 6). Among them, the STELLAR-3, 4 trial of an apoptosis signal-regulating kinase 1 inhibitor (selonsertib) in NASH subjects with advanced liver fibrosis ${ }^{344}$ and the RESOLVE-IT trial of a PPAR- $a / \delta$ agonist (elafibranor) in NASH patients with stages 1-3 of liver fibrosis have failed to demonstrate therapeutic efficacy in the interim results. Consequently, the development of both drugs was discontinued. In the REGENERATE trial in NASH subjects with hepatic fibrosis stage $1-3$, the farnesoid $X$ receptor agonist (obeticholic acid; Ocaliva ${ }^{\circledR}$ ) showed dose-dependent primary treatment efficacy, an improvement in liver fibrosis of at least 1 stage, in the $10 \mathrm{mg}$ and $25 \mathrm{mg}$ treatment groups (18\% and $23 \%)$ compared with the control group (12\%) after 18 months of treatment. ${ }^{345}$ However, the US Food and Drug Administration rejected conditional approval of the drug as a treatment for NASH, judging that severe itching and the increased risk of CVD caused by increased LDL-C outweighed the benefits of treatment. To date, no drugs under development have met their efficacy targets in more than $50 \%$ of patients. Considering the complicated pathophysiology of NASH and the various treatment responses observed in clinical trials for individual drugs, it is highly likely that combination treatments or personalized treatments will become the standard. 
Table 6. NASH treatment drugs in phase 3 clinical trials

\begin{tabular}{|c|c|c|c|}
\hline Drug & Clinical trial & Chemical type & Therapeutic target \\
\hline Obeticholic acid & REGENERATE REVERSE & Synthetic bile acid derivative & Farnesoid X receptor \\
\hline Selonsertib & $\begin{array}{l}\text { STELLAR-3, } 4 \text { (discontinued } \\
\text { development) }\end{array}$ & Antifibrotic agents & Apoptosis signal-regulating kinase 1 \\
\hline Elafibranor & RESOLVE-IT (discontinued development) & PPAR agonist & PPAR- $a / \delta$ \\
\hline Cenicriviroc & AURORA & Chemokine receptor antagonist & CCR2, 5 \\
\hline Resmetirom & MAESTRO-NASH & $\begin{array}{l}\text { Hepatic thyroid hormone receptor } \\
\beta \text {-selective agonist }\end{array}$ & THR $\beta$ \\
\hline Aramchol & ARMOR & Synthetic fatty acid/bile acid conjugate & Stearoyl coenzyme A desaturase 1 \\
\hline
\end{tabular}

PPAR, peroxisome proliferator-activated receptor; CCR, chemokine receptor; THR, thyroid hormone receptor.

\section{Bariatric surgery and LT}

What are the indications for and post-operative management of bariatric surgery?

Bariatric surgery has been performed in NASH patients with obesity who did not respond to medical treatment for weight loss. In Western countries, bariatric surgery is considered to be indicated for patients with a BMI greater than $35 \mathrm{~kg} / \mathrm{m}^{2}$ that is accompanied by hypertension or diabetes mellitus or a BMI greater than $40 \mathrm{~kg} / \mathrm{m}^{2} .{ }^{284,318,346}$ Several studies reported significant weight loss in addition to improvement in NAFLD. ${ }^{347-351}$ In Korea, the Health Insurance Review and Assessment Service allows bariatric surgery to be covered by the national health insurance for patients who have had no response to medical treatment and lifestyle modifications and whose BMI is greater than $35 \mathrm{~kg} / \mathrm{m}^{2}$ or $30 \mathrm{~kg} / \mathrm{m}^{2}$ and associated with hypertension, diabetes mellitus, or NAFLD.

In a 5-year follow-up study of biopsy-confirmed NASH patients who underwent bariatric surgery, BMI, the amount of fat in the liver, and NAS were all found to be reduced, and histological improvement in the fibrosis stage was noted after surgery. ${ }^{352}$ Recent meta-analyses identified that bariatric surgery effectively reduced the amount of fat in the liver, inflammation, and fibrosis in NASH patients. ${ }^{353,354}$ However, histological worsening after surgery was observed in some patients. Therefore, well-designed, randomized controlled studies should be performed to confirm the benefits of bariatric surgery in NASH patients. ${ }^{348}$ The limitation of bariatric surgery is the risk of lethal liver failure that can be generated by rapid weight loss. Also, the safety of bariatric surgery for cirrhotic patients is still controversial, so a careful approach is needed. ${ }^{355-358}$ Before deciding to undertake bariatric surgery, intraoperative complications, long-term malnutrition, and other factors need to be considered comprehensively. ${ }^{359-361}$

\section{[Recommendations]}

1. Bariatric surgery can be considered for NASH patients with obesity who do not respond to medical treatment and lifestyle modification. (B1)

2. The effectiveness and safety of bariatric surgery have not been established in patients with cirrhosis. (B1)

What are the indications for LT and post-LT management?

LT can be considered in patients with end-stage liver disease caused by NAFLD-associated cirrhosis, liver failure, or HCC, according to the clinical practice guideline for LT. NASH patients experience a high risk of mortality from cardiovascular complications, so a meticulous pretransplant cardiovascular evaluation is needed. ${ }^{80,362,363}$ Posttransplant outcomes for NAFLD patients, including 3- and 5-year survival, were comparable to those of nonNAFLD patients, whereas the risk of graft failure was lower. ${ }^{364}$ Overall survival was associated with BMI and the presence of diabetes mellitus. LT patients with a BMI greater than $35 \mathrm{~kg} / \mathrm{m}^{2}$ experienced a higher transplant failure rate and lower 1-year survival rate than LT patients with a BMI lower than $35 \mathrm{~kg} / \mathrm{m}^{2}$. ${ }^{365}$

Posttransplant management is similar to that for other NASH patients. Maintaining a healthy weight and diet is important, especially given that weight gain is common following $\mathrm{LT}^{363,366} \mathrm{He}$ patic steatosis ${ }^{367}$ or metabolic syndrome ${ }^{368}$ is very common after LT, especially in patients with a history of NASH. Thus, careful attention should be paid to posttransplant management.

\section{[Recommendations]}

1. Liver transplantation could be considered in NASH patients with end-stage liver disease or HCC, according to the clinical practice guideline for LT. (A1) 


\section{NAFLD IN CHILDREN AND ADOLESCENTS}

\section{Epidemiology}

\section{What is the prevalence rate?}

The National Health and Nutrition Survey conducted between 2015 and 2017 defined cases with ALT of 26 IU/L (boys) and 22 IU/L (girls) as NAFLD, and the estimated prevalence of this disease in children was $11.2 \%$ (14.7\% for boys and $7.4 \%$ for girls). ${ }^{369}$ In 2001-2005, the prevalence was 7.8\% (10.6\% for boys and 4.6\% for girls), so the prevalence is increasing, and $40-45 \%$ of obese adolescents have NAFLD. ${ }^{369,370}$ The obesity rate of children and adolescents aged 7-18 years increased from $8.4 \%$ in 2008 to $14.3 \%$ in 2016 , so the prevalence of NAFLD is expected to increase rapidly in the future. ${ }^{371,372}$

\section{Summary}

1. The prevalence of NAFLD among children and adolescents in Korea is increasing as their obesity rate increases.

\section{How does NAFLD progress?}

The natural course and prognosis of NAFLD in children and adolescents are not well known. Unlike NAFL, NASH can progress to cirrhosis in children and adolescents. ${ }^{373}$ In a foreign study that followed 66 children and adolescents with NAFLD for 20 years, the exacerbation of liver disease and risk of early death increased by 14 times compared with the control group. ${ }^{374}$ There was also a case in which $\mathrm{HCC}$ occurred in a 7-year-old child diagnosed with NAFLD. ${ }^{375}$ In recent years, LT has increased in children, adolescents, and young adults due to end-stage liver disease related to NAFLD. ${ }^{376,377}$

\section{Summary}

1. NASH in children and adolescents can progress to end-stage liver disease, including cirrhosis, in young adults.

\section{What genetic diseases are associated with risk factors?}

The risk factors for NAFLD in children and adolescents are obesity, adolescent age, and being male. ${ }^{378,379}$ This disease is common in adolescence because the increased sex hormones that occur at puberty cause changes in insulin resistance and body composition, with the hormones of boys perhaps causing more NAFLD than those of girls. In patients with abdominal obesity and ob- structive sleep apnea, NAFLD is likely to be associated with acanthosis nigricans. ${ }^{376,377}$

Unlike in adults, in children and adolescents, steatosis sometimes appears as a phenotype of genetic disease. Therefore, through medical history, examination, and testing, Wilson's disease, Bardet-Biedl syndrome, polycystic ovary syndrome, PraderWilli syndrome, Turner syndrome, Cohen syndrome, alpha1-antitrypsin deficiency, glycogen storage disease, genetic tyrosinemia type 1, homocystinuria, Refsum disease, citrullinemia, and lysosomal acid lipase deficiency should be differentiated. ${ }^{373}$

\section{Summary}

1. Obesity, adolescent age, and being male are risk factors for nonalcoholic fatty liver disease in children and adolescents.

2. If steatosis is found in children and adolescents, potential accompanying genetic diseases should be considered.

\section{Genetic factors}

\section{Is related NAFLD related to family history and genetic predisposition?}

Children and adolescents with a family history of NAFLD are at high risk of developing it. In children and adolescents diagnosed with NAFLD, $59 \%$ of their siblings and $78 \%$ of their parents also had NAFLD. On the other hand, in obese children and adolescent patients without NAFLD, NAFLD was found in only $17 \%$ of their siblings and $37 \%$ of their parents. ${ }^{380}$ NAFLD occurs from a variety of causes, but family outbreaks, twin studies, and differences in prevalence among races confirm that more than $50 \%$ of patients with this disease are likely to have a genetic predisposition to it. ${ }^{381}$

In a genome-wide association study, an increase in liver fat mass was associated with mutations in the PNPLA3, TM6SF2, LY$P L A L 1$, and GCKR genes. ${ }^{382}$ Genetic polymorphisms reported in children and adolescents include MBOAT7, PNPLA3, TM6SF2, and $G C K R{ }^{383-390}$ Studies also showed an association with monoallelic ABHD5 mutations. ${ }^{391}$

\section{Summary}

1. Children and adolescents are at increased risk of NAFLD if there is a family history of it.

2. NAFLD in children and adolescents can be associated with genetic variations and genetic polymorphism. 


\section{Screening and diagnosis}

\section{Who should be targeted for NAFLD screening, and how is screening conducted?}

NAFLD is common in children and adolescents who are overweight (above the 85th percentile and below the 95th percentile of BMI) or obese (above the 95th percentile of BMI). Therefore, screening is necessary for those groups. Overweight and obesity are checked during school health checkups in the 4th and 6th grades of elementary school, the 1st grade of middle school, and the 1st grade of high school in Korea. In overweight young people, screening tests are performed using liver enzyme levels. ${ }^{392}$

ALT is used as a screening method for NAFLD in overweight and obese children and adolescents. In 2007, the US Expert Committee also recommended AST and ALT as screening tests. ${ }^{393-395}$ However, because the normal ranges of ALT by age and sex are unclear, European authorities recommended abdominal ultrasound along with ALT as a screening test. ${ }^{396}$ In the 2019 guidelines for obesity in children and adolescents, those who were overweight or obese and had an ALT of 26 IU/L (boys) or $22 \mathrm{IU} / \mathrm{L}$ (girls) or more were diagnosed with NAFLD and recommended for abdominal ultrasound when necessary. ${ }^{397}$ In 2017, the North American Society of Pediatric and Gastrointestinal Nutrition recommended ALT as a screening test for obese and overweight children aged 9-11 years with insulin resistance, pre-diabetes, diabetes, or dyslipidemia. ${ }^{398}$ Based on the limited research results available for the cost-effectiveness of screening tests in overweight and obese children and adolescents, the American Liver Association did not recommend screening for NAFLD using ALT in obese children and adolescents. ${ }^{399}$ However, the 2019 guidelines for pediatric and adolescent obesity did recommend screening tests for NAFLD and other concomitant diseases in overweight and obese children and adolescents.

\section{[Recommendations]}

1. NAFLD screening tests can be performed in overweight and obese children and adolescents. (B1)

2. The preferred screening test for NAFLD in children and adolescents is ALT, and abdominal ultrasound can also be performed. (B1)

\section{What are the diagnostic methods?}

The standard test for diagnosing NAFLD is liver biopsy. However, because that method is invasive, its application to children and adolescents is limited. The pathologic findings of NAFLD in children and adolescents can differ from those found in adults. Representative differences are that steatosis is more widely observed, balloon degeneration of hepatocytes and hepatic lobular inflammation are milder, and inflammation and fibrosis of the portal region are often present. Sinusoid fibrosis in zone 3, which is commonly observed in adults, is relatively rare in NAFLD in children and adolescents.

As a non-invasive method for diagnosing NAFLD, a method using cytokeratin-18, which is produced during hepatocyte death, can be used..$^{400}$ In addition, various non-invasive panels are being studied, but they have not yet been recommended for clinical practice. Other additional methods include abdominal ultrasound, liver fibrosis scans, and MRI-PDFF.

\section{[Recommendations]}

1. In addition to liver biopsy, non-invasive tests such as abdominal ultrasound, liver fibrosis scans, and MRI-PDFF can be performed. (B1)

\section{Treatment}

\section{Who should be treated, and how?}

Overweight and obese children and adolescents with NAFLD are subject to treatment, and these patients are recommended to correct their lifestyle habits first. There are insufficient studies on the long-term prognosis of NAFLD in children and adolescents, and few prospective randomized controlled studies have been done. However, when the disease is diagnosed at an early age, the possibility of long-term complications is high.

Most of children and adolescents with NAFLD are associated with obesity, so it is important to correct lifestyle habits to improve obesity. Various studies have been conducted on the correction of lifestyle habits. Based on randomized controlled studies, the North American Society of Pediatric Gastrointestinal Nutrition recommended in 2017 that simple sugar-added beverages be restricted, moderate physical activity be increased, and screen time (time exposed to the screens of electronic devices such as TVs, computers, and smartphones) be reduced to less than 2 hours per day. . $^{41-403}$

According to the TONIC trial, a large multicenter randomized controlled study comparing vitamin $\mathrm{E}$, metformin, and placebo in NAFLD patients aged 8-17 years, the three groups did not differ in terms of a sustained decrease in ALT. In the vitamin E group, 
histological improvement was observed. However, long-term use of high-dose vitamin $\mathrm{E}$ is not recommended because of concerns about side effects. ${ }^{404-407}$ In addition, a small randomized controlled study tested ursodeoxycholic acid, docosahexaenoic acid, and fish oil, and no significant effect was found. ${ }^{408,409}$ In conclusion, no drug treatment is currently recommended for NAFLD in children and adolescents.

Although there is no guideline for surgical treatment of NAFLD, it can be performed in cases of severe obesity (BMI 97th percentile or higher) based on the results of research in adults..$^{410}$ In the domestic guidelines for obesity in children and adolescents, obesity surgery is recommended when BMI is 40 or more, or 35 or more and accompanied by major complications related to obesity, and lifestyle improvements and drug treatment have produced no effects. ${ }^{397}$ Because children and adolescents are growing, growth should be considered when deciding on the timing of surgery. In general, surgery should be considered only when skeletal growth is almost complete (i.e., 13-14 years old for girls, 15-16 years old for boys), and it is recommended that surgery be performed when the Tanner stage (division stage considering the degree of development of male and female genitals according to the stage of puberty) is 4 or higher. ${ }^{411,412}$

\section{[Recommendations]}

1. In NAFLD in children and adolescents who are overweight or obese, lifestyle correction such as improvement of dietary habits, increase in physical activity, and restriction of screen time is needed first. (A1)

\section{Authors' contributions}

Study conception and design: Seong Hee Kang, Hye Won Lee, Jeong-Ju Yoo, Yuri Cho Seung Up Kim and Yong Kyun Cho; Report writing: Seong Hee Kang, Hye Won Lee, Jeong-Ju Yoo, Yuri Cho Seung Up Kim, Tae Hee Lee, Byoung Kuk Jang, Sang Gyune Kim, Sang Bong Ahn, Haeryoung Kim, Dae Won Jun, Joon-II Choi, Do Seon Song, Won Kim, Soung Won Jeong, Moon Young Kim, Hong Koh, Sujin Jeong, Jin-Woo Lee and Yong Kyun Cho; Review: Seong Hee Kang, Hye Won Lee, Jeong-Ju Yoo, Yuri Cho Seung Up Kim and Yong Kyun Cho; Final approval of the submission of the manuscript: Seong Hee Kang, Hye Won Lee, Jeong-Ju Yoo, Yuri Cho Seung Up Kim, Tae Hee Lee, Byoung Kuk Jang, Sang Gyune Kim, Sang Bong Ahn, Haeryoung Kim, Dae Won Jun, Joon-II Choi, Do Seon Song, Won Kim, Soung Won Jeong, Moon Young Kim, Hong Koh, Sujin Jeong, Jin-Woo Lee and Yong Kyun Cho.

\section{Acknowledgements}

This study was supported by the Korean Association for the Study of the Liver (KASL).

This manuscript was reviewed by native speakers for English proof readings (Eworld Editing; KASL2104-01).

\section{Conflicts of Interest}

Yong Kyun Cho is a speaker for Samil Pharm, Bukwang and DaeWoong. He has received a research grant from DaeWoong, Dong-A, Celltrion and Ildong.

Seung Up Kim has served as an advisory committee member of Gilead Sciences, Bayer, Eisai, Novo Nordisk, and GreenCross. He is a speaker for Gilead Sciences, GSK, Bayer, Eisai, Abbvie, EchoSens, MSD, Eisai, Otsuka, Bristol-Myers Squibb, Yuhan, Samil Pharm, Ildong, Celltrion, PharmaKING, DaeWoong, Samjin, DongA, Hanmi, BuKwang, Echme medical, Hanwha, Sysmax, and ChongKunDang. He has also received a research grant from Abbvie, Bristol-Myers Squibb, ChongKunDang, DaeWoong, Hanmi, Samil Pharm, and Echme Medical.

Jeong-Ju Yoo is a speaker for DaeWoong, Ildong, Pharmaking, Dong-A, BMS, Samil Pharm and Bukwang.

Tae Hee Lee is a speaker for Abbvie, Gilead, Samil Pharm and Yuhan. He has received a research grant from Eisai, Celltrion, PharmaKING and GC Wellbeing.

Byoung Kuk Jang is a speaker for Gilead. He has received a research grant from PharmaKING, Novo Nordisk Pharma, Vaccitech and GC Wellbeing.

Sang Gyune Kim has received grants from GE healthcare, Samsung Medison, BMS, Samil, Ildong; received honoraria from BMS, MSD, Gilead, Daewoog, Hanwha; consulted Samsung Medison.

Sang Bong Ahn has received grants from Hanwha, Samjin, IIdong, and Hanmi.

Dae Won Jun has served as an advisory committee member of Sysmax, J2H, and Future medicine. He is a speaker for Gilead Sciences, Bristol-Myers Squibb, Yuhan, Chong Kun Dang, Ildong, Donga, Samil, Phamaking, Celltrion, and Daewoong. He has also received a research grant from Yuhan.

Joon-II Choi previously received grants from Bayer Healthcare, Guerbet Korea, Bracco Korea and Samsung Medison. He previously received honorariums from Bayer Healthcare, Guerbet Korea and Bracco Korea.

Won Kim has served as an advisory committee member of Boehringer-Ingelheim, HK inno.N, GreenCross, Standigm, Pharmaking, KOBIOLABS, Eisai, Zydus and Novonordisk. He is a speaker for Gilead, Boehringer-Ingelheim, Samil, I-dong, LG 
chemistry and Bukwang. He has also received a research grant from Gilead, Il-dong, GreenCross, Bukwang, Roche, Galmed, Novartis, Pfizer, Springbank, Altimmune, MSD, BMS, Novonordisk, Hitachi Aloka, JW medical, Dicerna and Enyo.

Soung Won Jeong is a speaker for Daewoong, Samil and Pharmaking. He has received a research grant from Dong-A ST, IIdong and Chongkundang.

Moon Young Kim is a speaker for Samjin and Gilead. He has received a research grant from Yuhan.

Jin-Woo Lee has served as an advisory committee member of Abbvie and Novo Nordisk. He has received a research grant from Galectin Therapeutics Inc, BMS, MSD and Ipsen.

The other authors declare that they have no competing interests.

\section{REFERENCES}

1. European Association for the Study of the Liver (EASL); European Association for the Study of Diabetes (EASD); European Association for the Study of Obesity (EASO). EASL-EASD-EASO clinical practice guidelines for the management of non-alcoholic fatty liver disease. Obes Facts 2016;9:65-90.

2. The Lancet Gastroenterology Hepatology. Redefining non-alcoholic fatty liver disease: what's in a name? Lancet Gastroenterol Hepatol 2020;5:419.

3. Eslam M, Sanyal AJ, George J; International Consensus Panel. MAFLD: a consensus-driven proposed nomenclature for metabolic associated fatty liver disease. Gastroenterology 2020;158:19992014.e1.

4. Chang $Y$, Ryu S, Sung E, Jang Y. Higher concentrations of alanine aminotransferase within the reference interval predict nonalcoholic fatty liver disease. Clin Chem 2007;53:686-692.

5. Chang Y, Jung HS, Cho J, Zhang Y, Yun KE, Lazo M, et al. Metabolically healthy obesity and the development of nonalcoholic fatty liver disease. Am J Gastroenterol 2016;111:1133-1140.

6. Lee MJ, Kim EH, Bae SJ, Kim GA, Park SW, Choe J, et al. Age-related decrease in skeletal muscle mass is an independent risk factor for incident nonalcoholic fatty liver disease: a 10-year retrospective cohort study. Gut Liver 2019;13:67-76.

7. Kim D, Chung GE, Kwak MS, Seo HB, Kang JH, Kim W, et al. Body fat distribution and risk of incident and regressed nonalcoholic fatty liver disease. Clin Gastroenterol Hepatol 2016;14:132-138.e4.

8. Jung HS, Chang Y, Kwon MJ, Sung E, Yun KE, Cho YK, et al. Smoking and the risk of non-alcoholic fatty liver disease: a cohort study. Am J Gastroenterol 2019;114:453-463.

9. Kim D, Chung GE, Kwak MS, Kim YJ, Yoon JH. Effect of longitudinal changes of body fat on the incidence and regression of nonalcoholic fatty liver disease. Dig Liver Dis 2018;50:389-395.

10. Kim TJ, Sinn DH, Min YW, Son HJ, Kim JJ, Chang Y, et al. A cohort study on Helicobacter pylori infection associated with nonalcoholic fatty liver disease. J Gastroenterol 2017;52:1201-1210.

11. Sinn DH, Cho SJ, Gu S, Seong D, Kang D, Kim H, et al. Persistent nonalcoholic fatty liver disease increases risk for carotid atherosclerosis. Gastroenterology 2016;151:481-488.e1.

12. Kim G, Lee SE, Lee YB, Jun JE, Ahn J, Bae JC, et al. Relationship between relative skeletal muscle mass and nonalcoholic fatty liver disease: a 7-year longitudinal study. Hepatology 2018;68:17551768.

13. Li J, Zou B, Yeo YH, Feng Y, Xie $X$, Lee $D H$, et al. Prevalence, incidence, and outcome of non-alcoholic fatty liver disease in Asia, 1999-2019: a systematic review and meta-analysis. Lancet Gastroenterol Hepatol 2019;4:389-398.

14. Younossi ZM, Koenig AB, Abdelatif D, Fazel Y, Henry L, Wymer M. Global epidemiology of nonalcoholic fatty liver disease-metaanalytic assessment of prevalence, incidence, and outcomes. Hepatology 2016;64:73-84.

15. Kim HJ, Kim DJ, Kim SK, Kim SH, Rhee YM, Ahn CW, et al. Metabolic abnormalities according to severity of non-alcoholic fatty liver disease in Korean adults. Endocrinol Metab 2002;17:514-525.

16. Jeong EH, Jun DW, Cho YK, Choe YG, Ryu S, Lee SM, et al. Regional prevalence of non-alcoholic fatty liver disease in Seoul and Gyeonggi-do, Korea. Clin Mol Hepatol 2013;19:266-272.

17. Chang Y, Jung HS, Yun KE, Cho J, Cho YK, Ryu S. Cohort study of non-alcoholic fatty liver disease, NAFLD fibrosis score, and the risk of incident diabetes in a Korean population. Am J Gastroenterol 2013;108:1861-1868.

18. Lee SB, Park GM, Lee JY, Lee BU, Park JH, Kim BG, et al. Association between non-alcoholic fatty liver disease and subclinical coronary atherosclerosis: an observational cohort study. J Hepatol 2018;68:1018-1024.

19. Jang HR, Kang D, Sinn DH, Gu S, Cho SJ, Lee JE, et al. Nonalcoholic fatty liver disease accelerates kidney function decline in patients with chronic kidney disease: a cohort study. Sci Rep 2018;8:4718.

20. Chang Y, Cho YK, Cho J, Jung HS, Yun KE, Ahn J, et al. Alcoholic and nonalcoholic fatty liver disease and liver-related mortality: a cohort study. Am J Gastroenterol 2019;114:620-629.

21. Jang EH, Chang Y, Ryu S, Kim S, Kim YH, Sung KC, et al. Cardiovascular health metrics in the development and regression of nonalcoholic fatty liver disease: a cohort study. J Clin Med 2019;8:610.

22. Kim JH, Jung DH, Kwon YJ, Lee JI, Shim JY. The impact of the sleep duration on NAFLD score in Korean middle-aged adults: a community-based cohort study. Sleep Med 2019;57:144-150.

23. Sung KC, Lee MY, Lee JY, Lee SH, Kim SH, Kim SH. Utility of ALT concentration in men and women with nonalcoholic fatty liver dis- 
ease: cohort study. J Clin Med 2019;8:445

24. Huh JH, Kim JY, Choi E, Kim JS, Chang Y, Sung KC. The fatty liver index as a predictor of incident chronic kidney disease in a 10-year prospective cohort study. PLoS One 2017;12:e0180951.

25. Lee HW, Kim BK, Kim SU, Park JY, Kim DY, Ahn SH, et al. Prevalence and predictors of significant fibrosis among subjects with transient elastography-defined nonalcoholic fatty liver disease. Dig Dis Sci 2017;62:2150-2158.

26. Lee JY, Kim KM, Lee SG, Yu E, Lim YS, Lee HC, et al. Prevalence and risk factors of non-alcoholic fatty liver disease in potential living liver donors in Korea: a review of 589 consecutive liver biopsies in a single center. J Hepatol 2007;47:239-244.

27. Kim HJ, Kim HJ, Lee KE, Kim DJ, Kim SK, Ahn CW, et al. Metabolic significance of nonalcoholic fatty liver disease in nonobese, nondiabetic adults. Arch Intern Med 2004;164:2169-2175.

28. Sung KC, Ryan MC, Wilson AM. The severity of nonalcoholic fatty liver disease is associated with increased cardiovascular risk in a large cohort of non-obese Asian subjects. Atherosclerosis 2009;203:581-586.

29. Chon CW, Kim BS, Cho YK, Sung KC, Bae JC, Kim TW, et al. Effect of nonalcoholic fatty liver disease on the development of type 2 diabetes in nonobese, nondiabetic Korean men. Gut Liver 2012;6:368-373.

30. Sinn DH, Gwak GY, Park HN, Kim JE, Min YW, Kim KM, et al. Ultrasonographically detected non-alcoholic fatty liver disease is an independent predictor for identifying patients with insulin resistance in non-obese, non-diabetic middle-aged Asian adults. Am J Gastroenterol 2012;107:561-567.

31. Kim NH, Kim JH, Kim YJ, Yoo HJ, Kim HY, Seo JA, et al. Clinical and metabolic factors associated with development and regression of nonalcoholic fatty liver disease in nonobese subjects. Liver Int 2014;34:604-611.

32. Cho HC. Prevalence and factors associated with nonalcoholic fatty liver disease in a nonobese Korean population. Gut Liver 2016;10:117-125.

33. Yang MH, Sung J, Gwak GY. The associations between apolipoprotein $B, A 1$, and the $B / A 1$ ratio and nonalcoholic fatty liver disease in both normal-weight and overweight Korean population. J Clin Lipidol 2016;10:289-298.

34. Kim SS, Cho HJ, Kim HJ, Kang DR, Berry JR, Kim JH, et al. Nonalcoholic fatty liver disease as a sentinel marker for the development of diabetes mellitus in non-obese subjects. Dig Liver Dis 2018;50:370377.

35. Wong VW, Wong GL, Choi PC, Chan AW, Li MK, Chan HY, et al. Disease progression of non-alcoholic fatty liver disease: a prospective study with paired liver biopsies at 3 years. Gut 2010;59:969974.

36. Pais R, Charlotte F, Fedchuk L, Bedossa P, Lebray P, Poynard T, et al. A systematic review of follow-up biopsies reveals disease progression in patients with non-alcoholic fatty liver. J Hepatol 2013:59:550-556.

37. McPherson S, Hardy T, Henderson E, Burt AD, Day CP, Anstee QM. Evidence of NAFLD progression from steatosis to fibrosingsteatohepatitis using paired biopsies: implications for prognosis and clinical management. J Hepatol 2015;62:1148-1155.

38. Singh S, Allen AM, Wang Z, Prokop LJ, Murad MH, Loomba R. Fibrosis progression in nonalcoholic fatty liver vs nonalcoholic steatohepatitis: a systematic review and meta-analysis of pairedbiopsy studies. Clin Gastroenterol Hepatol 2015;13:643-654.e1-e9; quiz e39-e40.

39. Matteoni CA, Younossi ZM, Gramlich T, Boparai N, Liu YC, MCCullough AJ. Nonalcoholic fatty liver disease: a spectrum of clinical and pathological severity. Gastroenterology 1999;116:1413-1419.

40. Ahmed A, Wong RJ, Harrison SA. Nonalcoholic fatty liver disease review: diagnosis, treatment, and outcomes. Clin Gastroenterol Hepatol 2015;13:2062-2070.

41. Wong RJ, Aguilar M, Cheung R, Perumpail RB, Harrison SA, Younossi ZM, et al. Nonalcoholic steatohepatitis is the second leading etiology of liver disease among adults awaiting liver transplantation in the United States. Gastroenterology 2015;148:547-555.

42. Mohamad B, Shah V, Onyshchenko M, Elshamy M, Aucejo F, Lopez $\mathrm{R}$, et al. Characterization of hepatocellular carcinoma (HCC) in non-alcoholic fatty liver disease (NAFLD) patients without cirrhosis. Hepatol Int 2016;10:632-639.

43. Younossi ZM, Otgonsuren M, Henry L, Venkatesan C, Mishra A, Erario $M$, et al. Association of nonalcoholic fatty liver disease (NAFLD) with hepatocellular carcinoma (HCC) in the United States from 2004 to 2009. Hepatology 2015;62:1723-1730.

44. Mittal S, El-Serag HB, Sada YH, Kanwal F, Duan Z, Temple S, et al. Hepatocellular carcinoma in the absence of cirrhosis in United States veterans is associated with nonalcoholic fatty liver disease. Clin Gastroenterol Hepatol 2016;14:124-131.e1.

45. Paradis V, Zalinski S, Chelbi E, Guedj N, Degos F, Vilgrain V, et al. Hepatocellular carcinomas in patients with metabolic syndrome often develop without significant liver fibrosis: a pathological analysis. Hepatology 2009;49:851-859.

46. Yasui K, Hashimoto E, Komorizono Y, Koike K, Arii S, Imai Y, et al. Characteristics of patients with nonalcoholic steatohepatitis who develop hepatocellular carcinoma. Clin Gastroenterol Hepatol 2011;9:428-433; quiz e50.

47. Paik JM, Henry L, De Avila L, Younossi E, Racila A, Younossi ZM. Mortality related to nonalcoholic fatty liver disease is increasing in the United States. Hepatol Commun 2019;3:1459-1471.

48. Musso G, Gambino R, Cassader M, Pagano G. Meta-analysis: natural history of non-alcoholic fatty liver disease (NAFLD) and diagnostic accuracy of non-invasive tests for liver disease severity. 
Ann Med 2011;43:617-649.

49. Bril F, Sninsky JJ, Baca AM, Superko HR, Portillo Sanchez P, Biernacki $D$, et al. Hepatic steatosis and insulin resistance, but not steatohepatitis, promote atherogenic dyslipidemia in NAFLD. J Clin Endocrinol Metab 2016;101:644-652.

50. Jepsen P, Vilstrup H, Mellemkjaer L, Thulstrup AM, Olsen JH, Baron $J A$, et al. Prognosis of patients with a diagnosis of fatty liver--a registry-based cohort study. Hepatogastroenterology 2003;50:21012104.

51. Angulo P, Kleiner DE, Dam-Larsen S, Adams LA, Bjornsson ES, Charatcharoenwitthaya $\mathrm{P}$, et al. Liver fibrosis, but no other histologic features, is associated with long-term outcomes of patients with nonalcoholic fatty liver disease. Gastroenterology 2015;149:389397.e10.

52. Hagström H, Nasr P, Ekstedt M, Hammar U, Stål P, Hultcrantz R, et al. Fibrosis stage but not NASH predicts mortality and time to development of severe liver disease in biopsy-proven NAFLD. J Hepatol 2017;67:1265-1273.

53. Simon TG, Roelstraete $B$, Khalili $H$, Hagström $H$, Ludvigsson JF. Mortality in biopsy-confirmed nonalcoholic fatty liver disease: results from a nationwide cohort. Gut 2021;70:1375-1382.

54. Younossi ZM. Non-alcoholic fatty liver disease - a global public health perspective. J Hepatol 2019;70:531-544.

55. Udelsman BV, Corey KE, Lindvall C, Gee DW, Meireles OR, Hutter $M M$, et al. Risk factors and prevalence of liver disease in review of 2557 routine liver biopsies performed during bariatric surgery. Surg Obes Relat Dis 2019;15:843-849.

56. Younossi Z, Tacke F, Arrese M, Chander Sharma B, Mostafa I, Bugianesi $E$, et al. Global perspectives on nonalcoholic fatty liver disease and nonalcoholic steatohepatitis. Hepatology 2019;69:26722682.

57. Non-alcoholic Fatty Liver Disease Study Group, Lonardo A, Bellentani S, Argo CK, Ballestri S, Byrne CD, et al. Epidemiological modifiers of non-alcoholic fatty liver disease: focus on high-risk groups. Dig Liver Dis 2015;47:997-1006.

58. Kotronen A, Westerbacka J, Bergholm R, Pietiläinen KH, Yki-Järvinen $\mathrm{H}$. Liver fat in the metabolic syndrome. J Clin Endocrinol Metab 2007;92:3490-3497.

59. Assy N, Kaita K, Mymin D, Levy C, Rosser B, Minuk G. Fatty infiltration of liver in hyperlipidemic patients. Dig Dis Sci 2000;45:19291934.

60. Wu KT, Kuo PL, Su SB, Chen YY, Yeh ML, Huang Cl, et al. Nonalcoholic fatty liver disease severity is associated with the ratios of total cholesterol and triglycerides to high-density lipoprotein cholesterol. J Clin Lipidol 2016;10:420-425.e1.

61. Guo Z, Li M, Han B, Qi X. Association of non-alcoholic fatty liver disease with thyroid function: a systematic review and metaanalysis. Dig Liver Dis 2018;50:1153-1162.
62. Kumarendran B, O'Reilly MW, Manolopoulos KN, Toulis KA, Gokhale KM, Sitch AJ, et al. Polycystic ovary syndrome, androgen excess, and the risk of nonalcoholic fatty liver disease in women: a longitudinal study based on a United Kingdom primary care database. PLoS Med 2018;15:e1002542.

63. Mesarwi OA, Loomba R, Malhotra A. Obstructive sleep apnea, hypoxia, and nonalcoholic fatty liver disease. Am J Respir Crit Care Med 2019;199:830-841.

64. Adams LA, Feldstein A, Lindor KD, Angulo P. Nonalcoholic fatty liver disease among patients with hypothalamic and pituitary dysfunction. Hepatology 2004;39:909-914.

65. Mintziori G, Poulakos P, Tsametis C, Goulis DG. Hypogonadism and non-alcoholic fatty liver disease. Minerva Endocrinol 2017;42:145150.

66. Fujii Y, Nanashima A, Hiyoshi M, Imamura N, Yano K, Hamada T. Risk factors for development of nonalcoholic fatty liver disease after pancreatoduodenectomy. Ann Gastroenterol Surg 2017;1:226231.

67. Ramos AN, de Oliveira Rocha B, de Almeida Rêgo VR, Follador I, de Oliveira MF. The linkage between psoriasis and non-alcoholic fatty liver disease: a literature review. Acta Dermatovenerol Croat 2014;22:132-136.

68. Hong HC, Hwang SY, Choi HY, Yoo HJ, Seo JA, Kim SG, et al. Relationship between sarcopenia and nonalcoholic fatty liver disease: the Korean Sarcopenic Obesity Study. Hepatology 2014;59:17721778.

69. Lee YH, Jung KS, Kim SU, Yoon HJ, Yun YJ, Lee BW, et al. Sarcopaenia is associated with NAFLD independently of obesity and insulin resistance: nationwide surveys (KNHANES 2008-2011). J Hepatol 2015;63:486-493.

70. Hsieh SD, Yoshinaga H, Muto T, Sakurai Y. Regular physical activity and coronary risk factors in Japanese men. Circulation 1998;97:661-665

71. Perseghin G, Lattuada G, De Cobelli F, Ragogna F, Ntali G, Esposito A, et al. Habitual physical activity is associated with intrahepatic fat content in humans. Diabetes Care 2007;30:683-688.

72. Nader PR, Bradley RH, Houts RM, McRitchie SL, O'Brien M. Moderate-to-vigorous physical activity from ages 9 to 15 years. JAMA 2008;300:295-305.

73. Chung GE, Lee Y, Yim JY, Choe EK, Kwak MS, Yang Jl, et al. Genetic polymorphisms of PNPLA3 and SAMM50 are associated with nonalcoholic fatty liver disease in a Korean population. Gut Liver 2018;12:316-323.

74. Eslam M, Newsome PN, Sarin SK, Anstee QM, Targher G, RomeroGomez $M$, et al. A new definition for metabolic dysfunctionassociated fatty liver disease: an international expert consensus statement. J Hepatol 2020;73:202-209.

75. Lonardo A, Nascimbeni F, Mantovani A, Targher G. Hypertension, 
diabetes, atherosclerosis and NASH: cause or consequence? J Hepatol 2018;68:335-352.

76. Li AA, Ahmed A, Kim D. Extrahepatic manifestations of nonalcoholic fatty liver disease. Gut Liver 2020;14:168-178.

77. Ballestri S, Zona S, Targher G, Romagnoli D, Baldelli E, Nascimbeni F, et al. Nonalcoholic fatty liver disease is associated with an almost twofold increased risk of incident type 2 diabetes and metabolic syndrome. Evidence from a systematic review and meta-analysis. J Gastroenterol Hepatol 2016;31:936-944.

78. Ekstedt $M$, Hagström $H$, Nasr $P$, Fredrikson $M$, Stål $P$, Kechagias $S$, et al. Fibrosis stage is the strongest predictor for disease-specific mortality in NAFLD after up to 33 years of follow-up. Hepatology 2015;61:1547-1554.

79. Zeb I, Li D, Budoff MJ, Katz R, Lloyd-Jones D, Agatston A, et al. Nonalcoholic fatty liver disease and incident cardiac events: the multi-ethnic study of atherosclerosis. J Am Coll Cardiol 2016;67:1965-1966.

80. Targher G, Byrne CD, Lonardo A, Zoppini G, Barbui C. Non-alcoholic fatty liver disease and risk of incident cardiovascular disease: a meta-analysis. J Hepatol 2016;65:589-600.

81. Sinn DH, Kang D, Chang Y, Ryu S, Gu S, Kim H, et al. Non-alcoholic fatty liver disease and progression of coronary artery calcium score: a retrospective cohort study. Gut 2017;66:323-329.

82. Anstee QM, Targher G, Day CP. Progression of NAFLD to diabetes mellitus, cardiovascular disease or cirrhosis. Nat Rev Gastroenterol Hepatol 2013;10:330-344.

83. Park J, Lee EY, Li J, Jun MJ, Yoon E, Ahn SB, et al. NASH/liver fibrosis prevalence and incidence of non-liver comorbidities among people with NAFLD and incidence of NAFLD by metabolic comorbidites: lessons from South Korea. Dig Dis. 2021 Feb 3. doi: 10.1159/000514953.

84. Mantovani A, Byrne CD, Bonora E, Targher G. nonalcoholic fatty liver disease and risk of incident type 2 diabetes: a meta-analysis. Diabetes Care 2018;41:372-382.

85. Ryoo JH, Choi JM, Moon SY, Suh YJ, Shin JY, Shin HC, et al. The clinical availability of non alcoholic fatty liver disease as an early predictor of the metabolic syndrome in Korean men: 5-year's prospective cohort study. Atherosclerosis 2013;227:398-403.

86. Targher G, Chonchol MB, Byrne CD. CKD and nonalcoholic fatty liver disease. Am J Kidney Dis 2014;64:638-652.

87. Targher G, Bertolini L, Rodella S, Lippi G, Zoppini G, Chonchol $M$. Relationship between kidney function and liver histology in subjects with nonalcoholic steatohepatitis. Clin J Am Soc Nephrol 2010;5:2166-2171.

88. Hwang ST, Cho YK, Yun JW, Park JH, Kim HJ, Park DI, et al. Impact of non-alcoholic fatty liver disease on microalbuminuria in patients with prediabetes and diabetes. Intern Med J 2010;40:437-442.

89. Chang Y, Ryu S, Sung E, Woo HY, Oh E, Cha K, et al. Nonalcoholic fatty liver disease predicts chronic kidney disease in nonhypertensive and nondiabetic Korean men. Metabolism 2008;57:569-576.

90. Musso G, Gambino R, Tabibian JH, Ekstedt M, Kechagias S, Hamaguchi $M$, et al. Association of non-alcoholic fatty liver disease with chronic kidney disease: a systematic review and meta-analysis. PLoS Med 2014;11:e1001680.

91. Sinn DH, Kang D, Jang HR, Gu S, Cho SJ, Paik SW, et al. Development of chronic kidney disease in patients with non-alcoholic fatty liver disease: a cohort study. J Hepatol 2017;67:1274-1280.

92. Mantovani A, Ballestri S, Lonardo A, Targher G. Cardiovascular disease and myocardial abnormalities in nonalcoholic fatty liver disease. Dig Dis Sci 2016;61:1246-1267.

93. Targher G, Lonardo A, Rossini M. Nonalcoholic fatty liver disease and decreased bone mineral density: is there a link? J Endocrinol Invest 2015;38:817-825.

94. Kim GA, Lee HC, Choe J, Kim MJ, Lee MJ, Chang HS, et al. Association between non-alcoholic fatty liver disease and cancer incidence rate. J Hepatol 2018;68:140-146.

95. Noureddin M, Jones C, Alkhouri N, Gomez EV, Dieterich DT, Rinella $M E$, et al. Screening for nonalcoholic fatty liver disease in persons with type 2 diabetes in the United States is cost-effective: a comprehensive cost-utility analysis. Gastroenterology 2020;159:19851987.e4.

96. Huang HL, Lin WY, Lee LT, Wang HH, Lee WJ, Huang KC. Metabolic syndrome is related to nonalcoholic steatohepatitis in severely obese subjects. Obes Surg 2007;17:1457-1463.

97. Rockey DC, Caldwell SH, Goodman ZD, Nelson RC, Smith AD; American Association for the Study of Liver Diseases. Liver biopsy. Hepatology 2009;49:1017-1044.

98. Poynard T, Munteanu M, Imbert-Bismut F, Charlotte F, Thabut D, Le Calvez $\mathrm{S}$, et al. Prospective analysis of discordant results between biochemical markers and biopsy in patients with chronic hepatitis $C$. Clin Chem 2004;50:1344-1355.

99. Ryan CK, Johnson LA, Germin BI, Marcos A. One hundred consecutive hepatic biopsies in the workup of living donors for right lobe liver transplantation. Liver Transpl 2002;8:1114-1122.

100. Wu J, You J, Yerian L, Shiba A, Schauer PR, Sessler DI. Prevalence of liver steatosis and fibrosis and the diagnostic accuracy of ultrasound in bariatric surgery patients. Obes Surg 2012;22:240-247.

101. Saadeh S, Younossi ZM, Remer EM, Gramlich T, Ong JP, Hurley M, et al. The utility of radiological imaging in nonalcoholic fatty liver disease. Gastroenterology 2002;123:745-750.

102. Kramer H, Pickhardt PJ, Kliewer MA, Hernando D, Chen GH, Zagzebski JA, et al. Accuracy of liver fat quantification with advanced $\mathrm{CT}, \mathrm{MRI}$, and ultrasound techniques: prospective comparison with MR spectroscopy. AJR Am J Roentgenol 2017;208:92-100.

103. Myers RP, Pollett A, Kirsch R, Pomier-Layrargues $G$, Beaton $M$, Levstik $\mathrm{M}$, et al. Controlled attenuation parameter (CAP): a non- 
invasive method for the detection of hepatic steatosis based on transient elastography. Liver Int 2012;32:902-910.

104. Chan WK, Nik Mustapha NR, Mahadeva S. Controlled attenuation parameter for the detection and quantification of hepatic steatosis in nonalcoholic fatty liver disease. J Gastroenterol Hepatol 2014;29:1470-1476.

105. Chon YE, Jung KS, Kim KJ, Joo DJ, Kim BK, Park JY, et al. Normal controlled attenuation parameter values: a prospective study of healthy subjects undergoing health checkups and liver donors in Korea. Dig Dis Sci 2015;60:234-242.

106. Hong YM, Yoon KT, Cho M, Chu CW, Rhu JH, Yang KH, et al. Clinical usefulness of controlled attenuation parameter to screen hepatic steatosis for potential donor of living donor liver transplant. Eur J Gastroenterol Hepatol 2017;29:805-810.

107. Chon YE, Jung KS, Kim SU, Park JY, Park YN, Kim DY, et al. Controlled attenuation parameter (CAP) for detection of hepatic steatosis in patients with chronic liver diseases: a prospective study of a native Korean population. Liver Int 2014;34:102-109.

108. Pu K, Wang Y, Bai S, Wei H, Zhou Y, Fan J, et al. Diagnostic accuracy of controlled attenuation parameter (CAP) as a non-invasive test for steatosis in suspected non-alcoholic fatty liver disease: a systematic review and meta-analysis. BMC Gastroenterol 2019;19:51.

109. Wong GL. Transient elastography: kill two birds with one stone? World J Hepatol 2013;5:264-274.

110. Kim TH, Jeong CW, Jun HY, Lee C, Noh S, Kim JE, et al. Accuracy of proton magnetic resonance for diagnosing non-alcoholic steatohepatitis: a meta-analysis. Sci Rep 2019;9:15002.

111. Ahn SB, Jun DW, Kang BK, Kim M, Chang M, Nam E. Optimal cutoff value for assessing changes in intrahepatic fat amount by using the controlled attenuation parameter in a longitudinal setting. Medicine (Baltimore) 2018;97:e13636.

112. Ozturk A, Grajo JR, Gee MS, Benjamin A, Zubajlo RE, Thomenius $K E$, et al. Quantitative hepatic fat quantification in non-alcoholic fatty liver disease using ultrasound-based techniques: a review of literature and their diagnostic performance. Ultrasound Med Biol 2018:44:2461-2475.

113. Bae JS, Lee DH, Lee JY, Kim H, Yu SJ, Lee JH, et al. Assessment of hepatic steatosis by using attenuation imaging: a quantitative, easy-to-perform ultrasound technique. Eur Radiol 2019;29:64996507.

114. Park SH, Kim PN, Kim KW, Lee SW, Yoon SE, Park SW, et al. Macrovesicular hepatic steatosis in living liver donors: use of CT for quantitative and qualitative assessment. Radiology 2006;239:105112.

115. Pickhardt PJ, Park SH, Hahn L, Lee SG, Bae KT, Yu ES. Specificity of unenhanced CT for non-invasive diagnosis of hepatic steatosis: implications for the investigation of the natural history of incidental steatosis. Eur Radiol 2012;22:1075-1082.
116. Fritz GA, Schoellnast $H$, Deutschmann HA, Wiltgen $M$, Brader $P$, Berghold $A$, et al. Density histogram analysis of unenhanced hepatic computed tomography in patients with diffuse liver diseases. J Comput Assist Tomogr 2006;30:201-205.

117. Limanond P, Raman SS, Lassman C, Sayre J, Ghobrial RM, Busuttil RW, et al. Macrovesicular hepatic steatosis in living related liver donors: correlation between CT and histologic findings. Radiology 2004;230:276-280.

118. Fishbein M, Castro F, Cheruku S, Jain S, Webb B, Gleason T, et al. Hepatic MRI for fat quantitation: its relationship to fat morphology, diagnosis, and ultrasound. J Clin Gastroenterol 2005;39:619-625.

119. Wong VW, Vergniol J, Wong GL, Foucher J, Chan AW, Chermak F, et al. Liver stiffness measurement using $\mathrm{XL}$ probe in patients with nonalcoholic fatty liver disease. Am J Gastroenterol 2012;107:18621871.

120. Szczepaniak LS, Nurenberg P, Leonard D, Browning JD, Reingold JS, Grundy S, et al. Magnetic resonance spectroscopy to measure hepatic triglyceride content: prevalence of hepatic steatosis in the general population. Am J Physiol Endocrinol Metab 2005;288:E462-E468.

121. Idilman IS, Aniktar H, Idilman R, Kabacam G, Savas B, Elhan A, et al. Hepatic steatosis: quantification by proton density fat fraction with MR imaging versus liver biopsy. Radiology 2013;267:767-775.

122. Middleton MS, Heba ER, Hooker CA, Bashir MR, Fowler KJ, Sandrasegaran $K$, et al. Agreement between magnetic resonance imaging proton density fat fraction measurements and pathologistassigned steatosis grades of liver biopsies from adults with nonalcoholic steatohepatitis. Gastroenterology 2017;153:753-761.

123. Gu J, Liu S, Du S, Zhang Q, Xiao J, Dong Q, et al. Diagnostic value of MRI-PDFF for hepatic steatosis in patients with non-alcoholic fatty liver disease: a meta-analysis. Eur Radiol 2019;29:3564-3573.

124. Park CC, Nguyen P, Hernandez C, Bettencourt R, Ramirez K, Fortney $L$, et al. Magnetic resonance elastography vs transient elastography in detection of fibrosis and noninvasive measurement of steatosis in patients with biopsy-proven nonalcoholic fatty liver disease. Gastroenterology 2017;152:598-607.e2.

125. Boudinaud C, Abergel A, Joubert-Zakeyh J, Fontarensky M, Pereira B, Chauveau B, et al. Quantification of steatosis in alcoholic and nonalcoholic fatty liver disease: evaluation of four MR techniques versus biopsy. Eur J Radiol 2019;118:169-174.

126. Bedogni G, Bellentani S, Miglioli L, Masutti F, Passalacqua M, Castiglione $A$, et al. The fatty liver index: a simple and accurate predictor of hepatic steatosis in the general population. BMC Gastroenterol 2006;6:33.

127. Kim JH, Kwon SY, Lee SW, Lee $\mathrm{CH}$. Validation of fatty liver index and lipid accumulation product for predicting fatty liver in Korean population. Liver Int 2011;31:1600-1601.

128. Kim JH, Moon JS, Byun SJ, Lee JH, Kang DR, Sung KC, et al. Fatty 
liver index and development of cardiovascular disease in Koreans without pre-existing myocardial infarction and ischemic stroke: a large population-based study. Cardiovasc Diabetol 2020;19:51.

129. Kotronen A, Peltonen M, Hakkarainen A, Sevastianova K, Bergholm $R$, Johansson $L M$, et al. Prediction of non-alcoholic fatty liver disease and liver fat using metabolic and genetic factors. Gastroenterology 2009;137:865-872.

130. Jung JY, Shim JJ, Park SK, Ryoo JH, Choi JM, Oh IH, et al. Serum ferritin level is associated with liver steatosis and fibrosis in Korean general population. Hepatol Int 2019;13:222-233.

131. Lee JH, Kim D, Kim HJ, Lee CH, Yang J, Kim W, et al. Hepatic steatosis index: a simple screening tool reflecting nonalcoholic fatty liver disease. Dig Liver Dis 2010;42:503-508.

132. Chang JW, Lee HW, Kim BK, Park JY, Kim DY, Ahn SH, et al. Hepatic steatosis index in the detection of fatty liver in patients with chronic hepatitis $B$ receiving antiviral therapy. Gut Liver 2020;15:117-127.

133. Lee HW, Park SY, Kim SU, Jang JY, Park H, Kim JK, et al. Discrimination of nonalcoholic steatohepatitis using transient elastography in patients with nonalcoholic fatty liver disease. PLoS One 2016;11:e0157358.

134. Cusi K, Chang Z, Harrison S, Lomonaco R, Bril F, Orsak B, et al. Limited value of plasma cytokeratin-18 as a biomarker for NASH and fibrosis in patients with non-alcoholic fatty liver disease. J Hepatol 2014;60:167-174.

135. Kwok R, Tse YK, Wong GL, Ha Y, Lee AU, Ngu MC, et al. Systematic review with meta-analysis: non-invasive assessment of nonalcoholic fatty liver disease--the role of transient elastography and plasma cytokeratin-18 fragments. Aliment Pharmacol Ther 2014;39:254-269.

136. Thomas EL, Hamilton G, Patel N, O'Dwyer R, Doré CJ, Goldin RD, et al. Hepatic triglyceride content and its relation to body adiposity: a magnetic resonance imaging and proton magnetic resonance spectroscopy study. Gut 2005;54:122-127.

137. Sugimoto K, Moriyasu F, Oshiro H, Takeuchi H, Yoshimasu Y, Kasai Y, et al. Clinical utilization of shear wave dispersion imaging in diffuse liver disease. Ultrasonography 2020;39:3-10.

138. Chen J, Talwalkar JA, Yin M, Glaser KJ, Sanderson SO, Ehman RL. Early detection of nonalcoholic steatohepatitis in patients with nonalcoholic fatty liver disease by using MR elastography. Radiology 2011;259:749-756.

139. Allen AM, Shah VH, Therneau TM, Venkatesh SK, Mounajjed T, Larson JJ, et al. The role of three-dimensional magnetic resonance elastography in the diagnosis of nonalcoholic steatohepatitis in obese patients undergoing bariatric surgery. Hepatology 2020;71:510-521.

140. Kim JW, Lee YS, Park YS, Kim BH, Lee SY, Yeon JE, et al. Multiparametric MR index for the diagnosis of non-alcoholic steato- hepatitis in patients with non-alcoholic fatty liver disease. Sci Rep 2020;10:2671.

141. Imajo K, Kessoku T, Honda Y, Tomeno W, Ogawa Y, Mawatari H, et al. Magnetic resonance imaging more accurately classifies steatosis and fibrosis in patients with nonalcoholic fatty liver disease than transient elastography. Gastroenterology 2016;150:626-637.e7.

142. Castéra L, Foucher J, Bernard PH, Carvalho F, Allaix D, Merrouche $W$, et al. Pitfalls of liver stiffness measurement: a 5-year prospective study of 13,369 examinations. Hepatology 2010;51:828-835.

143. Vuppalanchi R, Siddiqui MS, Van Natta ML, Hallinan E, Brandman D, Kowdley K, et al. Performance characteristics of vibrationcontrolled transient elastography for evaluation of nonalcoholic fatty liver disease. Hepatology 2018;67:134-144.

144. Karlas T, Dietrich A, Peter V, Wittekind C, Lichtinghagen R, Garnov $N$, et al. Evaluation of transient elastography, acoustic radiation force impulse imaging (ARFI), and enhanced liver function (ELF) score for detection of fibrosis in morbidly obese patients. PLoS One 2015;10:e0141649.

145. Liu H, Fu J, Hong R, Liu L, Li F. Acoustic radiation force impulse elastography for the non-invasive evaluation of hepatic fibrosis in non-alcoholic fatty liver disease patients: a systematic review \& meta-analysis. PLoS One 2015;10:e0127782.

146. Yoneda M, Suzuki K, Kato S, Fujita K, Nozaki Y, Hosono K, et al. Nonalcoholic fatty liver disease: US-based acoustic radiation force impulse elastography. Radiology 2010;256:640-647.

147. Bota S, Herkner H, Sporea I, Salzl P, Sirli R, Neghina AM, et al. Meta-analysis: ARFI elastography versus transient elastography for the evaluation of liver fibrosis. Liver Int 2013;33:1138-1147.

148. Joo I, Kim SY, Park HS, Lee ES, Kang HJ, Lee JM. Validation of a new point shear-wave elastography method for noninvasive assessment of liver fibrosis: a prospective multicenter study. Korean J Radiol 2019;20:1527-1535.

149. Poynard T, Munteanu M, Luckina E, Perazzo H, Ngo Y, Royer L, et al. Liver fibrosis evaluation using real-time shear wave elastography: applicability and diagnostic performance using methods without a gold standard. J Hepatol 2013;58:928-935.

150. Imajo K, Honda Y, Kobayashi T, Nagai K, Ozaki A, Iwaki M, et al. Direct comparison of US and MR elastography for staging liver fibrosis in patients with nonalcoholic fatty liver disease. Clin Gastroenterol Hepatol. 2020 Dec 17. doi: 10.1016/j.cgh.2020.12.016.

151. Loomba R, Wolfson T, Ang B, Hooker J, Behling C, Peterson M, et al. Magnetic resonance elastography predicts advanced fibrosis in patients with nonalcoholic fatty liver disease: a prospective study. Hepatology 2014;60:1920-1928.

152. Kim D, Kim WR, Talwalkar JA, Kim HJ, Ehman RL. Advanced fibrosis in nonalcoholic fatty liver disease: noninvasive assessment with MR elastography. Radiology 2013;268:411-419.

153. Hsu C, Caussy C, Imajo K, Chen J, Singh S, Kaulback K, et al. Mag- 
netic resonance vs transient elastography analysis of patients with nonalcoholic fatty liver disease: a systematic review and pooled analysis of individual participants. Clin Gastroenterol Hepatol 2019;17:630-637.e8.

154. Singh S, Venkatesh SK, Wang Z, Miller FH, Motosugi U, Low RN, et al. Diagnostic performance of magnetic resonance elastography in staging liver fibrosis: a systematic review and meta-analysis of individual participant data. Clin Gastroenterol Hepatol 2015;13:440451.e6.

155. Singh S, Venkatesh SK, Loomba R, Wang Z, Sirlin C, Chen J, et al. Magnetic resonance elastography for staging liver fibrosis in non-alcoholic fatty liver disease: a diagnostic accuracy systematic review and individual participant data pooled analysis. Eur Radiol 2016;26:1431-1440.

156. Trout AT, Serai S, Mahley AD, Wang H, Zhang Y, Zhang B, et al. Liver stiffness measurements with MR elastography: agreement and repeatability across imaging systems, field strengths, and pulse sequences. Radiology 2016;281:793-804.

157. Shire NJ, Yin M, Chen J, Railkar RA, Fox-Bosetti S, Johnson SM, et al. Test-retest repeatability of MR elastography for noninvasive liver fibrosis assessment in hepatitis C. J Magn Reson Imaging 2011;34: 947-955.

158. Wang J, Glaser KJ, Zhang T, Shan Q, He B, Chen J, et al. Assessment of advanced hepatic MR elastography methods for susceptibility artifact suppression in clinical patients. J Magn Reson Imaging 2018;47:976-987.

159. Srinivasa Babu A, Wells ML, Teytelboym OM, Mackey JE, Miller $\mathrm{FH}$, Yeh BM, et al. Elastography in chronic liver disease: modalities, techniques, limitations, and future directions. Radiographics 2016;36:1987-2006.

160. Angulo P, Hui JM, Marchesini G, Bugianesi E, George J, Farrell GC, et al. The NAFLD fibrosis score: a noninvasive system that identifies liver fibrosis in patients with NAFLD. Hepatology 2007;45:846854.

161. Qureshi K, Clements RH, Abrams GA. The utility of the "NAFLD fibrosis score" in morbidly obese subjects with NAFLD. Obes Surg 2008;18:264-270.

162. Wong VW, Wong GL, Chim AM, Tse AM, Tsang SW, Hui AY, et al. Validation of the NAFLD fibrosis score in a Chinese population with low prevalence of advanced fibrosis. Am J Gastroenterol 2008;103:1682-1688.

163. Guha IN, Parkes J, Roderick P, Chattopadhyay D, Cross R, Harris $S$, et al. Noninvasive markers of fibrosis in nonalcoholic fatty liver disease: validating the european liver fibrosis panel and exploring simple markers. Hepatology 2008;47:455-460.

164. Guturu P, Steffer K, Petersen JR, Snyder N. A new risk index for the estimation of fibrosis in non alcoholic fatty liver disease (NAFLD): comparison with the Mayo Score and the AST platelet ratio index
(APRI). Hepatology 2008;48:522A.

165. Harrison SA, Oliver D, Arnold HL, Gogia S, Neuschwander-Tetri BA. Development and validation of a simple NAFLD clinical scoring system for identifying patients without advanced disease. Gut 2008;57:1441-1447.

166. Calès P, Lainé F, Boursier J, Deugnier $Y$, Moal V, Oberti F, et al. Comparison of blood tests for liver fibrosis specific or not to NAFLD. J Hepatol 2009;50:165-173.

167. Ruffillo G, Fassio E, Alvarez E, Landeira G, Longo C, Domínguez $\mathrm{N}$, et al. Comparison of NAFLD fibrosis score and BARD score in predicting fibrosis in nonalcoholic fatty liver disease. J Hepatol 2011;54:160-163.

168. Parker R, Collins P, McCune A. Can clinical scoring systems replace liver biopsy in non-alcoholic fatty liver disease? J Hepatol 2009;51:189.

169. Wong VW, Vergniol J, Wong GL, Foucher J, Chan HL, Le Bail B, et al. Diagnosis of fibrosis and cirrhosis using liver stiffness measurement in nonalcoholic fatty liver disease. Hepatology 2010;51:454462

170. Fuji H, Enomoto M, Fukushima W, Tamori A, Sakaguchi H, Kawada N. Application of non-invasive laboratory tests for the assessment of fi brosis staging in Japanese patients with NAFLD [Abstract]. EASL Special Conference on NAFLD/NASH and Related Metabolic Disorders 2009; 2009 Sep 24-26, 2009; Bologna. Elsevier; 2009. $134 \mathrm{p}$.

171. Sumida Y, Yoneda M, Hyogo H, Yamaguchi K, Ono M, Fujii H, et al. A simple clinical scoring system using ferritin, fasting insulin, and type IV collagen 7S for predicting steatohepatitis in nonalcoholic fatty liver disease. J Gastroenterol 2011;46:257-268.

172. Pimentel SK, Strobel R, Gonçalves CG, Sakamoto DG, Ivano FH, Coelho JC. Evaluation of the nonalcoholic fat liver disease fibrosis score for patients undergoing bariatric surgery. Arq Gastroenterol 2010;47:170-173.

173. Jun DW, Kim SG, Park SH, Jin SY, Lee JS, Lee JW, et al. External validation of the non-alcoholic fatty liver disease fibrosis score for assessing advanced fibrosis in Korean patients. J Gastroenterol Hepatol 2017;32:1094-1099.

174. Joo SK, Kim W, Kim D, Kim JH, Oh S, Lee KL, et al. Steatosis severity affects the diagnostic performances of noninvasive fibrosis tests in nonalcoholic fatty liver disease. Liver Int 2018;38:331-341.

175. Sterling RK, Lissen E, Clumeck N, Sola R, Correa MC, Montaner J, et al. Development of a simple noninvasive index to predict significant fibrosis in patients with HIV/HCV coinfection. Hepatology 2006:43:1317-1325.

176. Tamaki N, Higuchi M, Kurosaki M, Kirino S, Osawa L, Watakabe K, et al. Wisteria floribunda agglutinin-positive mac-2 binding protein as an age-independent fibrosis marker in nonalcoholic fatty liver disease. Sci Rep 2019;9:10109. 
177. Jekarl DW, Choi H, Lee S, Kwon JH, Lee SW, Yu H, et al. Diagnosis of liver fibrosis with Wisteria floribunda agglutinin-positive Mac-2 binding protein (WFA-M2BP) among chronic hepatitis B patients. Ann Lab Med 2018;38:348-354.

178. Heo JY, Kim SU, Kim BK, Park JY, Kim DY, Ahn SH, et al. Use of Wisteria floribunda agglutinin-positive human Mac-2 binding protein in assessing risk of hepatocellular carcinoma due to hepatitis B virus. Medicine (Baltimore) 2016;95:e3328.

179. Kim SU, Jeon MY, Lim TS. Diagnostic performance of serum asialoa1-acid glycoprotein for advanced liver fibrosis or cirrhosis in patients with chronic hepatitis B or nonalcoholic fatty liver disease. Korean J Gastroenterol 2019;74:341-348.

180. European Association for the Study of the Liver (EASL); European Association for the Study of Diabetes (EASD); European Association for the Study of Obesity (EASO). EASL-EASD-EASO clinical practice guidelines for the management of non-alcoholic fatty liver disease. J Hepatol 2016;64:1388-1402.

181. Noureddin M, Lam J, Peterson MR, Middleton M, Hamilton G, Le $T A$, et al. Utility of magnetic resonance imaging versus histology for quantifying changes in liver fat in nonalcoholic fatty liver disease trials. Hepatology 2013;58:1930-1940.

182. Caussy C, Reeder SB, Sirlin CB, Loomba R. Noninvasive, quantitative assessment of liver fat by MRI-PDFF as an endpoint in NASH trials. Hepatology 2018;68:763-772.

183. Ratziu V, Charlotte F, Heurtier A, Gombert S, Giral P, Bruckert E, et al. Sampling variability of liver biopsy in nonalcoholic fatty liver disease. Gastroenterology 2005;128:1898-1906.

184. Chalasani N, Younossi Z, Lavine JE, Diehl AM, Brunt EM, Cusi K, et al. The diagnosis and management of non-alcoholic fatty liver disease: practice guideline by the American Gastroenterological Association, American Association for the Study of Liver Diseases, and American College of Gastroenterology. Gastroenterology 2012;142:1592-1609.

185. Ratziu V, Bellentani S, Cortez-Pinto H, Day C, Marchesini G. A position statement on NAFLD/NASH based on the EASL 2009 special conference. J Hepatol 2010;53:372-384.

186. Boursier J, Vergniol J, Guillet A, Hiriart JB, Lannes A, Le Bail B, et al. Diagnostic accuracy and prognostic significance of blood fibrosis tests and liver stiffness measurement by FibroScan in nonalcoholic fatty liver disease. J Hepatol 2016;65:570-578.

187. Tapper EB, Sengupta N, Hunink MG, Afdhal NH, Lai M. Costeffective evaluation of nonalcoholic fatty liver disease with NAFLD fibrosis score and vibration controlled transient elastography. Am J Gastroenterol 2015;110:1298-1304.

188. Gunn NT, Shiffman ML. The use of liver biopsy in nonalcoholic fatty liver disease: when to biopsy and in whom. Clin Liver Dis 2018;22:109-119.

189. Janiec DJ, Jacobson ER, Freeth A, Spaulding L, Blaszyk H. Histologic variation of grade and stage of non-alcoholic fatty liver disease in liver biopsies. Obes Surg 2005;15:497-501.

190. Merriman RB, Ferrell LD, Patti MG, Weston SR, Pabst MS, Aouizerat $\mathrm{BE}$, et al. Correlation of paired liver biopsies in morbidly obese patients with suspected nonalcoholic fatty liver disease. Hepatology 2006;44:874-880.

191. Younossi ZM, Gramlich T, Liu YC, Matteoni C, Petrelli M, Goldblum J, et al. Nonalcoholic fatty liver disease: assessment of variability in pathologic interpretations. Mod Pathol 1998;11:560-565.

192. Sanyal AJ, Brunt EM, Kleiner DE, Kowdley KV, Chalasani N, Lavine $J E$, et al. Endpoints and clinical trial design for nonalcoholic steatohepatitis. Hepatology 2011;54:344-353.

193. Brunt EM, Janney CG, Di Bisceglie AM, Neuschwander-Tetri BA, Bacon BR. Nonalcoholic steatohepatitis: a proposal for grading and staging the histological lesions. Am J Gastroenterol 1999;94:24672474.

194. Bedossa P, Poitou C, Veyrie N, Bouillot JL, Basdevant A, Paradis $V$, et al. Histopathological algorithm and scoring system for evaluation of liver lesions in morbidly obese patients. Hepatology 2012;56:1751-1759.

195. Kleiner DE, Brunt EM, Van Natta M, Behling C, Contos MJ, Cummings $\mathrm{OW}$, et al. Design and validation of a histological scoring system for nonalcoholic fatty liver disease. Hepatology 2005;41:13131321.

196. Ascha MS, Hanouneh IA, Lopez R, Tamimi TA, Feldstein AF, Zein NN. The incidence and risk factors of hepatocellular carcinoma in patients with nonalcoholic steatohepatitis. Hepatology 2010;51:1972-1978.

197. Yatsuji S, Hashimoto E, Tobari M, Taniai M, Tokushige K, Shiratori K. Clinical features and outcomes of cirrhosis due to non-alcoholic steatohepatitis compared with cirrhosis caused by chronic hepatitis C. J Gastroenterol Hepatol 2009;24:248-254.

198. Loomba R, Lim JK, Patton H, El-Serag HB. AGA clinical practice update on screening and surveillance for hepatocellular carcinoma in patients with nonalcoholic fatty liver disease: expert review. Gastroenterology 2020;158:1822-1830.

199. Castera L, Friedrich-Rust M, Loomba R. Noninvasive assessment of liver disease in patients with nonalcoholic fatty liver disease. Gastroenterology 2019;156:1264-1281.e4.

200. Tapper EB, Lok ASF. Use of liver imaging and biopsy in clinical practice. N Engl J Med 2017;377:2296-2297.

201. Tapper EB, Loomba R. Noninvasive imaging biomarker assessment of liver fibrosis by elastography in NAFLD. Nat Rev Gastroenterol Hepatol 2018;15:274-282.

202. Reig M, Gambato M, Man NK, Roberts JP, Victor D, Orci LA, et al. Should patients with NAFLD/NASH be surveyed for HCC? Transplantation 2019;103:39-44.

203. White DL, Kanwal F, El-Serag HB. Association between nonalco- 
holic fatty liver disease and risk for hepatocellular cancer, based on systematic review. Clin Gastroenterol Hepatol 2012;10:1342-1359. e2.

204. Kanwal F, Kramer JR, Mapakshi S, Natarajan Y, Chayanupatkul M, Richardson PA, et al. Risk of hepatocellular cancer in patients with non-alcoholic fatty liver disease. Gastroenterology 2018;155:18281837.e2.

205. Del Poggio P, Olmi S, Ciccarese F, Di Marco M, Rapaccini GL, Benvegnù $L$, et al. Factors that affect efficacy of ultrasound surveillance for early stage hepatocellular carcinoma in patients with cirrhosis. Clin Gastroenterol Hepatol 2014;12:1927-1933.e2.

206. Simmons O, Fetzer DT, Yokoo T, Marrero JA, Yopp A, Kono Y, et al. Predictors of adequate ultrasound quality for hepatocellular carcinoma surveillance in patients with cirrhosis. Aliment Pharmacol Ther 2017;45:169-177.

207. Lee YC, Cohet C, Yang YC, Stayner L, Hashibe M, Straif K. Metaanalysis of epidemiologic studies on cigarette smoking and liver cancer. Int J Epidemiol 2009;38:1497-1511.

208. Petrick JL, Campbell PT, Koshiol J, Thistle JE, Andreotti G, BeaneFreeman LE, et al. Tobacco, alcohol use and risk of hepatocellular carcinoma and intrahepatic cholangiocarcinoma: the liver cancer pooling project. Br J Cancer 2018;118:1005-1012.

209. Turati F, Galeone C, Rota M, Pelucchi C, Negri E, Bagnardi V, et al. Alcohol and liver cancer: a systematic review and meta-analysis of prospective studies. Ann Oncol 2014;25:1526-1535.

210. Bagnardi V, Rota M, Botteri E, Tramacere I, Islami F, Fedirko V, et al. Alcohol consumption and site-specific cancer risk: a comprehensive dose-response meta-analysis. Br J Cancer 2015;112:580-593.

211. Simon TG, King LY, Chong DQ, Nguyen LH, Ma Y, VoPham T, et al. Diabetes, metabolic comorbidities, and risk of hepatocellular carcinoma: results from two prospective cohort studies. Hepatology 2018:67:1797-1806.

212. El-Serag HB, Hampel H, Javadi F. The association between diabetes and hepatocellular carcinoma: a systematic review of epidemiologic evidence. Clin Gastroenterol Hepatol 2006;4:369-380.

213. Wang C, Wang X, Gong G, Ben Q, Qiu W, Chen Y, et al. Increased risk of hepatocellular carcinoma in patients with diabetes mellitus: a systematic review and meta-analysis of cohort studies. Int J Cancer 2012;130:1639-1648.

214. Yang WS, Va P, Bray F, Gao S, Gao J, Li HL, et al. The role of preexisting diabetes mellitus on hepatocellular carcinoma occurrence and prognosis: a meta-analysis of prospective cohort studies. PLoS One 2011;6:e27326.

215. Stefan N, Häring HU, Cusi K. Non-alcoholic fatty liver disease: causes, diagnosis, cardiometabolic consequences, and treatment strategies. Lancet Diabetes Endocrinol 2019;7:313-324.

216. Singh S, Singh PP, Singh AG, Murad MH, Sanchez W. Anti-diabetic medications and the risk of hepatocellular cancer: a systematic review and meta-analysis. Am J Gastroenterol 2013;108:881-891; quiz 892.

217. Cusi K, Orsak B, Bril F, Lomonaco R, Hecht J, Ortiz-Lopez C, et al. Long-term pioglitazone treatment for patients with nonalcoholic steatohepatitis and prediabetes or type 2 diabetes mellitus: a randomized trial. Ann Intern Med 2016;165:305-315.

218. Armstrong MJ, Gaunt P, Aithal GP, Barton D, Hull D, Parker R, et al. Liraglutide safety and efficacy in patients with non-alcoholic steatohepatitis (LEAN): a multicentre, double-blind, randomised, placebo-controlled phase 2 study. Lancet 2016;387:679-690.

219. Younossi ZM, Loomba R, Rinella ME, Bugianesi E, Marchesini G, Neuschwander-Tetri BA, et al. Current and future therapeutic regimens for nonalcoholic fatty liver disease and nonalcoholic steatohepatitis. Hepatology 2018;68:361-371.

220. Singh S, Khera R, Allen AM, Murad MH, Loomba R. Comparative effectiveness of pharmacological interventions for nonalcoholic steatohepatitis: a systematic review and network meta-analysis. Hepatology 2015;62:1417-1432.

221. Singh S, Singh PP, Singh AG, Murad MH, Sanchez W. Statins are associated with a reduced risk of hepatocellular cancer: a systematic review and meta-analysis. Gastroenterology 2013;144:323-332.

222. Friis S, Poulsen AH, Johnsen SP, McLaughlin JK, Fryzek JP, Dalton SO, et al. Cancer risk among statin users: a population-based cohort study. Int J Cancer 2005;114:643-647.

223. El-Serag HB, Johnson ML, Hachem C, Morgana RO. Statins are associated with a reduced risk of hepatocellular carcinoma in a large cohort of patients with diabetes. Gastroenterology 2009;136:16011608.

224. Wong CR, Nguyen MH, Lim JK. Hepatocellular carcinoma in patients with non-alcoholic fatty liver disease. World J Gastroenterol 2016;22:8294-8303.

225. Ekstedt M, Franzén LE, Mathiesen UL, Thorelius L, Holmqvist M, Bodemar $G$, et al. Long-term follow-up of patients with NAFLD and elevated liver enzymes. Hepatology 2006;44:865-873.

226. Adams LA, Lymp JF, St Sauver J, Sanderson SO, Lindor KD, Feldstein $A$, et al. The natural history of nonalcoholic fatty liver disease: a population-based cohort study. Gastroenterology 2005;129:113121.

227. Dulai PS, Singh S, Patel J, Soni M, Prokop LJ, Younossi Z, et al. Increased risk of mortality by fibrosis stage in nonalcoholic fatty liver disease: systematic review and meta-analysis. Hepatology 2017;65:1557-1565.

228. Taylor RS, Taylor RJ, Bayliss S, Hagström H, Nasr P, Schattenberg $J M$, et al. Association between fibrosis stage and outcomes of patients with nonalcoholic fatty liver disease: a systematic review and meta-analysis. Gastroenterology 2020;158:1611-1625.e12.

229. Kleiner DE, Brunt EM, Wilson LA, Behling C, Guy C, Contos M, et al. Association of histologic disease activity with progression 
of nonalcoholic fatty liver disease. JAMA Netw Open 2019;2: e1912565.

230. Brunt EM, Kleiner DE, Wilson LA, Sanyal AJ, Neuschwander-Tetri BA; Nonalcoholic Steatohepatitis Clinical Research Network. Improvements in histologic features and diagnosis associated with improvement in fibrosis in nonalcoholic steatohepatitis: results from the nonalcoholic steatohepatitis clinical research network treatment trials. Hepatology 2019;70:522-531.

231. Lazo M, Solga SF, Horska A, Bonekamp S, Diehl AM, Brancati $\mathrm{FL}$, et al. Effect of a 12-month intensive lifestyle intervention on hepatic steatosis in adults with type 2 diabetes. Diabetes Care 2010;33:2156-2163.

232. Kirk E, Reeds DN, Finck BN, Mayurranjan SM, Patterson BW, Klein S. Dietary fat and carbohydrates differentially alter insulin sensitivity during caloric restriction. Gastroenterology 2009;136:1552-1560.

233. Promrat K, Kleiner DE, Niemeier HM, Jackvony E, Kearns M, Wands $J R$, et al. Randomized controlled trial testing the effects of weight loss on nonalcoholic steatohepatitis. Hepatology 2010;51:121-129.

234. Vilar-Gomez E, Martinez-Perez Y, Calzadilla-Bertot L, TorresGonzalez A, Gra-Oramas B, Gonzalez-Fabian L, et al. Weight loss through lifestyle modification significantly reduces features of nonalcoholic steatohepatitis. Gastroenterology 2015;149:367-378.e5; quiz e14-e15.

235. Jin YJ, Kim KM, Hwang S, Lee SG, Ha TY, Song GW, et al. Exercise and diet modification in non-obese non-alcoholic fatty liver disease: analysis of biopsies of living liver donors. J Gastroenterol Hepatol 2012;27:1341-1347.

236. Koutoukidis DA, Astbury NM, Tudor KE, Morris E, Henry JA, Noreik $M$, et al. Association of weight loss interventions with changes in biomarkers of nonalcoholic fatty liver disease: a systematic review and meta-analysis. JAMA Intern Med 2019;179:1262-1271.

237. Wong VW, Wong GL, Chan RS, Shu SS, Cheung BH, Li LS, et al. Beneficial effects of lifestyle intervention in non-obese patients with non-alcoholic fatty liver disease. J Hepatol 2018;69:13491356.

238. Huang MA, Greenson JK, Chao C, Anderson L, Peterman D, Jacobson J, et al. One-year intense nutritional counseling results in histological improvement in patients with non-alcoholic steatohepatitis: a pilot study. Am J Gastroenterol 2005;100:1072-1081.

239. Andersen T, Gluud C, Franzmann MB, Christoffersen P. Hepatic effects of dietary weight loss in morbidly obese subjects. J Hepatol 1991;12:224-229.

240. Tsai JH, Ferrell LD, Tan V, Yeh MM, Sarkar M, Gill RM. Aggressive non-alcoholic steatohepatitis following rapid weight loss and/or malnutrition. Mod Pathol 2017;30:834-842.

241. Haufe S, Engeli S, Kast P, Böhnke J, Utz W, Haas V, et al. Randomized comparison of reduced fat and reduced carbohydrate hypocaloric diets on intrahepatic fat in overweight and obese human subjects. Hepatology 2011;53:1504-1514.

242. Browning JD, Baker JA, Rogers T, Davis J, Satapati S, Burgess SC. Short-term weight loss and hepatic triglyceride reduction: evidence of a metabolic advantage with dietary carbohydrate restriction. Am J Clin Nutr 2011;93:1048-1052.

243. Seo MH, Lee WY, Kim SS, Kang JH, Kang JH, Kim KK, et al. 2018 Korean Society for the Study of Obesity guideline for the management of obesity in Korea. J Obes Metab Syndr 2019;28:40-45.

244. Kang H, Greenson JK, Omo JT, Chao C, Peterman D, Anderson L, et al. Metabolic syndrome is associated with greater histologic severity, higher carbohydrate, and lower fat diet in patients with NAFLD. Am J Gastroenterol 2006;101:2247-2253.

245. Toshimitsu K, Matsuura B, Ohkubo I, Niiya T, Furukawa S, Hiasa $Y$, et al. Dietary habits and nutrient intake in non-alcoholic steatohepatitis. Nutrition 2007;23:46-52.

246. Jun DW. Influence of dietary intake on non-alcoholic fatty liver disease in Korean. Cheongju: National Institute of Food and Drug Safety Evaluation, 2012.

247. Jang EC, Jun DW, Lee SM, Cho YK, Ahn SB. Comparison of efficacy of low-carbohydrate and low-fat diet education programs in nonalcoholic fatty liver disease: a randomized controlled study. Hepatol Res 2018;48:E22-E29.

248. Ahn J, Jun DW, Lee HY, Moon JH. Critical appraisal for low-carbohydrate diet in nonalcoholic fatty liver disease: review and metaanalyses. Clin Nutr 2019;38:2023-2030.

249. Castro-Quezada I, Román-Viñas B, Serra-Majem L. The Mediterranean diet and nutritional adequacy: a review. Nutrients 2014;6: 231-248.

250. Gepner Y, Shelef I, Komy O, Cohen N, Schwarzfuchs D, Bril N, et al. The beneficial effects of Mediterranean diet over low-fat diet may be mediated by decreasing hepatic fat content. J Hepatol 2019;71:379-388.

251. Properzi C, O'Sullivan TA, Sherriff JL, Ching HL, Jeffrey GP, Buckley $R F$, et al. Ad libitum mediterranean and low-fat diets both significantly reduce hepatic steatosis: a randomized controlled trial. Hepatology 2018;68:1741-1754.

252. Hydes TJ, Ravi S, Loomba R, Gray ME. Evidence-based clinical advice for nutrition and dietary weight loss strategies for the management of NAFLD and NASH. Clin Mol Hepatol 2020;26:383-400.

253. Scorletti E, West AL, Bhatia L, Hoile SP, McCormick KG, Burdge $G C$, et al. Treating liver fat and serum triglyceride levels in NAFLD, effects of PNPLA3 and TM6SF2 genotypes: results from the WELCOME trial. J Hepatol 2015;63:1476-1483.

254. Ryu S, Chang Y, Jung HS, Yun KE, Kwon MJ, Choi Y, et al. Relationship of sitting time and physical activity with non-alcoholic fatty liver disease. J Hepatol 2015;63:1229-1237.

255. Sung KC, Ryu S, Lee JY, Kim JY, Wild SH, Byrne CD. Effect of exercise on the development of new fatty liver and the resolution of 
existing fatty liver. J Hepatol 2016;65:791-797.

256. Kistler KD, Brunt EM, Clark JM, Diehl AM, Sallis JF, Schwimmer JB, et al. Physical activity recommendations, exercise intensity, and histological severity of nonalcoholic fatty liver disease. Am J Gastroenterol 2011;106:460-468; quiz 469.

257. Hallsworth K, Fattakhova G, Hollingsworth KG, Thoma C, Moore S, Taylor $R$, et al. Resistance exercise reduces liver fat and its mediators in non-alcoholic fatty liver disease independent of weight loss. Gut 2011;60:1278-1283.

258. Sullivan S, Kirk EP, Mittendorfer B, Patterson BW, Klein S. Randomized trial of exercise effect on intrahepatic triglyceride content and lipid kinetics in nonalcoholic fatty liver disease. Hepatology 2012;55:1738-1745.

259. Cassidy S, Thoma C, Hallsworth K, Parikh J, Hollingsworth KG, Taylor $\mathrm{R}$, et al. High intensity intermittent exercise improves cardiac structure and function and reduces liver fat in patients with type 2 diabetes: a randomised controlled trial. Diabetologia 2016;59:5666.

260. Johnson NA, Sachinwalla T, Walton DW, Smith $K$, Armstrong A, Thompson MW, et al. Aerobic exercise training reduces hepatic and visceral lipids in obese individuals without weight loss. Hepatology 2009;50:1105-1112.

261. Keating SE, Hackett DA, Parker HM, O'Connor HT, Gerofi JA, Sainsbury $A$, et al. Effect of aerobic exercise training dose on liver fat and visceral adiposity. J Hepatol 2015;63:174-182.

262. Houghton D, Thoma C, Hallsworth K, Cassidy S, Hardy T, Burt AD, et al. Exercise reduces liver lipids and visceral adiposity in patients with nonalcoholic steatohepatitis in a randomized controlled trial. Clin Gastroenterol Hepatol 2017;15:96-102.e3.

263. Keating SE, Hackett DA, George J, Johnson NA. Exercise and nonalcoholic fatty liver disease: a systematic review and meta-analysis. J Hepatol 2012;57:157-166.

264. Thoma C, Day CP, Trenell MI. Lifestyle interventions for the treatment of non-alcoholic fatty liver disease in adults: a systematic review. J Hepatol 2012;56:255-266.

265. Kenneally S, Sier JH, Moore JB. Efficacy of dietary and physical activity intervention in non-alcoholic fatty liver disease: a systematic review. BMJ Open Gastroenterol 2017;4:e000139.

266. Shamsoddini A, Sobhani V, Ghamar Chehreh ME, Alavian SM, Zaree A. Effect of aerobic and resistance exercise training on liver enzymes and hepatic fat in Iranian men with nonalcoholic fatty liver disease. Hepat Mon 2015;15:e31434.

267. Bacchi E, Negri C, Targher G, Faccioli N, Lanza M, Zoppini G, et al. Both resistance training and aerobic training reduce hepatic fat content in type 2 diabetic subjects with nonalcoholic fatty liver disease (the RAED2 Randomized Trial). Hepatology 2013;58:12871295.

268. World Health Organization (WHO). What is moderate-intensity and vigorous-intensity physical activity. WHO web site, <https://www. who.int/publications/i/item/9789241599979>. Accessed 17 Nov 2020.

269. Piercy KL, Troiano RP, Ballard RM, Carlson SA, Fulton JE, Galuska DA, et al. The physical activity guidelines for Americans. JAMA 2018;320:2020-2028.

270. Slentz CA, Bateman LA, Willis LH, Shields AT, Tanner CJ, Piner LW, et al. Effects of aerobic vs. resistance training on visceral and liver fat stores, liver enzymes, and insulin resistance by HOMA in overweight adults from STRRIDE AT/RT. Am J Physiol Endocrinol Metab 2011;301:E1033-E1039.

271. Hashida R, Kawaguchi T, Bekki M, Omoto M, Matsuse $H$, Nago $T$, et al. Aerobic vs. resistance exercise in non-alcoholic fatty liver disease: a systematic review. J Hepatol 2017;66:142-152.

272. Katsagoni CN, Georgoulis M, Papatheodoridis GV, Panagiotakos DB, Kontogianni MD. Effects of lifestyle interventions on clinical characteristics of patients with non-alcoholic fatty liver disease: a meta-analysis. Metabolism 2017;68:119-132.

273. Pugh CJ, Sprung VS, Jones H, Richardson P, Shojaee-Moradie F, Umpleby AM, et al. Exercise-induced improvements in liver fat and endothelial function are not sustained 12 months following cessation of exercise supervision in nonalcoholic fatty liver disease. Int J Obes (Lond) 2016;40:1927-1930.

274. Dunn W, Sanyal AJ, Brunt EM, Unalp-Arida A, Donohue M, MCCullough AJ, et al. Modest alcohol consumption is associated with decreased prevalence of steatohepatitis in patients with nonalcoholic fatty liver disease (NAFLD). J Hepatol 2012;57:384-391.

275. Dunn W, Xu R, Schwimmer JB. Modest wine drinking and decreased prevalence of suspected nonalcoholic fatty liver disease. Hepatology 2008;47:1947-1954.

276. Moriya A, Iwasaki Y, Ohguchi S, Kayashima E, Mitsumune T, Tani-

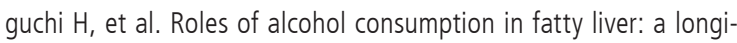
tudinal study. J Hepatol 2015;62:921-927.

277. Kwon HK, Greenson JK, Conjeevaram HS. Effect of lifetime alcohol consumption on the histological severity of non-alcoholic fatty liver disease. Liver Int 2014;34:129-135.

278. Dixon JB, Bhathal PS, O'Brien PE. Nonalcoholic fatty liver disease: predictors of nonalcoholic steatohepatitis and liver fibrosis in the severely obese. Gastroenterology 2001;121:91-100.

279. Mitchell T, Jeffrey GP, de Boer B, MacQuillan G, Garas G, Ching H, et al. Type and pattern of alcohol consumption is associated with liver fibrosis in patients with non-alcoholic fatty liver disease. Am J Gastroenterol 2018;113:1484-1493.

280. Hart CL, Morrison DS, Batty GD, Mitchell RJ, Davey Smith G. Effect of body mass index and alcohol consumption on liver disease: analysis of data from two prospective cohort studies. BMJ 2010;340:c1240.

281. Ekstedt M, Franzén LE, Holmqvist M, Bendtsen P, Mathiesen UL, 
Bodemar $\mathrm{G}$, et al. Alcohol consumption is associated with progression of hepatic fibrosis in non-alcoholic fatty liver disease. Scand J Gastroenterol 2009;44:366-374.

282. Lau K, Baumeister SE, Lieb W, Meffert PJ, Lerch MM, Mayerle J, et al. The combined effects of alcohol consumption and body mass index on hepatic steatosis in a general population sample of European men and women. Aliment Pharmacol Ther 2015;41:467-476.

283. Chang Y, Cho YK, Kim Y, Sung E, Ahn J, Jung HS, et al. Nonheavy drinking and worsening of noninvasive fibrosis markers in nonalcoholic fatty liver disease: a cohort study. Hepatology 2019;69:6475.

284. NIH conference. Gastrointestinal surgery for severe obesity. Consensus development conference panel. Ann Intern Med 1991;115: 956-961.

285. Marra F, Efsen E, Romanelli RG, Caligiuri A, Pastacaldi S, Batignani $G$, et al. Ligands of peroxisome proliferator-activated receptor gamma modulate profibrogenic and proinflammatory actions in hepatic stellate cells. Gastroenterology 2000;119:466-478.

286. Galli A, Crabb DW, Ceni E, Salzano R, Mello T, Svegliati-Baroni G, et al. Antidiabetic thiazolidinediones inhibit collagen synthesis and hepatic stellate cell activation in vivo and in vitro. Gastroenterology 2002;122:1924-1940.

287. Bril F, Kalavalapalli S, Clark VC, Lomonaco R, Soldevila-Pico C, Liu IC, et al. Response to pioglitazone in patients with nonalcoholic steatohepatitis with vs without type 2 diabetes. Clin Gastroenterol Hepatol 2018;16:558-566.e2.

288. Kalavalapalli S, Bril F, Koelmel JP, Abdo K, Guingab J, Andrews P, et al. Pioglitazone improves hepatic mitochondrial function in a mouse model of nonalcoholic steatohepatitis. Am J Physiol Endocrinol Metab 2018;315:E163-E173.

289. Belfort R, Harrison SA, Brown K, Darland C, Finch J, Hardies J, et al. A placebo-controlled trial of pioglitazone in subjects with nonalcoholic steatohepatitis. N Engl J Med 2006;355:2297-2307.

290. Aithal GP, Thomas JA, Kaye PV, Lawson A, Ryder SD, Spendlove I, et al. Randomized, placebo-controlled trial of pioglitazone in nondiabetic subjects with nonalcoholic steatohepatitis. Gastroenterology 2008;135:1176-1184.

291. Sanyal AJ, Chalasani N, Kowdley KV, McCullough A, Diehl AM, Bass NM, et al. Pioglitazone, vitamin $E$, or placebo for nonalcoholic steatohepatitis. N Engl J Med 2010;362:1675-1685.

292. Ratziu V, Giral P, Jacqueminet S, Charlotte F, Hartemann-Heurtier A, Serfaty L, et al. Rosiglitazone for nonalcoholic steatohepatitis: one-year results of the randomized placebo-controlled fatty liver improvement with rosiglitazone therapy (FLIRT) trial. Gastroenterology 2008;135:100-110.

293. Ratziu V, Charlotte F, Bernhardt C, Giral P, Halbron M, Lenaour G, et al. Long-term efficacy of rosiglitazone in nonalcoholic steatohepatitis: results of the fatty liver improvement by rosiglitazone therapy (FLIRT 2) extension trial. Hepatology 2010;51:445-453.

294. Mahady SE, Webster AC, Walker S, Sanyal A, George J. The role of thiazolidinediones in non-alcoholic steatohepatitis - a systematic review and meta analysis. J Hepatol 2011;55:1383-1390.

295. Kahn SE, Zinman B, Lachin JM, Haffner SM, Herman WH, Holman $R R$, et al. Rosiglitazone-associated fractures in type 2 diabetes: an analysis from a diabetes outcome progression trial (ADOPT). Diabetes Care 2008;31:845-851.

296. Lewis JD, Ferrara A, Peng T, Hedderson M, Bilker WB, Quesenberry $\mathrm{CP} J$ r, et al. Risk of bladder cancer among diabetic patients treated with pioglitazone: interim report of a longitudinal cohort study. Diabetes Care 2011;34:916-922.

297. Lincoff AM, Wolski K, Nicholls SJ, Nissen SE. Pioglitazone and risk of cardiovascular events in patients with type 2 diabetes mellitus: a meta-analysis of randomized trials. JAMA 2007;298:1180-1188.

298. Lin HZ, Yang SQ, Chuckaree C, Kuhajda F, Ronnet G, Diehl AM. Metformin reverses fatty liver disease in obese, leptin-deficient mice. Nat Med 2000;6:998-1003.

299. Zhou G, Myers R, Li Y, Chen Y, Shen X, Fenyk-Melody J, et al. Role of AMP-activated protein kinase in mechanism of metformin action. J Clin Invest 2001;108:1167-1174.

300. Bugianesi E, Gentilcore E, Manini R, Natale S, Vanni E, Villanova N, et al. A randomized controlled trial of metformin versus vitamin $E$ or prescriptive diet in nonalcoholic fatty liver disease. Am J Gastroenterol 2005;100:1082-1090.

301. Uygun A, Kadayifci A, Isik AT, Ozgurtas T, Deveci S, Tuzun A, et al. Metformin in the treatment of patients with non-alcoholic steatohepatitis. Aliment Pharmacol Ther 2004;19:537-544.

302. Haukeland JW, Konopski Z, Eggesbø HB, von Volkmann HL, Raschpichler G, Bjøro K, et al. Metformin in patients with nonalcoholic fatty liver disease: a randomized, controlled trial. Scand J Gastroenterol 2009;44:853-860.

303. Duseja A, Das A, Dhiman RK, Chawla YK, Thumburu KT, Bhadada $S$, et al. Metformin is effective in achieving biochemical response in patients with nonalcoholic fatty liver disease (NAFLD) not responding to lifestyle interventions. Ann Hepatol 2007;6:222-226.

304. Idilman R, Mizrak D, Corapcioglu D, Bektas M, Doganay B, Sayki $M$, et al. Clinical trial: insulin-sensitizing agents may reduce consequences of insulin resistance in individuals with non-alcoholic steatohepatitis. Aliment Pharmacol Ther 2008;28:200-208.

305. Nar A, Gedik O. The effect of metformin on leptin in obese patients with type 2 diabetes mellitus and nonalcoholic fatty liver disease. Acta Diabetol 2009;46:113-118.

306. Omer Z, Cetinkalp S, Akyildiz M, Yilmaz F, Batur Y, Yilmaz C, et al. Efficacy of insulin-sensitizing agents in nonalcoholic fatty liver disease. Eur J Gastroenterol Hepatol 2010;22:18-23.

307. Musso G, Cassader M, Rosina F, Gambino R. Impact of current treatments on liver disease, glucose metabolism and cardiovascu- 
lar risk in non-alcoholic fatty liver disease (NAFLD): a systematic review and meta-analysis of randomised trials. Diabetologia 2012;55:885-904.

308. Vilar-Gomez E, Vuppalanchi R, Desai AP, Gawrieh S, Ghabril M, Saxena $R$, et al. Long-term metformin use may improve clinical outcomes in diabetic patients with non-alcoholic steatohepatitis and bridging fibrosis or compensated cirrhosis. Aliment Pharmacol Ther 2019;50:317-328.

309. Kaplan DE, Serper M, John BV, Tessiatore KM, Lerer $R$, Mehta $R$, et al. Effects of metformin exposure on survival in a large national cohort of patients with diabetes and cirrhosis. Clin Gastroenterol Hepatol. 2020 Aug 13. doi: 10.1016/j.cgh.2020.08.026.

310. Newsome PN, Buchholtz K, Cusi K, Linder M, Okanoue T, Ratziu $V$, et al. A placebo-controlled trial of subcutaneous semaglutide in nonalcoholic steatohepatitis. N Engl J Med 2021;384:1113-1124.

311. Hasegawa T, Yoneda M, Nakamura K, Makino I, Terano A. Plasma transforming growth factor-beta1 level and efficacy of alphatocopherol in patients with non-alcoholic steatohepatitis: a pilot study. Aliment Pharmacol Ther 2001;15:1667-1672.

312. Harrison SA, Torgerson S, Hayashi P, Ward J, Schenker S. Vitamin E and vitamin $C$ treatment improves fibrosis in patients with nonalcoholic steatohepatitis. Am J Gastroenterol 2003;98:2485-2490.

313. Klein EA, Thompson IM Jr, Tangen CM, Crowley JJ, Lucia MS, Goodman PJ, et al. Vitamin $\mathrm{E}$ and the risk of prostate cancer: the selenium and vitamin E cancer prevention trial (SELECT). JAMA 2011;306:1549-1556.

314. Miller ER 3rd, Pastor-Barriuso R, Dalal D, Riemersma RA, Appel LJ, Guallar E. Meta-analysis: high-dosage vitamin E supplementation may increase all-cause mortality. Ann Intern Med 2005;142:37-46.

315. Curtis AJ, Bullen M, Piccenna L, McNeil JJ. Vitamin E supplementation and mortality in healthy people: a meta-analysis of randomised controlled trials. Cardiovasc Drugs Ther 2014;28:563-573.

316. Aune D, Keum N, Giovannucci E, Fadnes LT, Boffetta P, Greenwood $D C$, et al. Dietary intake and blood concentrations of antioxidants and the risk of cardiovascular disease, total cancer, and all-cause mortality: a systematic review and dose-response meta-analysis of prospective studies. Am J Clin Nutr 2018;108:1069-1091.

317. Vilar-Gomez E, Vuppalanchi R, Gawrieh S, Ghabril M, Saxena R, Cummings $\mathrm{OW}$, et al. Vitamin $\mathrm{E}$ improves transplant-free survival and hepatic decompensation among patients with nonalcoholic steatohepatitis and advanced fibrosis. Hepatology 2020;71:495509.

318. Chalasani N, Younossi Z, Lavine JE, Charlton M, Cusi K, Rinella M, et al. The diagnosis and management of nonalcoholic fatty liver disease: practice guidance from the American Association for the Study of Liver Diseases. Hepatology 2018;67:328-357.

319. Tabenkin H, Eaton CB, Roberts MB, Parker DR, McMurray JH, Borkan J. Differences in cardiovascular disease risk factor manage- ment in primary care by sex of physician and patient. Ann Fam Med 2010;8:25-32

320. Byrne CD, Targher G. NAFLD: a multisystem disease. J Hepatol 2015;62(1 Suppl):S47-S64.

321. Fracanzani AL, Burdick L, Raselli S, Pedotti P, Grigore L, Santorelli $G$, et al. Carotid artery intima-media thickness in nonalcoholic fatty liver disease. Am J Med 2008;121:72-78.

322. National cholesterol education program. Second report of the expert panel on detection, evaluation, and treatment of high blood cholesterol in adults (Adult Treatment Panel II). Circulation 1994;89:1333-1445.

323. Pastori D, Polimeni L, Baratta F, Pani A, Del Ben M, Angelico F. The efficacy and safety of statins for the treatment of non-alcoholic fatty liver disease. Dig Liver Dis 2015;47:4-11.

324. Arnett DK, Blumenthal RS, Albert MA, Buroker AB, Goldberger ZD, Hahn EJ, et al. 2019 ACC/AHA guideline on the primary prevention of cardiovascular disease: a report of the American College of Cardiology/American Heart Association Task Force on clinical practice guidelines. J Am Coll Cardiol 2019;74:e177-e232.

325. Athyros VG, Tziomalos K, Gossios TD, Griva T, Anagnostis P, Kargiotis $K$, et al. Safety and efficacy of long-term statin treatment for cardiovascular events in patients with coronary heart disease and abnormal liver tests in the Greek Atorvastatin and Coronary Heart Disease Evaluation (GREACE) study: a post-hoc analysis. Lancet 2010;376:1916-1922.

326. Lee Jl, Lee HW, Lee KS, Lee HS, Park JY. Effects of statin use on the development and progression of nonalcoholic fatty liver disease: a nationwide nested case-control study. Am J Gastroenterol 2020;116:116-124.

327. Khoo S, Wong VW, Goh GB, Fan J, Chan WK, Seto WK, et al. Suboptimal treatment of dyslipidemia in patients with nonalcoholic fatty liver disease. J Gastroenterol Hepatol 2020;35:320-325.

328. Chalasani N. Statins and hepatotoxicity: focus on patients with fatty liver. Hepatology 2005;41:690-695.

329. Dale KM, White CM, Henyan NN, Kluger J, Coleman Cl. Impact of statin dosing intensity on transaminase and creatine kinase. Am J Med 2007;120:706-712.

330. Law M, Rudnicka AR. Statin safety: a systematic review. Am J Cardiol 2006;97(8A):52C-60C.

331. Chalasani N, Aljadhey H, Kesterson J, Murray MD, Hall SD. Patients with elevated liver enzymes are not at higher risk for statin hepatotoxicity. Gastroenterology 2004;126:1287-1292.

332. Lewis JH, Mortensen ME, Zweig S, Fusco MJ, Medoff JR, Belder $\mathrm{R}$, et al. Efficacy and safety of high-dose pravastatin in hypercholesterolemic patients with well-compensated chronic liver disease: results of a prospective, randomized, double-blind, placebocontrolled, multicenter trial. Hepatology 2007;46:1453-1463.

333. Bays H, Cohen DE, Chalasani N, Harrison SA, The National Lipid 
Association's Statin Safety Task Force. An assessment by the Statin Liver Safety Task Force: 2014 update. J Clin Lipidol 2014;8(3 Suppl):S47-S57.

334. Cohen DE, Anania FA, Chalasani N; National Lipid Association Statin Safety Task Force Liver Expert Panel. An assessment of statin safety by hepatologists. Am J Cardiol 2006;97(8A):77C-81C.

335. Kumar S, Grace ND, Qamar AA. Statin use in patients with cirrhosis: a retrospective cohort study. Dig Dis Sci 2014;59:1958-1965.

336. Stone NJ, Robinson JG, Lichtenstein AH, Bairey Merz CN, Blum CB, Eckel RH, et al. 2013 ACC/AHA guideline on the treatment of blood cholesterol to reduce atherosclerotic cardiovascular risk in adults: a report of the American College of Cardiology/American Heart Association Task Force on practice guidelines. Circulation 2014;129(25 Suppl 2):S1-S45.

337. Watanabe $S$, Hashimoto E, Ikejima K, Uto H, Ono M, Sumida $Y$, et al. Evidence-based clinical practice guidelines for nonalcoholic fatty liver disease/nonalcoholic steatohepatitis. J Gastroenterol 2015;50:364-377.

338. Simon TG, Corey KE, Cannon CP, Blazing M, Park JG, O'Donoghue $\mathrm{ML}$, et al. The nonalcoholic fatty liver disease (NAFLD) fibrosis score, cardiovascular risk stratification and a strategy for secondary prevention with ezetimibe. Int J Cardiol 2018;270:245-252.

339. Parker HM, Johnson NA, Burdon CA, Cohn JS, O'Connor HT, George J. Omega-3 supplementation and non-alcoholic fatty liver disease: a systematic review and meta-analysis. J Hepatol 2012;56: 944-951.

340. Sanyal AJ, Abdelmalek MF, Suzuki A, Cummings OW, Chojkier M; EPE-A Study Group. No significant effects of ethyl-eicosapentanoic acid on histologic features of nonalcoholic steatohepatitis in a phase 2 trial. Gastroenterology 2014;147:377-384.e1.

341. Argo CK, Patrie JT, Lackner C, Henry TD, de Lange EE, Weltman $A L$, et al. Effects of $n-3$ fish oil on metabolic and histological parameters in NASH: a double-blind, randomized, placebo-controlled trial. J Hepatol 2015;62:190-197.

342. Grundy SM, Stone NJ, Bailey AL, Beam C, Birtcher KK, Blumenthal RS, et al. 2018 AHA/ACC/AACVPR/AAPA/ABC/ACPM/ADA/AGS/ APhA/ASPC/NLA/PCNA guideline on the management of blood cholesterol: a report of the American College of Cardiology/American Heart Association Task Force on clinical practice guidelines. Circulation 2019;139:e1082-e1143.

343. Scorletti E, Bhatia L, McCormick KG, Clough GF, Nash K, Hodson $L$, et al. Effects of purified eicosapentaenoic and docosahexaenoic acids in nonalcoholic fatty liver disease: results from the Welcome* study. Hepatology 2014;60:1211-1221.

344. Harrison SA, Wong VW, Okanoue T, Bzowej N, Vuppalanchi R, Younes $Z$, et al. Selonsertib for patients with bridging fibrosis or compensated cirrhosis due to NASH: results from randomized phase III STELLAR trials. J Hepatol 2020;73:26-39.
345. Younossi ZM, Ratziu V, Loomba R, Rinella M, Anstee QM, Goodman $Z$, et al. Obeticholic acid for the treatment of non-alcoholic steatohepatitis: interim analysis from a multicentre, randomised, placebo-controlled phase 3 trial. Lancet 2019;394:2184-2196.

346. Miller CM, Quintini C, Dhawan A, Durand F, Heimbach JK, KimSchluger $\mathrm{HL}$, et al. The international liver transplantation society living donor liver transplant recipient guideline. Transplantation 2017;101:938-944.

347. Pillai AA, Rinella ME. Non-alcoholic fatty liver disease: is bariatric surgery the answer? Clin Liver Dis 2009;13:689-710.

348. Lee Y, Doumouras AG, Yu J, Brar K, Banfield L, Gmora S, et al. Complete resolution of nonalcoholic fatty liver disease after bariatric surgery: a systematic review and meta-analysis. Clin Gastroenterol Hepatol 2019;17:1040-1060.e11.

349. Mathurin P, Hollebecque A, Arnalsteen L, Buob D, Leteurtre E, Caiazzo $R$, et al. Prospective study of the long-term effects of bariatric surgery on liver injury in patients without advanced disease. Gastroenterology 2009;137:532-540.

350. Mummadi RR, Kasturi KS, Chennareddygari S, Sood GK. Effect of bariatric surgery on nonalcoholic fatty liver disease: systematic review and meta-analysis. Clin Gastroenterol Hepatol 2008;6:13961402.

351. Chavez-Tapia NC, Tellez-Avila FI, Barrientos-Gutierrez T, MendezSanchez N, Lizardi-Cervera J, Uribe M. Bariatric surgery for nonalcoholic steatohepatitis in obese patients. Cochrane Database Syst Rev 2010;2010:CD007340.

352. Lassailly G, Caiazzo R, Ntandja-Wandji LC, Gnemmi V, Baud G, Verkindt $H$, et al. Bariatric surgery provides long-term resolution of nonalcoholic steatohepatitis and regression of fibrosis. Gastroenterology 2020;159:1290-1301.e5.

353. Fakhry TK, Mhaskar R, Schwitalla T, Muradova E, Gonzalvo JP, Murr MM. Bariatric surgery improves nonalcoholic fatty liver disease: a contemporary systematic review and meta-analysis. Surg Obes Relat Dis 2019;15:502-511.

354. Bower G, Toma T, Harling L, Jiao LR, Efthimiou E, Darzi A, et al. Bariatric surgery and non-alcoholic fatty liver disease: a systematic review of liver biochemistry and histology. Obes Surg 2015;25:2280-2289.

355. Brolin RE, Bradley LJ, Taliwal RV. Unsuspected cirrhosis discovered during elective obesity operations. Arch Surg 1998;133:84-88.

356. Dallal RM, Mattar SG, Lord JL, Watson AR, Cottam DR, Eid GM, et al. Results of laparoscopic gastric bypass in patients with cirrhosis. Obes Surg 2004;14:47-53.

357. Shimizu H, Phuong V, Maia M, Kroh M, Chand B, Schauer PR, et al. Bariatric surgery in patients with liver cirrhosis. Surg Obes Relat Dis 2013;9:1-6.

358. Jan A, Narwaria M, Mahawar KK. A systematic review of bariatric surgery in patients with liver cirrhosis. Obes Surg 2015;25:1518- 
1526.

359. Car Peterko A, Kirac I, Gaurina A, Diklić D, Bekavac-Bešlin M. Diagnosis and management of acute and early complications of/after bariatric surgery. Dig Dis 2012;30:178-181.

360. Hammer HF. Medical complications of bariatric surgery: focus on malabsorption and dumping syndrome. Dig Dis 2012;30:182-186.

361. Decker GA, Swain JM, Crowell MD, Scolapio JS. Gastrointestinal and nutritional complications after bariatric surgery. Am J Gastroenterol 2007;102:2571-2580; quiz 2581.

362. Charlton MR, Burns JM, Pedersen RA, Watt KD, Heimbach JK, Dierkhising RA. Frequency and outcomes of liver transplantation for nonalcoholic steatohepatitis in the United States. Gastroenterology 2011;141:1249-1253.

363. Tsochatzis E, Coilly A, Nadalin S, Levistky J, Tokat Y, Ghobrial M, et al. International liver transplantation consensus statement on endstage liver disease due to nonalcoholic steatohepatitis and liver transplantation. Transplantation 2019;103:45-56.

364. Wang X, Li J, Riaz DR, Shi G, Liu C, Dai Y. Outcomes of liver transplantation for nonalcoholic steatohepatitis: a systematic review and meta-analysis. Clin Gastroenterol Hepatol 2014;12:394-402. e1.

365. Heuer M, Kaiser GM, Kahraman A, Banysch M, Saner FH, Mathé Z,et al. Liver transplantation in nonalcoholic steatohepatitis is associated with high mortality and post-transplant complications: a single-center experience. Digestion 2012;86:107-113.

366. Everhart JE, Lombardero M, Lake JR, Wiesner RH, Zetterman RK, Hoofnagle JH. Weight change and obesity after liver transplantation: incidence and risk factors. Liver Transpl Surg 1998;4:285-296.

367. Patil DT, Yerian LM. Evolution of nonalcoholic fatty liver disease recurrence after liver transplantation. Liver Transpl 2012;18:11471153.

368. Laish I, Braun M, Mor E, Sulkes J, Harif Y, Ben Ari Z. Metabolic syndrome in liver transplant recipients: prevalence, risk factors, and association with cardiovascular events. Liver Transpl 2011;17:1522.

369. Park SH, Park YE, Lee J, Choi JH, Heo NY, Park J, et al. The change in prevalence of suspected non-alcoholic fatty liver disease in Korean adolescents from 2001 to 2017. Paediatr Int Child Health 2020;40:166-170.

370. Kang Y, Park S, Kim S, Koh H. Estimated prevalence of adolescents with nonalcoholic fatty liver disease in Korea. J Korean Med Sci 2018;33:e109.

371. Moon JS, Lee SY, Nam CM, Choi JM, Choe BK, Seo JW, et al. 2007 Korean national growth charts: review of developmental process and an outlook. Korean J Pediatr 2008;51:1-25.

372. Korea Centers fo Disease Control and Prevention. Korea National Health and Nutrition Examination Survey: Analytic guidelines. Korea Centers fo Disease Control and Prevention web site, <https:// knhanes.kdca.go.kr/knhanes/sub03/sub03_06_02.do>. Accessed 15 Jun 2019.

373. Roberts EA. Pediatric nonalcoholic fatty liver disease (NAFLD): a "growing" problem? J Hepatol 2007;46:1133-1142.

374. Feldstein AE, Charatcharoenwitthaya P, Treeprasertsuk S, Benson JT, Enders FB, Angulo P. The natural history of non-alcoholic fatty liver disease in children: a follow-up study for up to 20 years. Gut 2009:58:1538-1544.

375. Nobili V, Alisi A, Grimaldi C, Liccardo D, Francalanci P, Monti L, et al. Non-alcoholic fatty liver disease and hepatocellular carcinoma in a 7-year-old obese boy: coincidence or comorbidity? Pediatr Obes 2014;9:e99-e102.

376. Doycheva I, Issa D, Watt KD, Lopez R, Rifai G, Alkhouri N. Nonalcoholic steatohepatitis is the most rapidly increasing indication for liver transplantation in young adults in the United States. J Clin Gastroenterol 2018;52:339-346.

377. Alkhouri N, Hanouneh IA, Zein NN, Lopez R, Kelly D, Eghtesad $B$, et al. Liver transplantation for nonalcoholic steatohepatitis in young patients. Transpl Int 2016;29:418-424.

378. Loomba R, Sirlin CB, Schwimmer JB, Lavine JE. Advances in pediatric nonalcoholic fatty liver disease. Hepatology 2009;50:12821293.

379. Papandreou D, Rousso I, Mavromichalis I. Update on non-alcoholic fatty liver disease in children. Clin Nutr 2007;26:409-415.

380. Schwimmer JB, Celedon MA, Lavine JE, Salem R, Campbell N, Schork NJ, et al. Heritability of nonalcoholic fatty liver disease. Gastroenterology 2009;136:1585-1592.

381. Eslam M, Valenti L, Romeo S. Genetics and epigenetics of NAFLD and NASH: clinical impact. J Hepatol 2018;68:268-279.

382. Caussy C, Soni M, Cui J, Bettencourt R, Schork N, Chen CH, et al. Nonalcoholic fatty liver disease with cirrhosis increases familial risk for advanced fibrosis. J Clin Invest 2017;127:2697-2704.

383. Goyal NP, Schwimmer JB. The genetics of pediatric nonalcoholic fatty liver disease. Clin Liver Dis 2018;22:59-71.

384. Di Sessa A, Umano GR, Cirillo G, Del Prete A, lacomino R, Marzuillo $P$, et al. The membrane-bound 0-acyltransferase7 rs641738 variant in pediatric nonalcoholic fatty liver disease. J Pediatr Gastroenterol Nutr 2018;67:69-74.

385. Hudert CA, Selinski S, Rudolph B, Bläker H, Loddenkemper C, Thielhorn $R$, et al. Genetic determinants of steatosis and fibrosis progression in paediatric non-alcoholic fatty liver disease. Liver Int 2019;39:540-556.

386. Krawczyk M, Rau M, Schattenberg JM, Bantel H, Pathil A, Demir $M$, et al. Combined effects of the PNPLA3 rs738409, TM6SF2 rs58542926, and MBOAT7 rs641738 variants on NAFLD severity: a multicenter biopsy-based study. J Lipid Res 2017;58:247-255.

387. Lin YC, Chang PF, Hu FC, Yang WS, Chang MH, Ni YH. A common variant in the PNPLA3 gene is a risk factor for non-alcoholic fatty 
liver disease in obese Taiwanese children. J Pediatr 2011;158:740744.

388. Jain V, Kumar A, Ahmad N, Jana M, Kalaivani M, Kumar B, et al. Genetic polymorphisms associated with obesity and non-alcoholic fatty liver disease in Asian Indian adolescents. J Pediatr Endocrinol Metab 2019;32:749-758.

389. Lombardi R, Fargion S, Fracanzani AL. Combined use of genetic polymorphisms and elastographic techniques in NAFLD: fact or fiction? Curr Pharm Des 2020;26:1010-1018.

390. Stanislawski MA, Shaw J, Litkowski E, Lange EM, Perng W, Dabelea $D$, et al. Genetic risk for hepatic fat among an ethnically diverse cohort of youth: the exploring perinatal outcomes among children study. J Pediatr 2020;220:146-153.e2.

391. Youssefian L, Vahidnezhad H, Saeidian AH, Pajouhanfar S, Sotoudeh S, Mansouri $P$, et al. Inherited non-alcoholic fatty liver disease and dyslipidemia due to monoallelic ABHD5 mutations. J Hepatol 2019;71:366-370.

392. Lee EY, Choi HY, Cho H, Kim BH, Ki M. Health behavior associated with liver enzymes among obese Korean adolescents, 2009-2014. PLoS One 2018;13:e0190535.

393. Barlow SE; Expert Committee. Expert committee recommendations regarding the prevention, assessment, and treatment of child and adolescent overweight and obesity: summary report. Pediatrics 2007;120 Suppl 4:S164-S192.

394. Di Bonito P, Sanguigno E, Di Fraia T, Forziato C, Boccia G, Saitta F, et al. Association of elevated serum alanine aminotransferase with metabolic factors in obese children: sex-related analysis. Metabolism 2009;58:368-372.

395. Yoo J, Lee S, Kim K, Yoo S, Sung E, Yim J. Relationship between insulin resistance and serum alanine aminotransferase as a surrogate of NAFLD (nonalcoholic fatty liver disease) in obese Korean children. Diabetes Res Clin Pract 2008;81:321-326.

396. Vajro P, Lenta S, Socha P, Dhawan A, McKiernan P, Baumann U, et al. Diagnosis of nonalcoholic fatty liver disease in children and adolescents: position paper of the ESPGHAN Hepatology Committee. J Pediatr Gastroenterol Nutr 2012;54:700-713.

397. Yi DY, Kim SC, Lee JH, Lee EH, Kim JY, Kim YJ, et al. Clinical practice guideline for the diagnosis and treatment of pediatric obesity: recommendations from the Committee on Pediatric Obesity of the Korean Society of Pediatric Gastroenterology Hepatology and Nutrition. Korean J Pediatr 2019;62:3-21.

398. Vos MB, Abrams SH, Barlow SE, Caprio S, Daniels SR, Kohli R, et al. NASPGHAN clinical practice guideline for the diagnosis and treatment of nonalcoholic fatty liver disease in children: recommendations from the Expert Committee on NAFLD (ECON) and the North American Society of Pediatric Gastroenterology, Hepatology and Nutrition (NASPGHAN). J Pediatr Gastroenterol Nutr 2017;64:319334.
399. The diagnosis and management of nonalcoholic fatty liver disease: practice guidance from the American Association for the Study of Liver Diseases. Clin Liver Dis (Hoboken) 2018;11:81.

400. Vuppalanchi R, Jain AK, Deppe R, Yates K, Comerford M, Masuoka $H C$, et al. Relationship between changes in serum levels of keratin 18 and changes in liver histology in children and adults with nonalcoholic fatty liver disease. Clin Gastroenterol Hepatol 2014;12:2121-2130.e1-e2.

401. Ebbeling CB, Feldman HA, Chomitz VR, Antonelli TA, Gortmaker $\mathrm{SL}$, Osganian SK, et al. A randomized trial of sugar-sweetened beverages and adolescent body weight. N Engl J Med 2012;367:14071416.

402. Brown T, Moore TH, Hooper L, Gao Y, Zayegh A, ljaz S, et al. Interventions for preventing obesity in children. Cochrane Database Syst Rev 2019;7:CD001871.

403. de Ruyter JC, Olthof MR, Seidell JC, Katan MB. A trial of sugar-free or sugar-sweetened beverages and body weight in children. $\mathrm{N}$ Engl J Med 2012;367:1397-1406.

404. Bjelakovic G, Nikolova D, Gluud C. Antioxidant supplements and mortality. Curr Opin Clin Nutr Metab Care 2014;17:40-44.

405. Bjelakovic G, Nikolova D, Gluud LL, Simonetti RG, Gluud C. Antioxidant supplements for prevention of mortality in healthy participants and patients with various diseases. Cochrane Database Syst Rev 2012;(3):CD007176.

406. Gerss J, Köpcke W. The questionable association of vitamin $E$ supplementation and mortality--inconsistent results of different meta-analytic approaches. Cell Mol Biol (Noisy-le-grand) 2009;55 Suppl:OL1111-OL1120.

407. Lavine JE, Schwimmer JB, Van Natta ML, Molleston JP, Murray KF,

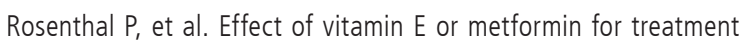
of nonalcoholic fatty liver disease in children and adolescents: the TONIC randomized controlled trial. JAMA 2011;305:1659-1668.

408. Lindor KD, Kowdley KV, Heathcote EJ, Harrison ME, Jorgensen $R$, Angulo $P$, et al. Ursodeoxycholic acid for treatment of nonalcoholic steatohepatitis: results of a randomized trial. Hepatology 2004;39:770-778.

409. Nobili V, Bedogni G, Alisi A, Pietrobattista A, Risé P, Galli C, et al. Docosahexaenoic acid supplementation decreases liver fat content in children with non-alcoholic fatty liver disease: double-blind randomised controlled clinical trial. Arch Dis Child 2011;96:350-353.

410. Barker KB, Palekar NA, Bowers SP, Goldberg JE, Pulcini JP, Harrison SA. Non-alcoholic steatohepatitis: effect of Roux-en-Y gastric bypass surgery. Am J Gastroenterol 2006;101:368-373.

411. O'Brien PE, Sawyer SM, Laurie C, Brown WA, Skinner S, Veit F, et al. Laparoscopic adjustable gastric banding in severely obese adolescents: a randomized trial. JAMA 2010;303:519-526.

412. Jensen MD, Ryan DH, Apovian CM, Ard JD, Comuzzie AG, Donato $\mathrm{KA}$, et al. $2013 \mathrm{AHA}$ /ACC/TOS guideline for the management of 
Seong Hee Kang, et al.

KASL clinical practice guidelines for NAFLD

overweight and obesity in adults: a report of the American College of Cardiology/American Heart Association Task Force on practice guidelines and The Obesity Society. Circulation 2014;129(25 Suppl 2):S102-S138.

413. Gordon SC, Kachru N, Parker E, Korrer S, Ozbay AB, Wong RJ. Health care use and costs among patients with nonalcoholic steatohepatitis with advanced fibrosis using the fibrosis-4 score. Hepatol Commun 2020;4:998-1011.

414. Vali Y, Lee J, Boursier J, Spijker R, Löffler J, Verheij J, et al. Enhanced liver fibrosis test for the non-invasive diagnosis of fibrosis in patients with NAFLD: a systematic review and meta-analysis. J Hepatol 2020;73:252-262. 